Carlos Henrique Fontana Vieira

\title{
Hidrolaparoscopia transvaginal no prognóstico cirúrgico de mulheres laqueadas candidatas à reversão da esterilização tubária
}

Tese apresentada à Faculdade de Medicina da Universidade de São Paulo para obtenção do título de Doutor em Ciências.

Área de concentração: Obstetrícia e Ginecologia Orientadora: Profa. Dra. Angela Maggio da Fonseca

São Paulo 
Aos meus amigos e familiares, em especial à minha mãe lzabel (in memoriam) e minha irmã Ligia (in memoriam), pelo esforço, apoio e dedicação incondicional à minha formação pessoal e profissional.

À minha esposa Sheila, pelo companheirismo, paciência, incentivo e compreensão pelos períodos de ausência durante a elaboração deste trabalho. 
Agradecimentos 
Ao Prof. Dr. Edmund Chadat Baracat, pela oportunidade de realizar este estudo e pelo grande apoio que oferece a todos que se dedicam à melhoria da saúde da mulher, com admirável liderança, bondade e bom senso, advindos de profundo conhecimento da alma do ser humano.

À Profa. Dra. Angela Maggio da Fonseca, pelo zelo, paciência, carinho e disponibilização de seu profundo conhecimento e de seu tempo na orientação à execução deste trabalho.

Ao companheiro Dr. Joji Ueno, pela idealização deste trabalho, assim como pelo apoio durante sua execução, e pela realização das minilaparotomias que confrontaram os achados da hidrolaparoscopia transvaginal.

Ao Dr. Nelson da Cruz Santos, pela oportunidade proporcionada no Setor de Endoscopia Ginecológica.

À colega Ana Cláudia Nogueira, pela colaboração na captação das imagens.

Aos estagiários e colegas do Centro de Referência da Saúde da Mulher, em especial ao Dr. Ivaldo A/ves Baratela, pela seleção e encaminhamento das pacientes, e ao Dr. José Fernando Gonçalves Pelicano, pela realização das 
anestesias das minilaparotomias quando da confirmação dos achados.

Aos residentes e estagiários dos Setores de Endoscopia Ginecológica e Reprodução Humana, pelo apoio e encaminhamento de pacientes.

A toda a equipe de enfermagem do ambulatório de ginecologia, em especial àquelas que mais estreitamente colaboraram na execução dos procedimentos, como as auxiliares Érica, Andréia e Rosângela.

À minha sobrinha, Dra. Adriana Angélica de Paula Vieira, pelas ilustrações.

A Claudia Aparecida Vieira, pelas diversas orientações e esclarecimentos. 
Sumário 


\section{Sumário}

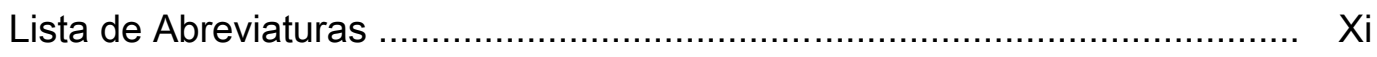

Lista de Figuras …………........................................................... Xii

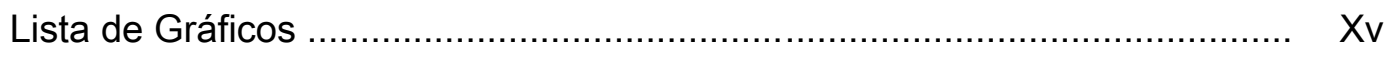

Lista de Tabelas .................................................................................. Xvi

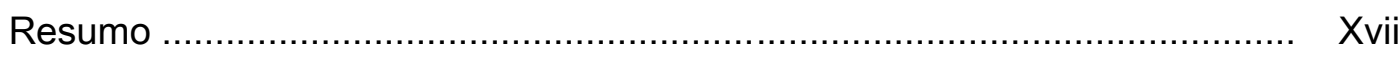

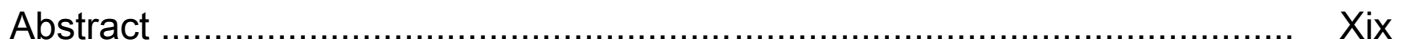

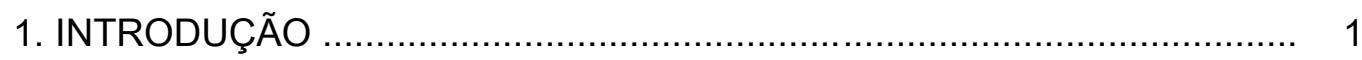

1.1 Laqueadura tubária ........................................................................ $\quad 5$

1.2 Avaliação do prognóstico de reversibilidade tubária …....................... 14

1.3 Técnicas de avaliação tubária ………............................................ 17

1.3.1 Histerossalpingografia ....................................................... 17

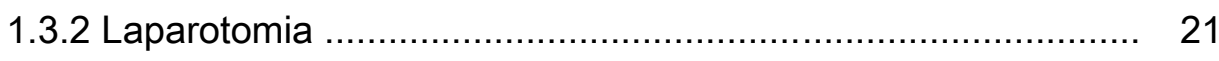

1.3.3 Métodos endoscópicos ...................................................... 22

1.3.3.1 Laparoscopia diagnóstica ....................................... 26

1.3.3.2 Técnicas endoscópicas transvaginais ..................... 29

A) Culdoscopia ……………………………...... 30

B) Fertiloscopia …………………………….... 32

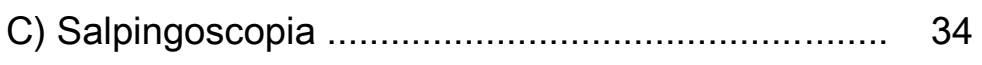

D) Hidrolaparoscopia transvaginal ......................... 36

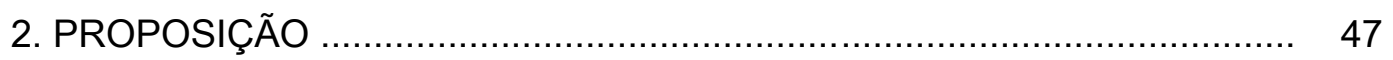


3. CASUÍSTICA E MÉTODOS ........................................................... 49

3.1 Casuística …......................................................................... 50

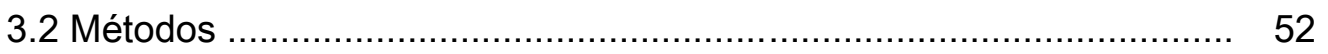

3.2.1 Hidrolaparoscopia transvaginal ...................................... 52

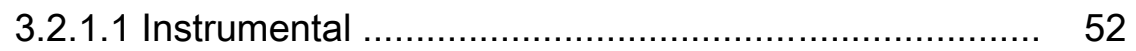

3.2.1.2 Técnica ....................................................... 54

3.2.2 Minilaparotomia ......................................................... 60

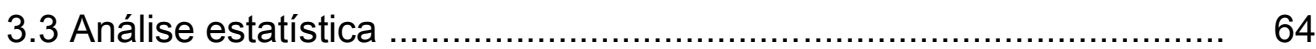

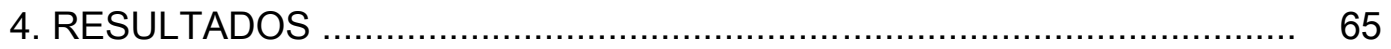

4.1 Acesso à cavidade pélvica ......................................................... 65

4.2 Avaliação das tubas pela hidrolaparoscopia transvaginal ............... 67

4.3 Prognóstico hidrolaparoscópico comparado com a decisão pela reversão cirúrgica no ato minilaparotômico ...................................... 73

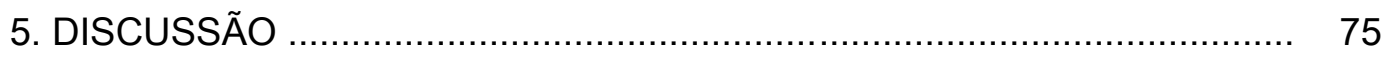

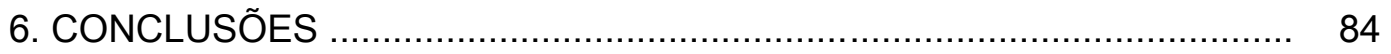

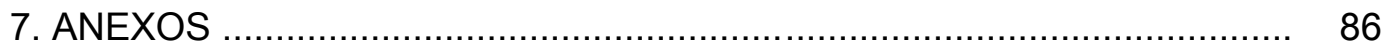

8. REFERÊNCIAS BIBLIOGRÁFICAS ............................................ 92 
Abreviaturas, Figuras,

Gráficos e Tabelas 


\section{Lista de Abreviaturas}

$\begin{array}{ll}\text { AVF } & \text { Anteversoflexão } \\ \text { FMC } & \text { Freqüência do movimento ciliar } \\ \text { EC } & \text { Esterilização cirúrgica } \\ \text { HLT } & \text { Hidrolaparoscopia transvaginal } \\ \text { HSG } & \text { Histerossalpingografia } \\ \text { IMC } & \text { Índice de massa corpórea } \\ \text { LT } & \text { Laqueadura tubária } \\ \text { RCL } & \text { Reversão cirúrgica da laqueadura } \\ \text { RVF } & \text { Retroversoflexão }\end{array}$




\section{Lista de Figuras}

Figura $1 \quad$ Gabriel Fallopius Mutin …................................................... 2

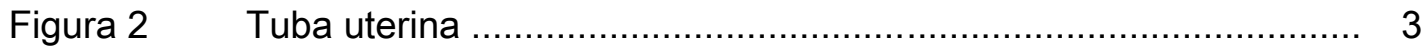

Figura 3 Técnicas de Pomeroy (à esquerda) e Parkland (à direita) para laqueadura tubária ....................................................................... 7

Figura $4 \quad$ Técnica de Uchida para laqueadura tubária .............................. 8

Figura 5 Técnica de Irwing para laqueadura tubária ............................... 9

Figura 6 Técnica de eletrocoagulação com corrente unipolar para laqueadura tubária ........................................................................... 9

Figura 7 Técnica de eletrocoagulação com corrente bipolar para laqueadu-

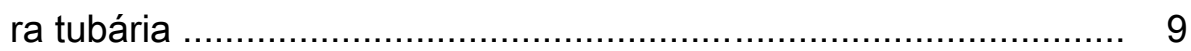

Figura $8 \quad$ Anel de Yoon para laqueadura tubária ....................................... 10

Figura $9 \quad$ Clipe de Hulka-Clemens para laqueadura tubária ........................ 10

Figura 10 Imagem da cavidade uterina e das tubas obtida por histerossalpingografia ........................................................................ 18

Figura 11 Speculum magnum matricis, Medicina Romana ....................... 22

Figura 12 Espéculo de bronze denominado catoptro para exame vaginal e retal, encontrado na Casa dos Cirurgiões, cerca de 62-79 d.C., em Pompéia ........................................................................ 22

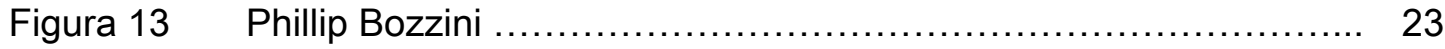

Figura 14 Réplica do endoscópio Lichtleiter ............................................ 23

Figura $15 \quad$ Endoscópio de Desormeaux …................................................ 24

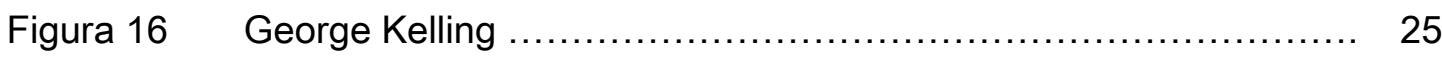

Figura 17 Instrumento para pneumoperitônio de Kelling ............................ 25 
Figura 18 Desenho esquemático da fertiloscopia ....................................... 33

Figura $19 \quad$ Imagem do interior da porção ampolar da tuba .......................... 35

Figura 20 Desenho esquemático da HLT .............................................. 36

Figura $21 \quad$ Material de uso geral para realização de HLT .............................. 53

Figura 22 Agulha e cânula de HLT …..................................................... 53

Figura 23 Base (à esquerda) e ponta (à direita) da agulha da HLT ............. 53

Figura 24 Botão anestésico em fórnice vaginal posterior .......................... 55

Figura 25 Ponta romba retrátil (à esquerda) e base da agulha (à direita) ...... 55

Figura 26 Punção do fundo-de-saco vaginal ............................................ 56

Figura 27 Observação da retração (à esquerda) e destravamento (à direita) do sistema de inserção .......................................................... 57

Figura 28 Detalhe da retração da agulha antes (à esquerda) e depois (à direita) de transpassar a parede vaginal .................................. 57

Figura $29 \quad$ Equipo de soro conectado à agulha ........................................ 58

Figura 30 Conexão do equipo de soro à cânula (à esquerda) e retirada da agulha do interior da cânula (à direita) ...................................... 58

Figura $31 \quad$ Introdução da óptica através da cânula ..................................... 59

Figura $32 \quad$ Manipulador uterino …....................................................... 62

Figura 33 Colocação do sistema de retração na cavidade abdominal .......... 62

Figura 34 Posição da paciente, equipe médica e campo visual .................. 63

Figura 35 Aspecto final da minilaparotomia ........................................ 64

Figura 36 Visualização de clipes de titânio em região ístmica da tuba pela HLT ................................................................................. 69

Figura 37 Visualização de clipes de titânio em região ístmica da tuba pela

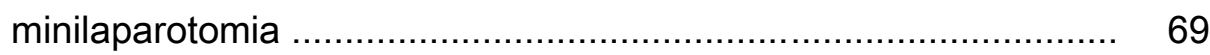


Figura 38 Achado da HLT em que se visualizam fímbrias ......................... 70

Figura 39 Achado da minilaparotomia: laqueadura em dois pontos e hidrossalpinge ....................................................................... 70

Figura 40 Achado da HTL em que se visualizam fímbrias não saudáveis ..... 71

Figura 41 Achado da minilaparotomia: laqueadura distal com hidrossalpinge proximal ................................................................. 71

Figura 42 Achado da HLT cuja visualização sugere viabilidade da RCL ....... 72

Figura 43 Achado da minilaparotomia: hidrossalpinge com péssimo prognóstico para RCL …........................................................... 72 


\section{Lista de Gráficos}

Gráfico 1 Distribuição das pacientes em relação à obtenção de acesso à cavidade pélvica durante HLT

Gráfico 2 Distribuição das pacientes em relação à avaliação das tubas pela HLT 


\section{Lista de Tabelas}

Tabela 1 Valores mínimo e máximo, média e desvio-padrão da idade, peso, altura e índice de massa corpórea (IMC) de 38 mulheres com laqueadura tubária candidatas à reversão cirúrgica

Tabela 2 Pacientes nas quais a HLT foi insatisfatória em avaliar a reversibilidade tubária

Tabela 3 Compatibilidade entre os achados da HLT e da minilaparotomia em 28 casos em que foi possível o acesso à cavidade pélvica pela HLT 
Vieira, CHF. Hidrolaparoscopia transvaginal no prognóstico cirúrgico de mulheres laqueadas candidatas à reversão da esterilização tubária [Tese de Doutorado]. São Paulo: Faculdade de Medicina, Universidade de São Paulo; 2007. 124 p.

Introdução: Aproximadamente $2 \%$ a $26 \%$ das mulheres submetidas à esterilização demonstram arrependimento em algum momento de sua vida. A reversão cirúrgica pode ser realizada por laparotomia, minilaparotomia ou laparoscopia. Para tanto, é necessário avaliarem-se as condições tubárias para prognosticar o procedimento cirúrgico. Para a avaliação anatômica da tuba procede-se à histerossalpingografia para a análise da porção proximal à cicatriz cirúrgica da laqueadura, e a laparoscopia para a porção distal. Neste estudo prospectivo transversal, avaliou-se a porção distal das tubas pela hidrolaparoscopia transvaginal (HLT) como alternativa à laparoscopia diagnóstica. Métodos: No período de agosto de 2001 a abril de 2004, 38 pacientes sem outra afecção pélvica, com idade inferior a 40 anos, índice de massa corpórea menor que $35 \mathrm{~kg} / \mathrm{m}^{2}$, e cujos parceiros não apresentavam espermograma alterado com indicação de fertilização in vitro, foram submetidas à HLT, em ambulatório e sob anestesia local. A reversão cirúrgica foi efetuada em 30 pacientes por minilaparotomia, que foi considerada "padrão-ouro" para determinar a acurácia dos achados da HLT. Resultados: 1) Obteve-se acesso à cavidade pélvica em 36 $(94,7 \%)$ pacientes; em duas $(5,3 \%)$ houve falha de acesso. 2$)$ Das 30 pacientes que se mantiveram no estudo, em duas $(6,7 \%)$ não se obteve acesso à cavidade pélvica, e das 28 (93,3\%) pacientes avaliadas em um total de 56 tubas, o prognóstico foi correto em 25 (89,3\%) e insatisfatório em três (10,7\%). A falha prognóstica decorreu de hidrossalpinge e laqueadura em dois pontos em cada uma das tubas em uma paciente e de hidrossalpinge em outras duas pacientes. 3) Não houve qualquer complicação nos 38 casos estudados. Conclusões: A HTL é método que permite a visualização das fímbrias e do coto distal das tubas de pacientes laqueadas. Constitui método com alto índice de acerto na análise da possibilidade de recanalização cirúrgica pós-laqueadura, mas a presença de hidrossalpinge prejudica a avaliação do prognóstico da reversibilidade.

Descritores: 1.CULDOSCOPIA/métodos 2.CULDOSCOPIA/utilização 3.LAPAROSCOPIA/métodos 4.LAPAROSCOPIA/utilização 5.ENDOSCOPIA/métodos 6.ENDOSCOPIA/utilização 7.ESTERILIZAÇÃO TUBÁRIA 8.INFERTILIDADE 9.TÉCNICAS DE DIAGNÓSTICO OBSTÉTRICO E GINECOLÓGICO 
Abstract 
Vieira, CHF. Transvaginal hydrolaparoscopy for evaluating surgical prognosis in sterilized women desiring a new pregnancy [Thesis]. São Paulo: Medicine School, University of São Paulo; 2007. 124 p.

Background: The rate of post sterilization regret in women is about $2 \%$ to $26 \%$ depending on the moment of life they are living. Surgical reversibility can be carried out with the use of laparotomy, minilaparotomy or laparoscopy. However, tubal conditions must be assessed for the surgical prognosis. Hysterosalpingography is useful for assessing the proximal surgical scar of the ligated tube, and laparoscopy is used for evaluating the distal portion. Distal portion of ligated tubes were evaluated by transvaginal hydrolaparoscopy (THL) as an alternative to laparoscopy in this investigation. Method: Between August 2001 and April 2004, 38 female candidates for sterilization reversal without any other pelvic disease, aged up to 40 years old, presenting body mass index $<35 \mathrm{~kg} / \mathrm{m}^{2}$, whose partners did not present abnormal espermogram, and without indication for in vitro fertilization were submitted to outpatient THL under local anesthesia. Surgical reversal was accomplished in 30 patients with minilaparotomy, considered the golden-pattern for analyzing the accuracy of THL findings. Results: 1) Pelvic cavity was achieved in 36 (94.7\%) patients, and the access failed in the other two (5.3\%). 2) Out of the 30 patients who were kept in the study, failure in achieving the pelvic cavity occurred in two $(6.7 \%)$ of them. In the remaining 28 (93.3\%) women or 56 tubes, THL diagnosis was correct in 25 (89.3\%) and unsatisfactory in the other three $(10.7 \%)$. Prognosis failure was result of hydrosalpinge, and one of these three patients presented two points ligated in both tubes as well. 3) There were no THL complications in all cases. Conclusion: THL is a technique useful for allowing visualization of fimbriae and distal stump of ligated tubes, and for accurately previewing the possibility of surgical reversal, although the presence of hydrosalpinge can interfere in the THL prognosis for tubal reversibility.

Keywords: 1.CULDOSCOPY/technique 2.CULDOSCOPY/use 3.LAPAROSCOPY/ technique 4.LAPAROSCOPY/use 5.ENDOSCOPY/technique 6.ENDOSCOPY/use 7.TUBAL STERILIZATION 8.INFERTILITY 9.OBSTETRIC AND GYNECOLOGIC DIAGNOSIS TECHNIQUE 
1. Introdução 


\section{Introdução}

Inicialmente descritas em 1562 por Fallopius (Figura 1), as tubas uterinas normais são órgãos simetricamente pareados que conectam a cavidade peritoneal à cavidade uterina (apud Clarke, 2006).

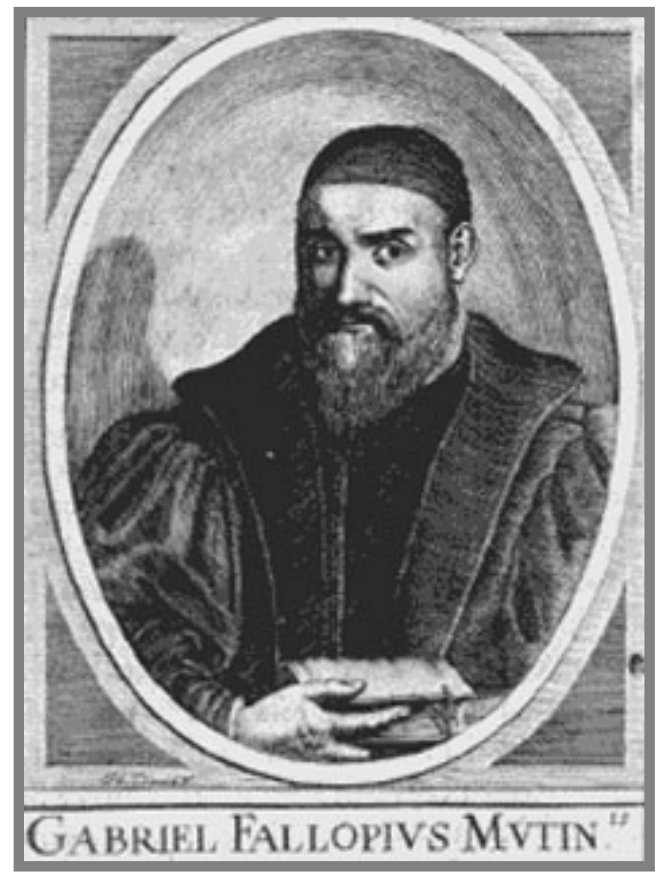

Figura 1. Gabriel Fallopius Mutin.

(Fonte: www.zol.be).

Anatomicamente, cada uma das duas tubas uterinas está situada na

margem superior (salpinge média) de um dos lados do útero (Figura 2). São 
divididas em quatro partes: (1) a extremidade fimbriada, em que está aderida

a fímbria ovariana; (2) a ampola, maior porção, que é extensa e relativamen-

te tortuosa, com paredes finas; (3) o ístmo, que é uma porção estreita, reta e com paredes também delgadas que se situa imediatamente adjacente ao útero; (4) uma porção intra-uterina ou intramural cujo lúmen chega a ser tão estreito quanto $1 \mathrm{~mm}$ ou menos quando penetra a parede uterina (Sklar, 2004; Zurawin, 2006).

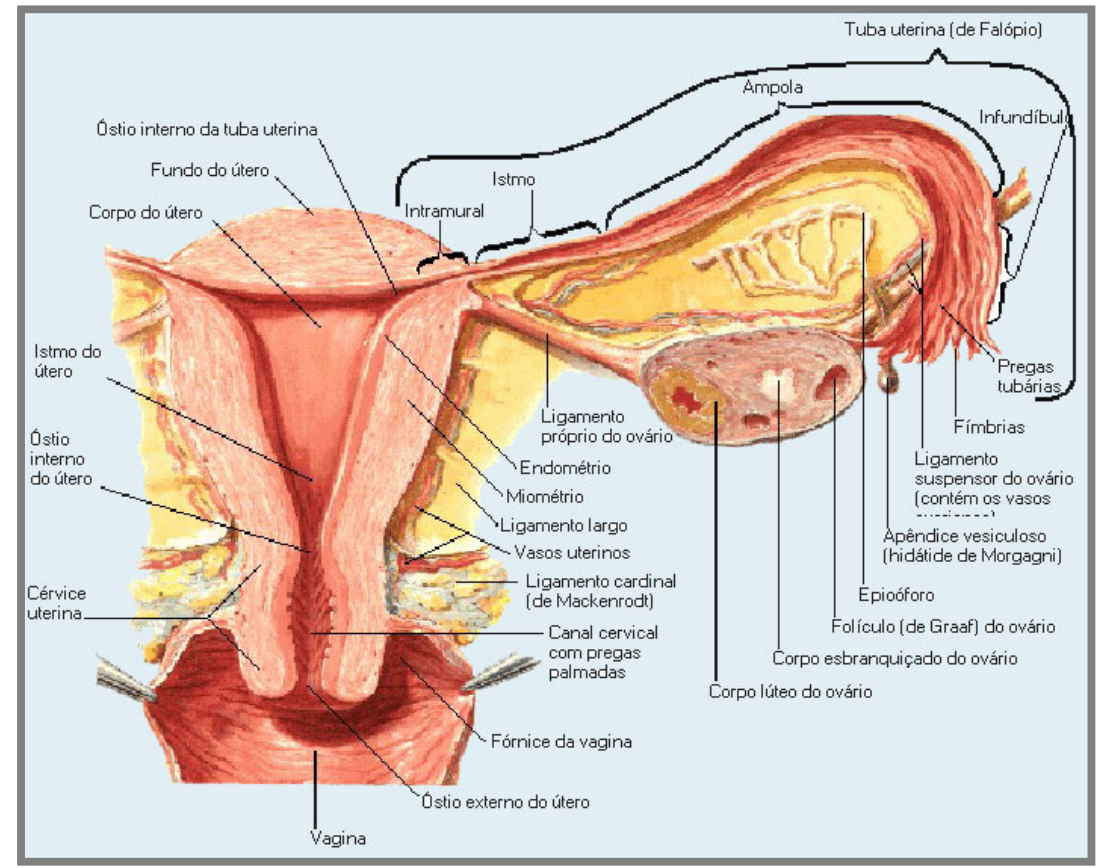

Figura 2. Tuba uterina.

(Fonte: www.geocities.com/genitalanato2002/tubas.htm.). 
Representam mais que simples conduto de um espaço a outro, pois é a tuba uterina que propicia o meio e as condições necessárias para a concepção e o desenvolvimento inicial do concepto, uma vez que a fertilização do óvulo assim como o desenvolvimento do zigoto em embrião e seu transporte até o endométrio ocorrem em seu interior (Boyle e Colon, 2006).

Tubas uterinas saudáveis e intactas são, portanto, elementos importantes para o processo natural de reprodução que sempre fascinou a Humanidade. Os mecanismos que levam ao comprometimento de suas funções são gerados por distorção anatômica, alteração da freqüência do movimento ciliar (FMC), alteração da peristalse tubária e alteração da secreção tubária, como inflamação crônica com alterações de macrófagos e atividade imunitária (Jansen, 1984; Halbert et al., 1976; 1989; Lyons et al., 2006).

Neste sentido, alterações anatomofuncionais, dentre as quais se destacam malformações congênitas, doença inflamatória pélvica, endometriose e salpingite, podem causar disfunção tubária distal ou proximal, ou mesmo o acometimento de toda a tuba (Kodaman et al., 2004). A doença tubária po- 
de, ainda, ser transitória, quando causada por obstrução, ou permanente, quando causada por oclusão (Decherney, 1987; Honore et al., 1999), sendo responsável por $25 \%$ a $35 \%$ dos casos de infertilidade feminina (Serafini e Batzolin, 1989).

As tubas uterinas podem também ter suas funções, que são múltiplas e complexas, comprometidas por causas iatrogênicas, como aderências decorrentes de cirurgias prévias ou, mais notadamente, pela laquedura tubária (LT), que é realizada mais adequadamente pela oclusão das suas porções ístmicas ou pela remissão de um de seus segmentos (Sklar, 2004; Zurawin, 2006)

Atualmente a LT é o método contraceptivo mais utilizado em todo o mundo (Kodaman et al., 2004).

\subsection{Laqueadura tubária}

Em 1823, Blundell (apud ACOG, 1996) apresentou à Sociedade Médica de Londres a tese de que a LT poderia constituir método contraceptivo 
eficaz, teoria essa pouco interessante para aquele momento histórico em que a função da mulher não era outra senão a de procriar; pelo contrário, deviam ter tantos filhos quantos fossem possíveis, ainda que pusessem em risco a própria saúde. Além disso, o controle da natalidade era tema extremamente controverso, quando não proibido (ACOG, 1996).

No entanto, 47 anos mais tarde, a primeira LT in vivo foi de fato realizada por Samuel Lungren, em 1880 (apud Bishop e Nelms, 1930), no estado norte-americano de Ohio, durante um parto cesáreo e com o objetivo de poupar a paciente de novas gestações de alto risco. Desde então, várias técnicas foram propostas para a realização da LT, dentre as quais se destacam as que seguem.

A técnica de Pomeroy (1930, apud Sklar, 2004) foi originalmente descrita como a ligação da porção média da tuba com fio duplo de categute cromado 1-0, seguida da ressecção da parte superior dessa ligação, e sofreu diversas modificações ao longo do tempo. O princípio dessa técnica se baseia na absorção imediata da sutura com a conseqüente separação das 
extremidades seccionadas da tuba que, então, são seladas por cicatrização espontânea e fibrose, resultando em falha natural de $2 \mathrm{~cm}$ a $3 \mathrm{~cm}$ entre os segmentos distal e proximal da tuba (Figura 3).

A técnica de Parkland, que propõe ressecção de segmento médio similar à técnica de Pomeroy (Figura 3), mas com ligação com pontos separados, foi desenvolvida para evitar a aproximação das extremidades seccionadas e, assim, eliminar o risco de aderências secundárias e recanalização (Sklar, 2004; Zurawin, 2006).

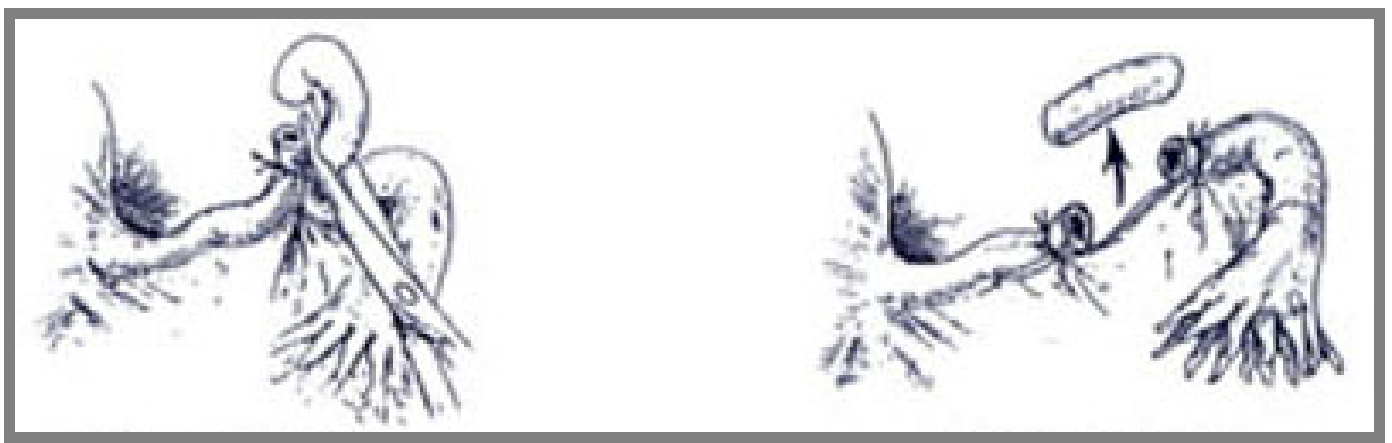

Figura 3. Técnicas de Pomeroy (à esquerda) e Parkland (à direita) para laqueadura tubária. (Fonte: www.clarkescope.com/spanish/techniques).

Na década de 1940, Uchida desenvolveu técnica (Figura 4) segundo a qual a camada muscular da porção média do istmo é ligada proximal ou dis- 
talmente com sutura simples de categute 0 ou 00 e, então, seccionada, e as extremidades serosas são reaproximadas (Sklar, 2004; Zurawin, 2006).

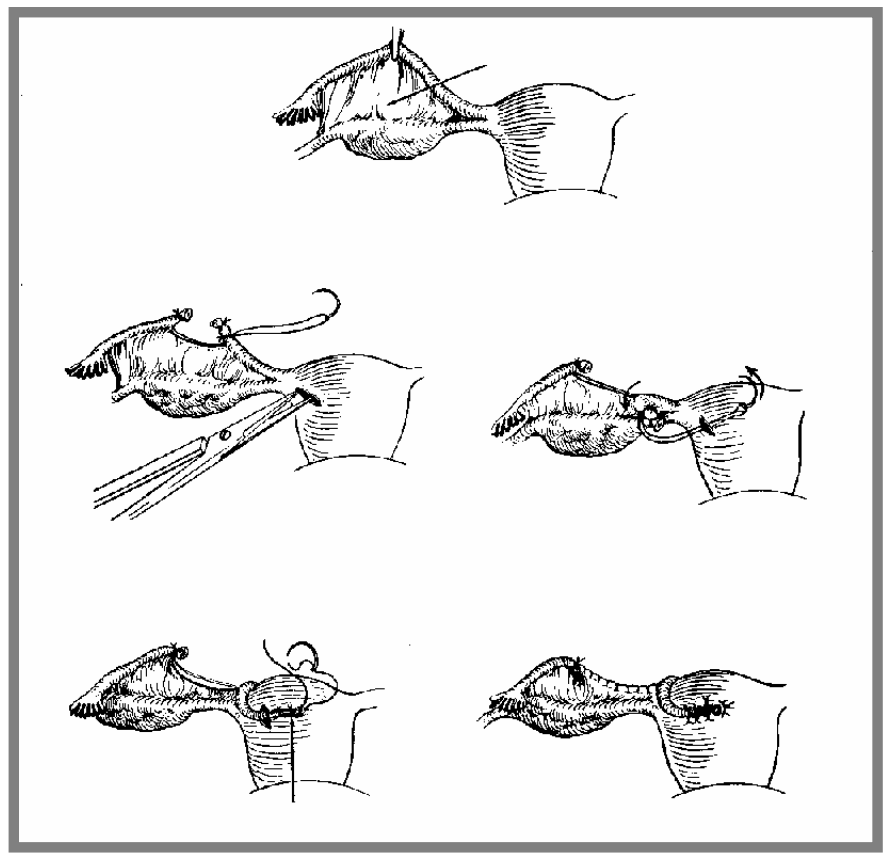

Figura 4. Técnica de Uchida para laqueadura tubária. (Fonte: www.clarkescope.com/spanish/techniques).

Outras técnicas para LT incluem a técnica de Irwing, desenvolvida para ser realizada por ocasião de parto cesáreo (Figura 5); as técnicas de eletrocoagulação (com corrente unipolar ou bipolar, conforme as Figuras 6 e 7, respectivamente); e as técnica mecânicas, como o anel de Yoon (Figura 8), o clipe de Hulka-Clemens (Figura 9) e o clipe de Filshie (Lipscomb et al., 1992). 


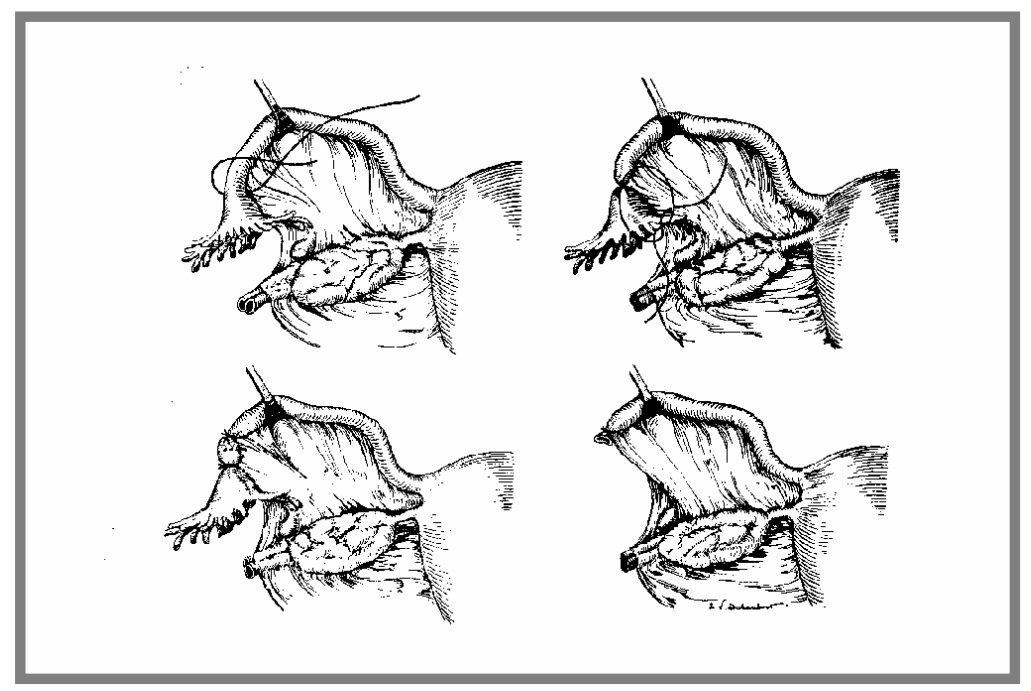

Figura 5. Técnica de Irwing para laqueadura tubária.

(Fonte: www.clarkescope.com/spanish/techniques).

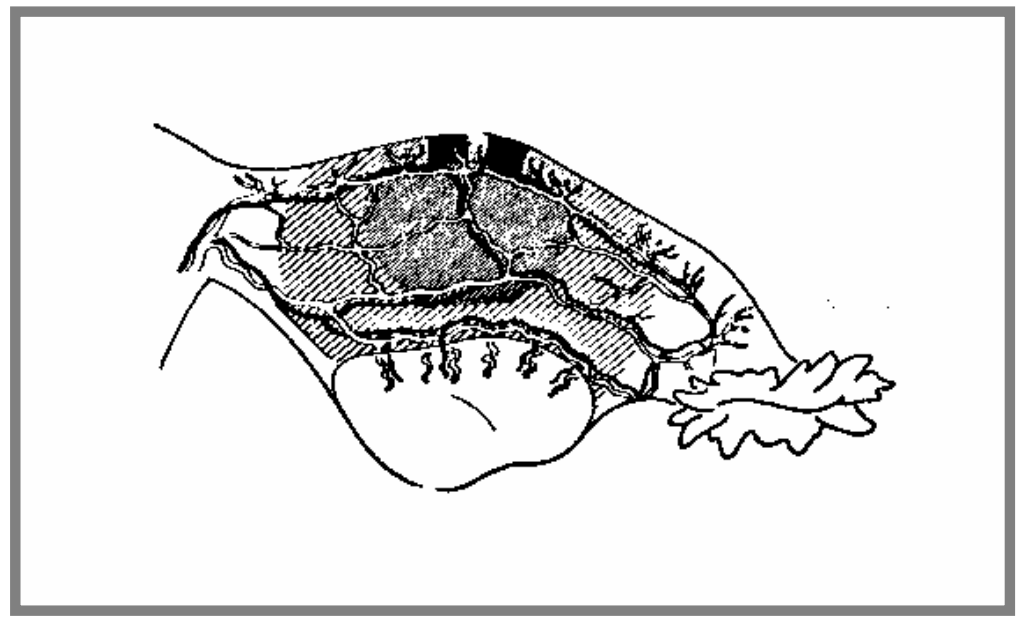

Figura 6. Técnica de eletrocoagulação com corrente unipolar para laqueadura tubária.

(Fonte: www.clarkescope.com/spanish/techniques).

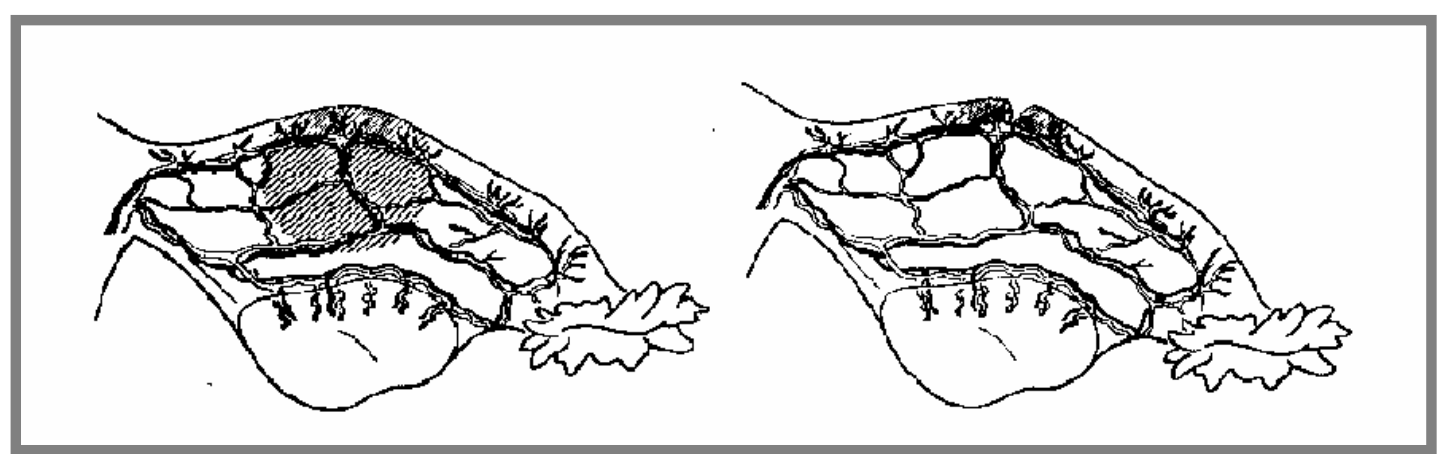

Figura 7. Técnica de eletrocoagulação com corrente bipolar para laqueadura tubária.

(Fonte: www.clarkescope.com/spanish/techniques). 


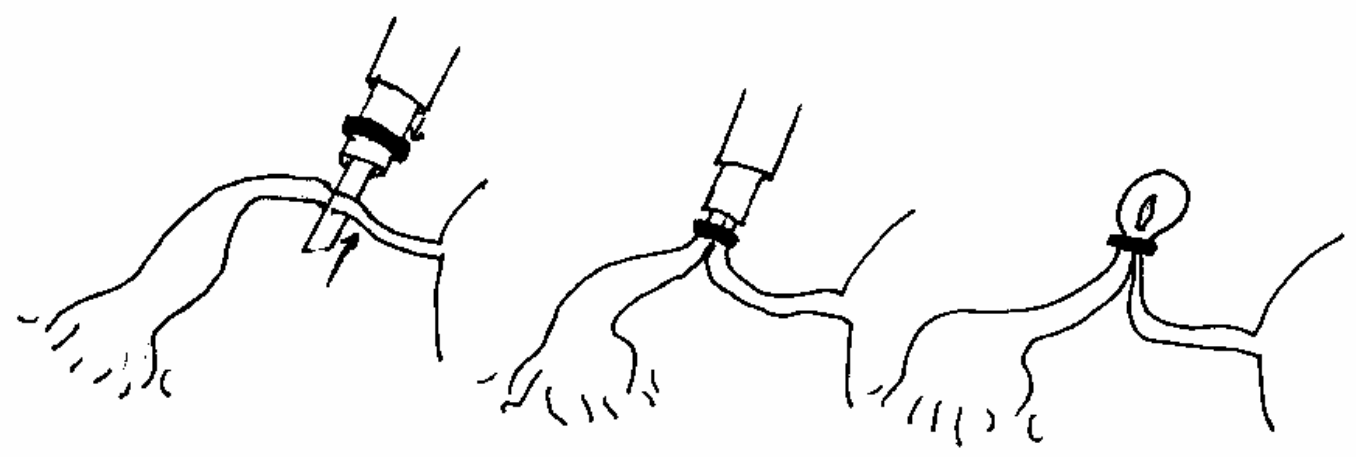

Figura 8. Anel de Yoon para laqueadura tubária.

(Fonte: www.clarkescope.com/spanish/techniques).

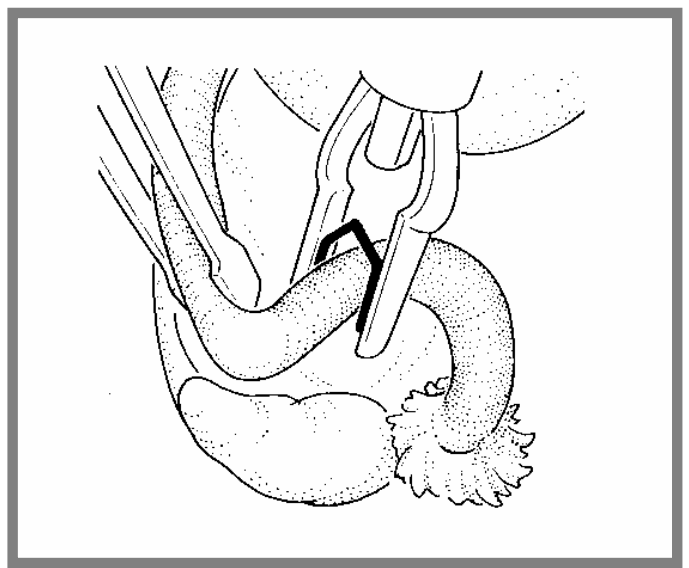

Figura 9. Clipe de Hulka-Clemens para laqueadura tubária.

(Fonte: www.endoscopiaemginecologia.com.br).

Bosch realizou a primeira oclusão tubária laparoscópica em 1963, ain-

da que a laparoscopia só tenha sido mais amplamente empregada a partir

do final da década de 1970 (Cunanan Jr. et al., 1980). Até meados dos anos

1970, a esterilização tubária envolvia procedimento cirúrgico abdominal que

requeria anestesia geral, longa permanência hospitalar e recuperação lenta 
e dolorosa (PPFA, 2002). Em 1971, Thompson e Wheeless (apud Cunanan Jr. et al., 1980) relataram a realização da esterilização tubária laparoscópica em regime ambulatorial em 666 pacientes.

A contracepção realizada por laparoscopia ganhou maior impulso, portanto, principalmente ao longo dos anos 1970 , e na década de 1990 se transformou no método contraceptivo mais popular do mundo. Estudo prospectivo multicêntrico envolvendo 9.475 mulheres norte-americanas submetidas à esterilização laparoscópica evidenciou que a taxa de complicações intra ou pósoperatórias foi inferior a $1 \%$, ratificando o caráter seguro e eficaz do procedimento para LT (Jamieson et al., 2000).

Hoje se estima que aproximadamente 700 mil LTs sejam realizadas anualmente nos EUA, e que mais de 190 milhões de casais em todo o mundo optem por esterilização cirúrgica (EC) como método seguro e confiável de contracepção permanente (Jamieson et al., 2000; Sklar, 2004; Zurawin, 2006).

No Brasil, o número de mulheres que optam por esse método de contracepção é ainda maior que na maioria dos países. Dados da PNDS (Pes- 
quisa Nacional de Demografia e Saúde) publicados em 1996 revelaram que $21 \%$ das mulheres com idade entre 25 e 29 anos e $37 \%$ das mulheres com idade entre 30 e 34 anos realizaram LT. Estudo mais recente com 13.112 mulheres entrevistadas na cidade de São Paulo evidenciou que $26 \%$ delas eram laqueadas (PAISM, 2005).

Apesar de a EC ser realizada para ter, a princípio, resultado permanente, o arrependimento pela sua realização é relativamente freqüente. Chi e Jones (1994) relataram que a taxa de arrependimento pode atingir de $2 \%$ a $26 \%$. Estudo colaborativo realizado nos EUA revelou que a taxa cumulativa de arrependimento ao longo dos 14 anos subseqüentes à EC é de 20,3\% entre mulheres que realizaram a LT antes dos 30 anos, e de 5,9\% entre muIheres que a realizaram após os 30 anos de idade (Hillis et al., 1999). Neste mesmo período de 14 anos após a LT, Schmidt (2000) encontrou taxa cumulativa de arrependimento de $14 \%$ no grupo geral analisado; no entanto, no subgrupo de mulheres com idades entre 18 e 24 anos, essa taxa aumentou para $40 \%$. A maioria dos estudos, porém, reporta taxas globais de arrependi- 
mento que variam entre $3 \%$ e $10 \%$ (RCOG, 2004).

Análise de dados obtidos de 2.253 mulheres laqueadas evidenciou forte correlação entre o arrependimento pela esterilização, idades mais jovens e mudanças na situação conjugal (Platz-Christensen et al., 1992), dados também observados em estudo brasileiro realizado no Hospital das Clínicas da Faculdade de Medicina da Universidade de São Paulo (Ades, 1996). A perda de um filho também constitui motivo freqüente para que a mulher com tubas laqueadas procure a possibilidade de reversão cirúrgica da laqueadura (RCL) (Escalona et al., 2006).

Por outro lado, a probabilidade de uma mulher arrependida de ter realizado a LT se submeter à RCL 14 anos após a esterilização é de 1\% (Schmidt, 2000), podendo chegar a $3 \%$ conforme a faixa etária em que a mulher se encontre (RCOG, 2004). Essa taxa é de $0,2 \%$ nos cinco primeiros anos após a LT (Sklar, 2004; Zurawin, 2006).

Em estudo retrospectivo realizado no Brasil compreendendo o período de 15 anos (1983-1998) registrou-se que 143 mulheres anteriormente sub- 
metidas à LT se arrependeram e procuraram informações em serviço especializado sobre a RCL. Apenas uma dessas mulheres havia realizado a LT após os 35 anos, e $60 \%$ optaram pela esterilização cirúrgica antes dos 25 anos de idade. Metade dessas mulheres desistiu da RCL já na primeira consulta; outras 22 foram desaconselhadas a prosseguir no tratamento por motivos diversos; 13 não apresentavam condições para a RCL. Por fim, 32 muIheres foram submetidas à RCL (Fernandes et al., 2001).

A reversão da LT passou, assim, a constituir nova preocupação dos pesquisadores, especialmente no que se refere a avaliar a sua viabilidade.

\subsection{Avaliação do prognóstico de reversibilidade tubária}

Para que se possa pensar na RCL, há que se considerar, antes, o método empregado para a realização da $L T$, já que a reversão só será possível mediante adequada extensão residual das tubas ligadas (Antoine et al., 1983; Kodaman et al., 2004). Sabe-se, por exemplo, que as LTs feitas por eletrocoagulação são as de reversão mais difícil, quando não impossível 
(Cantor e Riggall, 1979; Rock et al., 1987), enquanto as minilaparotomias com laqueadura de pequena porção do segmento ístmico pela técnica de Pomeroy e modificações parecem resultar em maior viabilidade para a $\mathrm{RCL}$ (Cantor e Riggall, 1979).

Além disso, a localização da anastomose realizada, a idade da paciente e a presença de outras alterações tubárias coexistentes também influenciam na viabilidade para RCL (Henderson, 1984; Benadiva et al., 1995).

A fertilização in vitro tem sido uma alternativa para $R C L$ inviáveis (Benadiva et al., 1995; Karande et al., 1999). Todavia, além de resultar em gestações mais complicadas (como gravidez ectópica recorrente) e em maior taxa de complicações (como hidrossalpinge), há maior resistência dos planos públicos e privados de saúde para disponibilizá-la, devido à sua relação custo-benefício (Karande et al., 1999).

Desta forma ressalta-se a necessidade da avaliação das tubas antes da realização da RCL, tendo em vista o fato de as alterações anatômicas poderem interferir de forma significativa no prognóstico de gravidez. Além 
disso, nem todas as mulheres que desejam a RCL apresentam os critérios mínimos para a sua indicação e realização (Escalona et al., 2006).

Antoine et al. (1983) analisaram 377 pacientes que desejavam a RCL e observaram que o procedimento não teria sucesso em $40 \%$ dos casos devido à destruição excessiva da tuba.

Kim et al. (1997a,b) reforçaram a importância de as mulhres encaminhados para RCL serem avaliadas quanto à história obstétrica, ginecológica e informações sobre a LT, e realizarem exame ginecológico, curva de temperatura basal, teste pós-coito, histerossalpingografia (HSG), além de serem submetidas à laparoscopia diagnóstica para avaliação das tubas restantes e para o diagnóstico de outras causas de infertilidade.

A American Society for Reproductive Medicine (ASRM) propôs classificação para oclusão tubária secundária à LT, na qual o prognóstico de gravidez subseqüente à RCL foi categorizado em excelente (prognóstico de concepção superior a $75 \%$ ), bom (entre $50 \%$ e $75 \%$ ), regular (entre $25 \%$ e $50 \%$ ), ruim (menor de $25 \%$ ) e péssimo (sem viabilidade para concepção). As anas- 
tomoses ístmo-ístmicas foram recomendadas como as de melhor resultado para os casos de RCL (ASRM, 1988).

Atualmente, algumas técnicas utilizadas para diagnóstico de disfunção tubária vêm sendo empregadas também para a determinação da viabilidade da RCL.

1.3 Técnicas de avaliação tubária

\subsubsection{Histerossalpingografia (HSG)}

A HSG foi utilizada pela primeira vez no estudo de mulheres inférteis por Holman, em 1949, e hoje representa um dos exames disponíveis para a avaliação da cavidade uterina e das tubas na pesquisa do casal infértil (ASRM, 2006). Trata-se de radiografia do útero e das trompas após injeção de material radiopaco (Figura 10) representado por meios iodados hidrossolúveis (Mitri et al., 1991), que podem ser introduzidos por cateter balão ou cânula, conforme a preferência do examinador e o objetivo do exame (Yoder e Hall, 1991). 


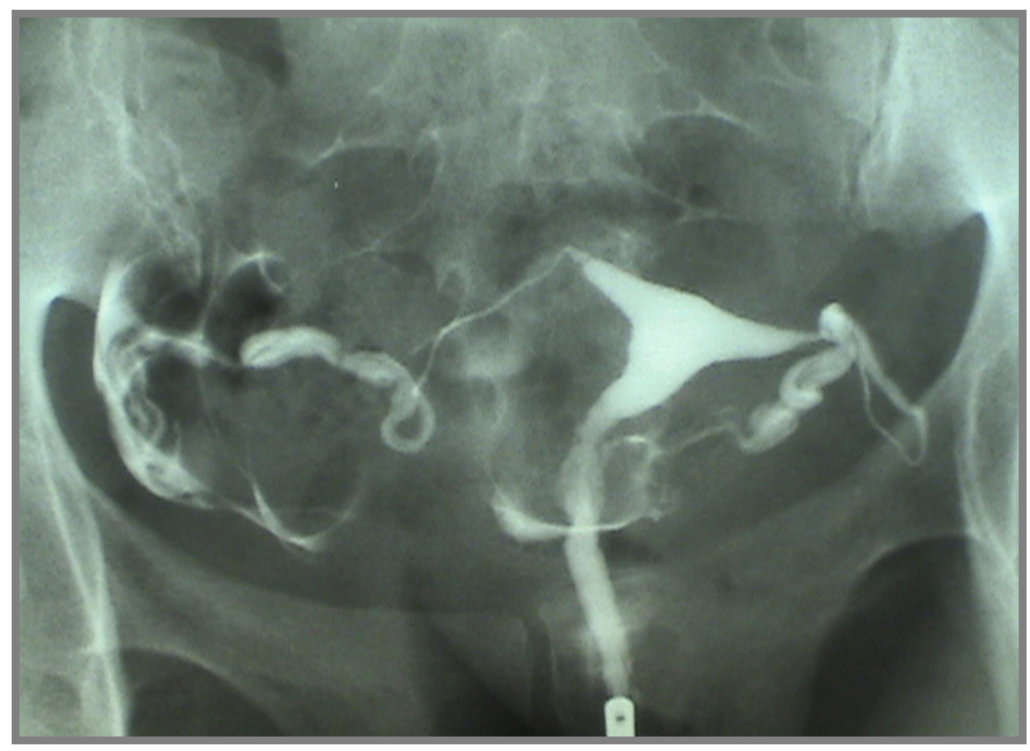

Figura 10. Imagem da cavidade uterina e das tubas obtida por histerossalpingografia.

A HSG é o método mais utilizado atualmente para o diagnóstico de fator tuboperitoneal por ser mais prático e de baixo custo (Almeida et al., 2000). A sensibilidade e a especificidade dessa técnica na avaliação da doença tubária variam amplamente em diversos estudos, mas está estabelecido que a sensibilidade é de $60 \%-65 \%$ e a especificidade se aproxima de 80\% (Karande et al., 1995).

Segundo Krysiewicz (1992), esta técnica apresenta a desvantagem de a dose de radiação média por um exame de cinco a 20 minutos variar entre 1,0 e 3,6 Gy, o que pode limitar o seu uso em infertilidade. 
Com o avanço das técnicas endoscópicas a partir da década de 1970, alguns autores compararam os resultados da HSG com os achados da endoscopia na avaliação da disfunção tubária. Moghissi e Sim (1975) observaram concordância completa dos dois exames em 53\% das 132 mulheres estudadas, e registraram resultados falsos-positivos e falsos-negativos em $5 \%$ e $14 \%$, respectivamente, dos achados da HSG. Gabos (1976) encontrou taxa de concordância similar (55\%), e sugeriu que, embora a HSG deva ser exame de escolha como parte da avaliação da disfunção tubária, é imprescindível que a mulher infértil seja submetida à endoscopia antes do diagnóstico definitivo. Ratificando estes achados, Swart et al. (1995) publicaram metanálise que demonstrou a não confiabilidade da HSG para determinação das condições das tubas, sendo apenas confiável para a determinação da sua permeabilidade.

Outros autores também têm comparado a eficácia diagnóstica da HSG e da laparoscopia. Lavy et al. (2004) concluíram que não há necessidade de realização da laparoscopia em mulheres com achados normais à HSG nem 
naquelas em que a HSG indica doença tubária distal unilateral, já que a indicação terapêutica é a mesma em $95 \%$ dos casos. Por outro lado, a laparoscopia deve ser realizada em mulheres cujos achados da HSG revelam suspeita de oclusão tubária bilateral, uma vez que o planejamento terapêutico deve ser modificado em $30 \%$ dos casos.

A HSG pode ser igualmente utilizada na avaliação da viabilidade da RCL. Karasick e Ehrlich (1989) concluíram que a HSG é técnica útil na determinação da condição da porção proximal da tuba no planejamento da RCL. Groff et al. (1990), por outro lado, desaconselharam a realização de rotina da HSG em pacientes com desejo de RCL. Em revisão publicada por Yoder e Hall (1991) os autores verificaram que a HSG era pouco indicada para avaliação da possibilidade de RCL.

Parece bem estabelecido que, embora a HSG forneça informações sobre a integridade das tubas, sobre a sua morfologia, e sobre a ausência de obstruções, trata-se de teste que não permite a identificação de estruturas como as fímbrias, de aderências pélvicas, das superfícies ovarianas, de le- 
sões do endométrio, nem da integridade do fundo de saco de Douglas, conferindo, assim, melhor valor diagnóstico às abordagens endoscópicas, especialmente à hidrolaparoscopia transvaginal associada com mini-histeroscopia (Cicinelli et al., 2001).

\subsubsection{Laparotomia}

A laparotomia permite o exame das tubas, porém é alternativa mais agressiva e com possibilidade diagnóstica inferior à laparoscopia diagnóstica no estudo da fertilidade feminina (Soares et al., 1997).

Embora autores como O'Brien et al. (1983) afirmem que a laparotomia constitui o único meio confiável de avaliação exata das condições das tubas, com o conhecimento e a eficácia das técnicas minimamente invasivas, a laparotomia vem sendo cada vez mais reservada para casos adequadamente selecionados (Tulandi, 1996; Barjot et al., 1999). 


\subsubsection{Métodos endoscópicos}

As primeiras referências à endoscopia datam da Antigüidade na Gré-

cia, quando Hipócrates utilizou espéculo para realizar exame do reto. Conco-

mitantemente, na medicina romana havia relatos de exames vaginais com a

utilização de espéculos (Figuras 11 e 12) (Mount Sinai School of Medicine, 2006).

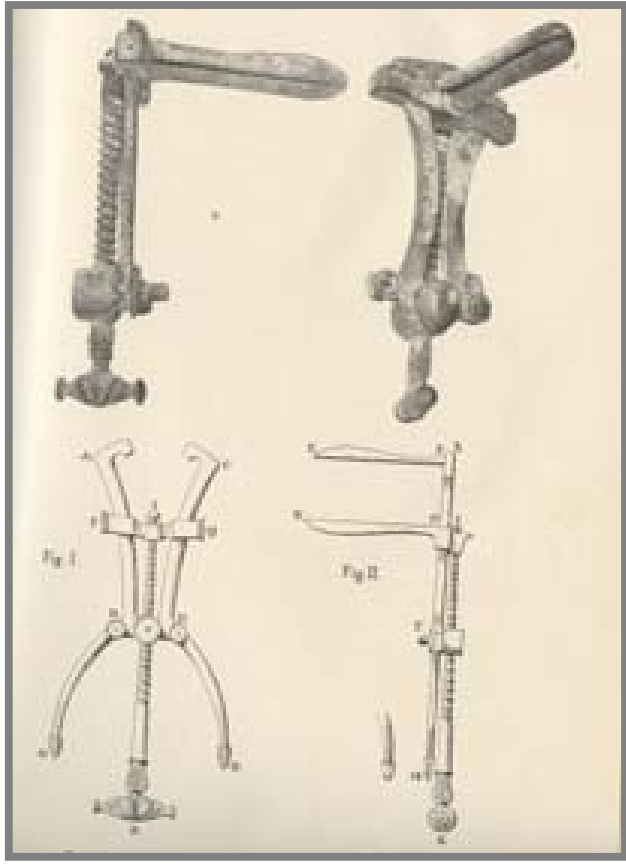

Figura 11. Speculum magnum matricis, Medicina Romana.

(Fonte: www.ab.dip-caceres.org).

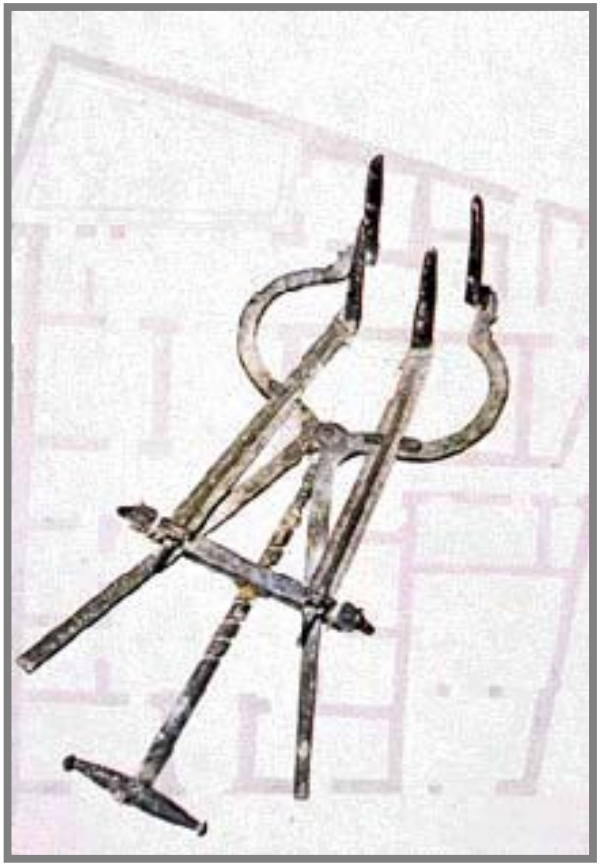

Figura 12. Espéculo de bronze denominado catoptro para exame vaginal e retal, encontrado na Casa dos Cirurgiões cerca de 62-79 d.C., em Pompéia. (Fonte: www.epub.org.br). 
Séculos mais tarde, Phillip Bozzini (Figura 13) construiu, em 1806, um aparelho que consistia de tubo metálico com jogo de espelhos que refletia a luz de uma vela, permitindo a visualização de órgãos internos do corpo humano, e que foi utilizado pela primeira vez para visualização da uretra (cf. www.hisandherhealth.com). Deu ao instrumento o nome de Lichtleiter(Figura 14).

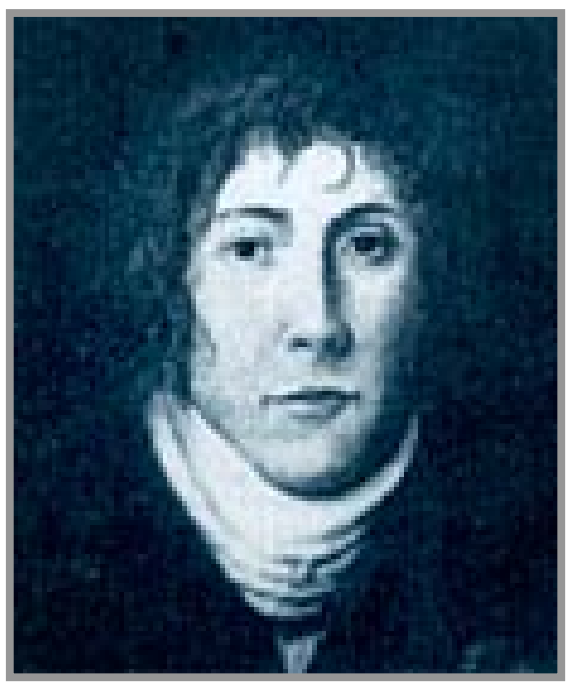

Figura 13. Phillip Bozzini.

(Fonte: www.bbraun.com).

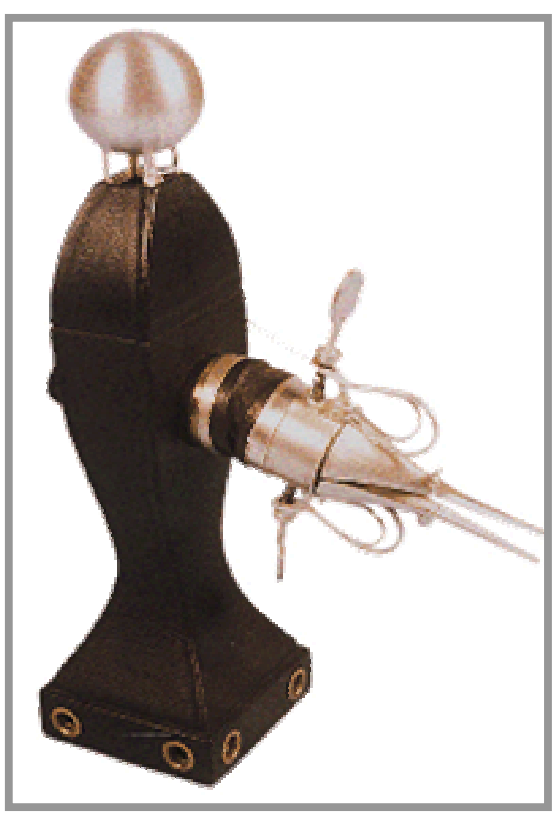

Figura 14. Réplica do endoscópio Lichtleiter.

(Fonte: www.hisandherhealth.com). 
Em 1853 o cirurgião francês Antoine Jean Desormeaux apresentou um

novo aparelho, semelhante ao desenvolvido por Bozzini, mas que utilizava

uma lâmpada de querosene como fonte de iluminação e que foi empregado

para a inspeção do trato geniturinário (Figura 15). Por esse invento, muitos

cirurgiões consideram Desormeaux como o "Pai da Endoscopia" (Belt e

Charnock, 1936 apud Guning, 1974).

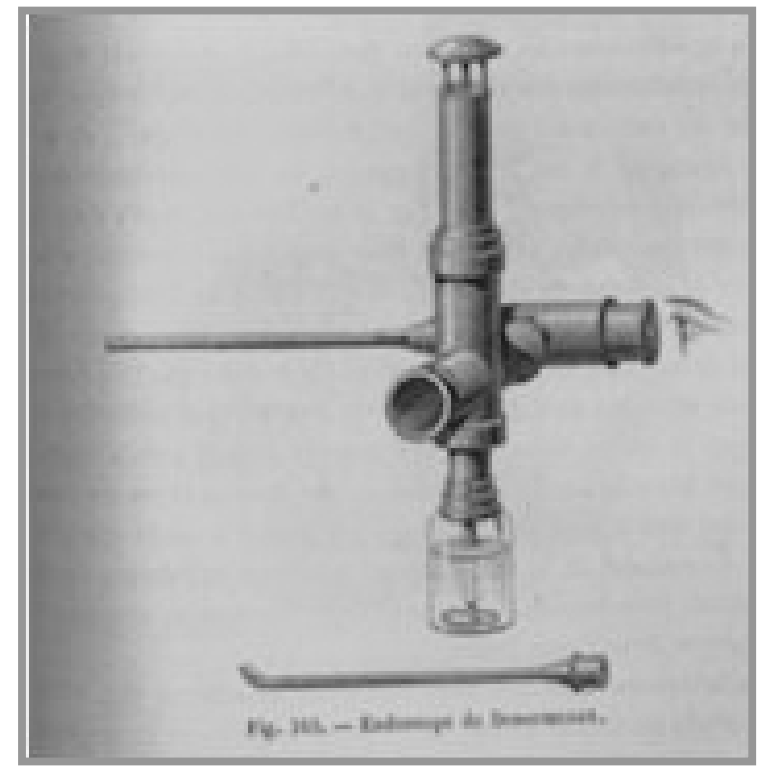

Figura 15. Endoscópio de Desormeaux.

(Fonte: www.scamilloforlanini.rm.it/laparoscopia).

A evolução desse tipo de instrumento associada às técnicas aprimora-

das de visualização resultou, dentre outras coisas, na primeira laparoscopia 
experimental, realizada em 1901 pelo cirurgião alemão George Kelling (Figura 16), que utilizou um cistoscópio para visualizar a cavidade abdominal de cães, denominando o método de "celioscopia". Kelling utilizou ar filtrado através de algodão estéril para produzir pneumoperitônio por uma agulha (Figura 17) (Belt e Charnock, 1936 apud Gunning, 1974).

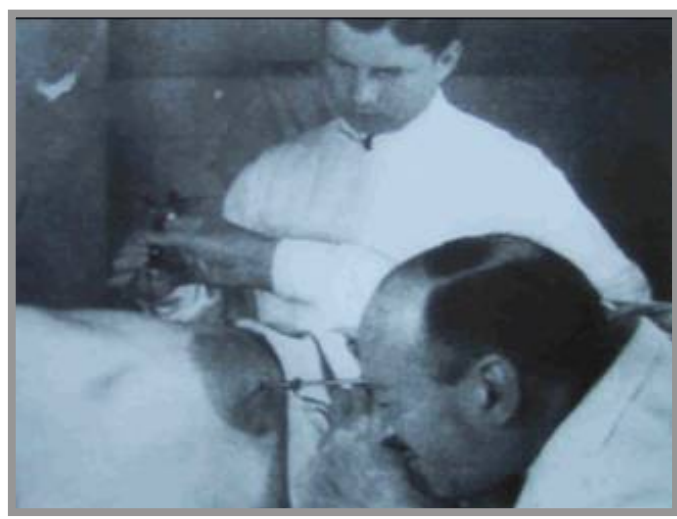

Figura 16. George Kelling.

(Fonte: www.laparoscopyhospital.com).

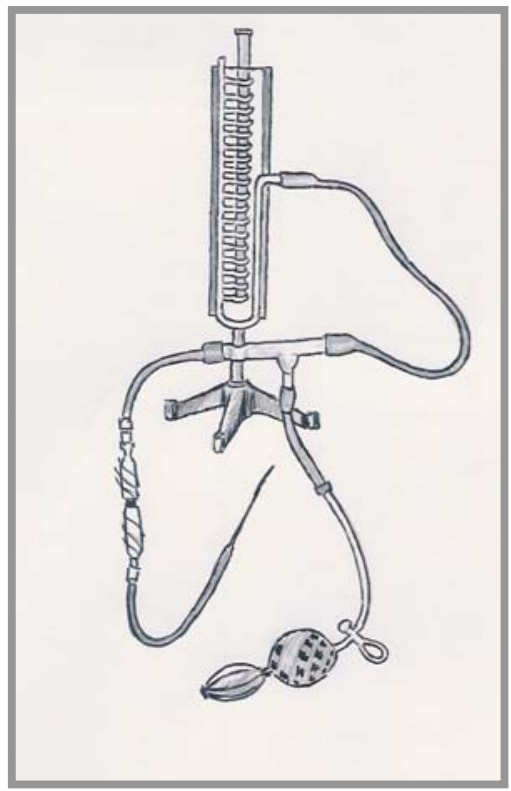

Figura 17. Instrumento para pneumoperitônio de Kelling.

(Fonte: www.lap-surg.com). 
O avanço contínuo nos conhecimentos da Humanidade resultou em uma

série de abordagens minimamente invasivas tanto com finalidades diagnósticas quanto terapêuticas.

\subsubsection{Laparoscopia diagnóstica}

Como resultado do enorme progresso das técnicas endoscópicas e da sofisticação dos instrumentais cirúrgicos, a laparoscopia se destaca como técnica minimamente invasiva que, além de fornecer visualização ampla e panorâmica dos órgãos pélvicos, também permite que a correção cirúrgica eventualmente necessária seja realizada já no momento de seu diagnóstico (Berker et al., 2005). Trata-se de exame endoscópico amplamente indicado para a avaliação da viabilidade de RCL (Silber e Cohen, 1980; Yoon et al., 1997).

Enquanto procedimento diagnóstico, a laparoscopia permite (1) avaliar aderências pélvicas e lesões tubárias antes de uma RCL; (2) mensurar o diâmetro de uma hidrossalpinge para determinar a viabilidade da RCL; e (3) 
identificar a porção distal da(s) tuba(s) antes da RCL. O procedimento também facilita a estimativa da extensão residual da tuba, além de permitir a reconstrução sob a mesma anestesia utilizada para a investigação diagnóstica, tanto por cirurgia laparoscópica quanto por laparotomia, se necessária, ainda que algumas poucas pacientes necessitem de novo procedimento cirúrgico em casos em que há indicação de laparotomia (Boyle e Colon, 2006). Opsahl e Klein (1987) demonstraram a importância do relatório cirúrgico da LT. As pacientes que apresentavam suposto bom prognóstico para reversão (técnica de Pomeroy, cauterização única ou clipe) eram encaminhadas diretamente para o procedimento. As outras com suspeita de prognóstico desfavorável ou sem relatório cirúrgico eram encaminhadas para laparoscopias diagnósticas antes da tentativa de RCL. Com isso, detectouse que $3,8 \%$ (sete de 185) das pacientes tinham tubas irrecuperáveis; por outro lado, evitaram-se $71 \%$ das laparoscopias cirúrgicas.

Sedbon et al. (1989) relataram o primeiro caso de reconstrução tubária realizada exclusivamente com laparoscopia tanto para o diagnóstico da via- 
bilidade da RCL quanto para a reconstrução tubária, em casos de LT com anel de Yoon. Embora o método fosse, então, aplicável a apenas uma tuba, havia a vantagem de, em caso de falha da outra tuba, vir a ser reconstruída por microcirurgia. Por outro lado, o sucesso da intervenção resultou em a laparotomia ter sido desnecessária, acarretando menor tempo de hospitalização e risco mínimo de aderências pós-operatórias.

Risquez et al. (1992) relataram os estudos com a microlaparoscopia. O diâmetro óptico reduzido permitiu menores acessos, mas com prejuízo da resolução óptica observada nos laparoscópios de diâmetros convencionais. A fabricação de novas lentes tem incrementado substancialmente o campo de visualização, sensibilidade à luz e resolução, melhorando os microlaparoscópios. Ademais, estes podem ser encaixados a qualquer tipo de equipamento laparoscópico (Bauer e Diedrich, 1997).

Embora a laparoscopia venha sendo sugerida como passo fundamental para descartar a presença de adesões peritubárias e endometriose, mesmo nos casos em que a HSG evidencia boas condições das tubas, Fatum et al. 
(2002) desaconselham a sua realização, considerando as baixas taxas de ocorrência de doença tubária clinicamente relevante mediante achados normais na HSG.

Ikeda (2002) realizou estudo utilizando a microlaparoscopia com anestesia local, mas preferiu realizá-la em centro cirúrgico, temendo ocorrer complicações e levando em conta as precárias condições de suporte para abordar tais eventos em ambulatório. Trata-se de técnica que utiliza instrumentais específicos, frágeis e pouco disponíveis.

\subsubsection{Técnicas endoscópicas transvaginais}

Nos últimos anos, surgiram outras formas de endoscopias transvaginais que ainda apresentam vários aspectos a serem estudados, derivadas da culdoscopia primariamente proposta por Decker e Cherry (1944): a hidrolaparoscopia transvaginal (HLT) (Gordts et al., 1998a,b), a fertiloscopia (Watrelot et al., 1997, 1998) e a vídeo-pelviscopia transvaginal (Ueno et al., 2000). 


\section{A) Culdoscopia}

A culdoscopia consiste na visualização endoscópica transvaginal de órgãos pélvicos através de punção no recesso vaginal posterior da vagina com a paciente em posição genupeitoral. Roland (1970) afirmava que, na culdoscopia, a visualização dos ovários e fímbrias era realizada mais facilmente e com melhor resolução visual que na laparoscopia, mas não fornecia informações de todas as estruturas pélvicas e do abdome superior.

As principais indicações da culdoscopia situavam-se no diagnóstico diferencial das afecções pélvicas agudas como, por exemplo, gravidez ectópica e doença inflamatória pélvica. Na pesquisa de algia pélvica crônica e de infertilidade, permitia diagnosticar enfermidades como endometriose e aderências. A culdoscopia também era útil no diagnóstico de miomas subserosos, cistos funcionais e tuberculose pélvica (Copenhever, 1970).

Na vigência de tumores que ocupavam o fórnice vaginal posterior, esta modalidade terapêutica era contra-indicada. Outros obstáculos para o seu uso rotineiro incluíam história de doença inflamatória pélvica, cervicites crô- 
nicas, vaginites, retroversão fixa do útero, atrofia vaginal, impossibilidade da posição genupeitoral (devido a doença pulmonar, cardíaca ou ortopédica) e tendência a hemorragias (Clyman, 1957).

A culdoscopia operatória foi descrita por Clyman em 1963, que realizou vários procedimentos, incluindo a fimbrioplastia. No entanto, mesmo em mãos experientes, havia certo número de falhas na punção do fundo de saco vaginal e dificuldades em atingir a cavidade peritoneal, na maioria das vezes relacionadas a aderências ou bloqueios locais, demonstráveis pela laparotomia. Com efeito, Clyman (1957) citou 39 (4,1\%) falhas dentre 960 culdoscopias realizadas.

Billingsley et al. (1963) citaram complicações significativas em 29 $(6,4 \%)$ e falha em $35(7,8 \%)$ dentre 450 pacientes estudadas. Revisando a literatura pertinente, dentre 4.685 casos, Hall (1967) referiu taxa de falhas de $6 \%$ com variação de $2,9 \%$ a $16,2 \%$; tais casos poderiam ser decorrentes da inadequação da visualização das estruturas pélvicas, como a impossibilidade de acesso ao fórnice vaginal posterior, e mesmo de erros diagnósticos. 
A culdoscopia começou a ser abandonada nos anos 70 em favor da laparoscopia, que fornecia visualização panorâmica da pelve e era superior quanto à esterilização tubária (McCann e Cole, 1978). Ainda assim, Scott e Magos (2002) sugeriram recentemente que a culdoscopia ainda se configura como alternativa para a laparoscopia em casos de infertilidade inespecífica, merecendo maior utilização como método diagnóstico.

B) Fertiloscopia

O uso de meio líquido através da culdoscopia foi introduzido por Odent (1973); a técnica foi modificada por Mintz (1987) para permitir o decúbito dorsal.

Surgia, assim, o conceito da hidrolaparoscopia, à qual Watrelot et al. (1997) acrescentaram a realização da cromotubagem com azul de metileno, da histeroscopia e, opcionalmente, da salpingoscopia, e denominaram o método de fertiloscopia (Figura 18).

Levando-se em consideração que propiciava boa visualização dos ovários e suas relações com as fímbrias tubárias, a fertiloscopia foi proposta 
como alternativa à laparoscopia diagnóstica na abordagem da mulher infértil

(Watrelot et al., 1998, 1999).

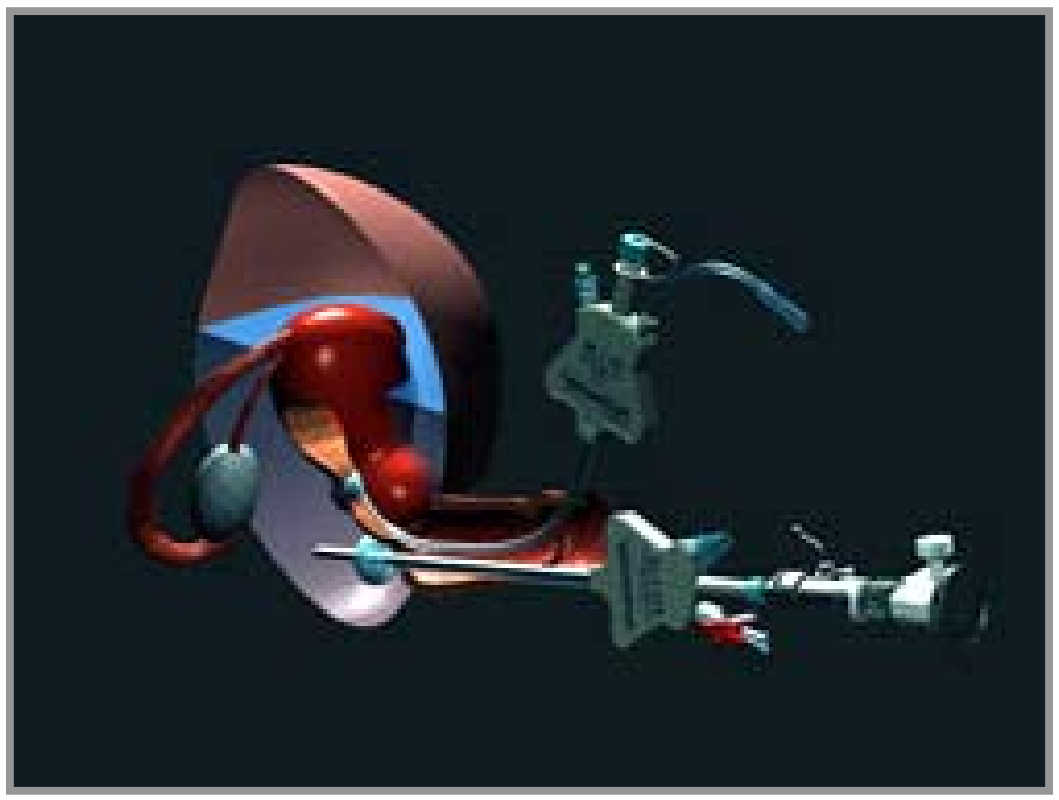

Figura 18. Desenho esquemático da fertiloscopia.

(Fonte: www.fertiloscopy.com).

Watrelot et al. (2003) afirmaram que a laparoscopia se mantém como

via de acesso preferencial quando há necessidade de correção cirúrgica en-

doscópica. Por outro lado, como a maioria das mulheres subférteis que são

submetidas à laparoscopia diagnóstica não apresenta qualquer alteração, a

fertiloscopia poderia ser uma primeira alternativa na avaliação destas paci-

entes. Ratificando-se isso se tem que a fertiloscopia tem a vantagem da 
simplicidade, podendo ser realizada em ambulatório com anestesia local, não acarreta incisões abdominais ou cicatrizes, apresenta baixo risco de lesões vasculares; além disso, foi demonstrado que o procedimento é menos doloroso que a HSG (Cicinelli et al., 2001). Finalmente, a grande magnificação oferecida possibilita alto grau de precisão diagnóstica na avaliação dos ovários e da parte distal das tubas.

Watrelot et al. (2003) estudaram 92 mulheres selecionadas em 14 hospitais-escola universitários que foram submetidas à fertiloscopia seguida de laparoscopia transabdominal, e encontraram alto grau de concordância entre as duas técnicas. Houve sensibilidade de $86 \%$ e $87 \%$ para a fertiloscopia e para a laparoscopia, respectivamente, enquanto o valor preditivo negativo foi de $64 \%$ e $67 \%$. A partir dos achados da fertiloscopia, teriam sido evitadas 75 (93\%) laparoscopias.

C) Salpingoscopia

A salpingoscopia é descrita como técnica utilizada para visualização da camada mucosa do segmento distal da tuba durante a realização da lapa- 
roscopia ou da laparotomia (Brosens et al., 1987); todavia, realizada no momento da laparotomia ou da laparoscopia, exige hospitalização e anestesia geral, motivo pelo qual Gordts et al. (1998c) a utilizaram como procedimento ambulatorial adjuvante à HLT, permitindo a exploração do interior da tuba com visualização da mucosa tubária em seu segmento distal (Figura 19).

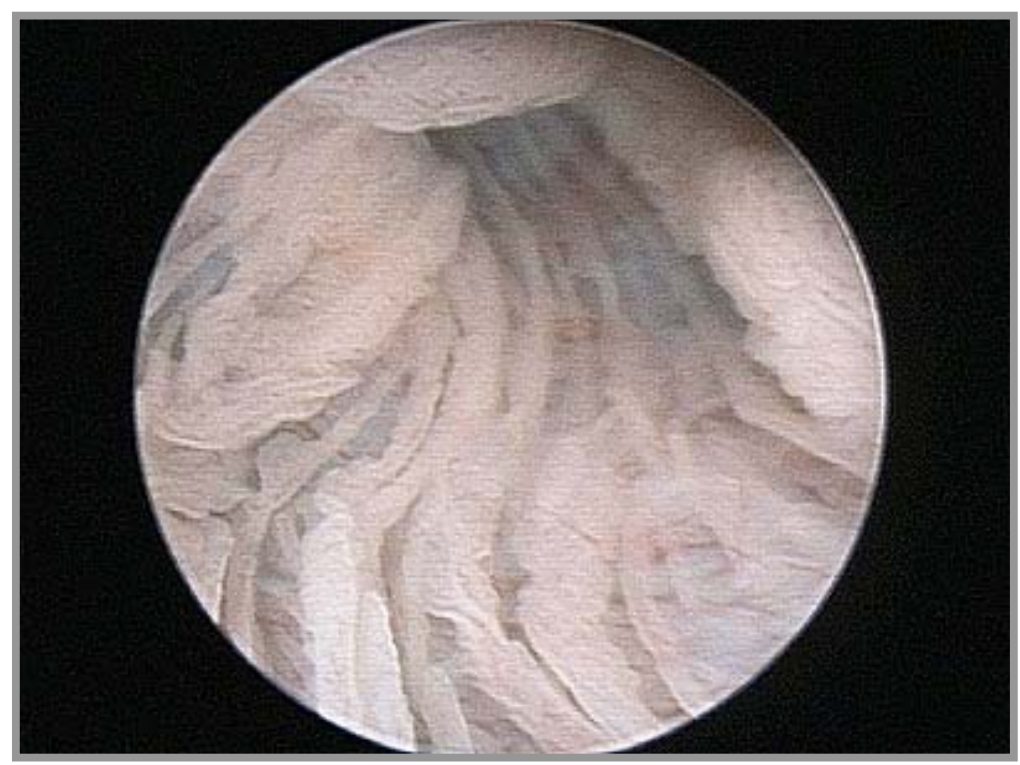

Figura 19. Imagem do interior da porção ampolar da tuba. (Fonte: www.fertiloscopy.com).

Marana et al. (2003) conduziram ampla revisão de literatura sobre a salpingoscopia adjuvante utilizada com a laparoscopia, a fertiloscopia e a HLT, e concluíram que a associação da salpingoscopia às técnicas transva- 
ginais resulta em redução drástica de laparoscopias diagnósticas.

D) Hidrolaparoscopia transvaginal (HLT)

A HLT (Figura 20) foi descrita pela primeira vez por Gordts et al (1998a,b) e utiliza ópticas de menor calibre e distensão abdominal com solução salina (Gordts et al., 1998c). Ainda no mesmo ano, Gordts et al. (1998d) demonstraram o uso da HLT como procedimento ambulatorial na visualização endoscópica do processo de captação do oócito pelas fímbrias em humanos.

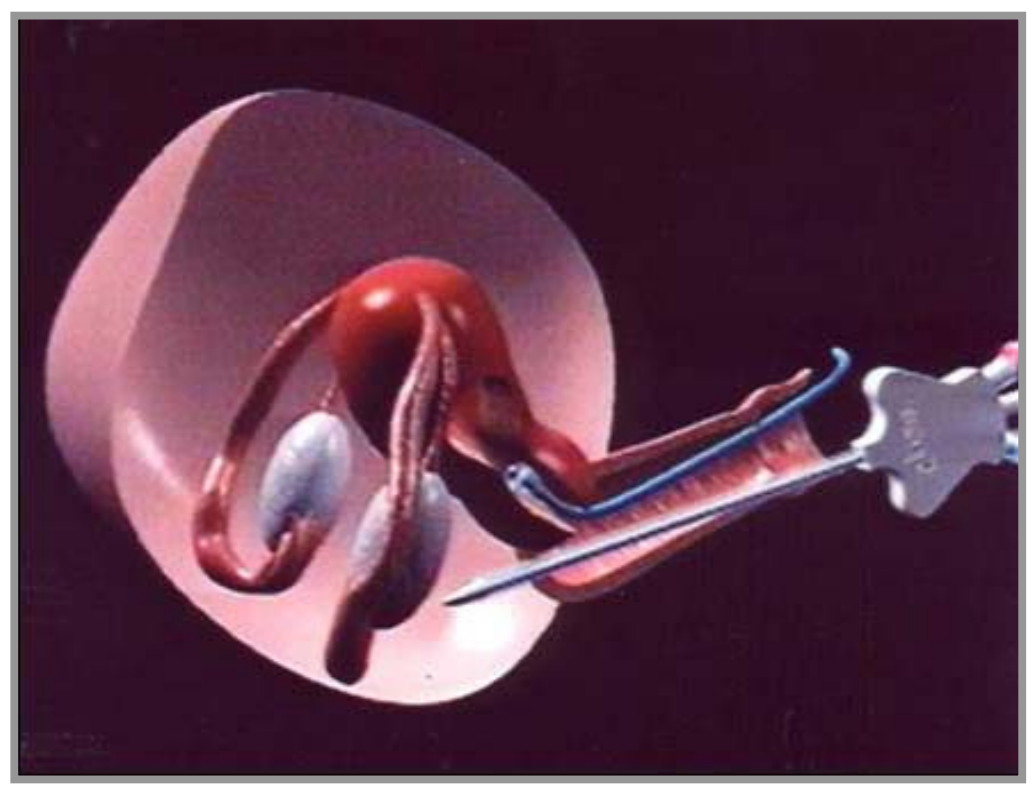

Figura 20. Desenho esquemático da HLT.

(Fonte: www.fertiloscopy.com). 
Brosens et al. (2001a) enfatizaram que a HLT oferece a oportunidade de demonstrar aderências periovarianas e peritubárias, que não seriam facilmente detectadas pela laparoscopia, sugerindo que a HLT seria opção melhor para a avaliação dessas condições.

Marik (2001), por sua vez, comentou o trabalho de Brosens et al. (2001a), argumentando que, em sua experiência de longos anos com a laparoscopia, a não identificação de aderências periovarianas e peritubárias pela laparoscopia seria mais um problema do laparoscopista do que da laparoscopia em si, o que não endossa o uso da HLT no lugar da laparoscopia. Também referiu a dificuldade de visualização do espaço anterior do saco de Douglas e da identificação de anormalidades como a endometriose e tumores pela $\mathrm{HLT}$.

Brosens et al. (2001b), no entanto, responderam aos argumentos de Marik (2001), enfatizando (1) a maior segurança na realização da HLT; (2) o menor risco de danos intestinais em comparação com a laparoscopia; (3) a maior aceitação do paciente pelo fato de o procedimento ser realizado em 
posição de litotomia e, em geral, sob anestesia local e sedação consciente.

Também focalizaram o fato de pacientes com endometriose diafragmática não se beneficiarem de fato da HLT, cuja indicação em outros casos é superior na avaliação pré-operatória.

Assim, os estudos comprovando o valor da HLT se multiplicaram, e diversos autores demonstraram que a HLT apresenta excelente acurácia em comparação à laparoscopia (Bajzak et al., 2000; Darai et al., 2000; Dechaud et al., 2001; Moore e Cohen, 2001; Moore et al., 2001; Shibahara et al., 2002).

Campo et al. (1999) estudaram 10 pacientes inférteis sem alteração pélvica evidente, com o objetivo de determinar a acurácia da HLT no diagnóstico de infertilidade em relação à laparoscopia. Em ambos os procedimentos foi diagnosticada endometriose mínima ou leve em sete pacientes e seqüela de doença pélvica inflamatória em uma. A concordância entre observadores para diagnóstico de aderências tubo-ovarianas foi de $74 \%$ na laparoscopia e de 95\% na HLT. Já as aderências ovarianas foram identificadas em $63 \%$ dos casos na HLT, e em $37 \%$ na laparoscopia. 
Darai et al. (2000) também investigaram a acurácia de HLT em relação à laparoscopia diagnóstica em estudo prospectivo duplo-cego envolvendo 60 mulheres submetidas à HLT imediatamente seguida da laparoscopia. O acesso à cavidade pélvica foi possível em $90,2 \%$ dos casos, e foram observadas complicações em 1,6\% das HLTs. Em 92,3\% dos casos o diagnóstico da HLT foi compatível ao da laparoscopia. Nos casos de achados anormais pela HLT, os achados laparoscópicos também foram anormais. Concluíram no estudo pela forte acurácia da HLT em relação à laparoscopia, contraindicando esse exame transvaginal apenas em casos de útero retrovertido.

Estudo de Marana et al. (2001) evidenciou que, embora a laparoscopia permaneça como primeira indicação para casos em que seja necessária vista panorâmica da cavidade pélvica (como aderências pélvicas extensas, sangramento intra-abdominal ou dor pélvica aguda), a HLT pode evitar a laparoscopia em $72 \%$ dos casos com história negativa e achados ultrasonográficos normais na investigação de mulheres inférteis e naquelas com dor pélvica crônica. 
Moore et al. (2001) realizaram revisão retrospectiva dos prontuários de 53 mulheres submetidas à HLT. O exame completo com acesso ideal à cavidade pélvica pôde ser realizado em $94 \%$ delas. Houve apenas uma complicação: perfuração de útero retrovertido. Os achados evidenciaram pelve normal em $49 \%$, endometriose em $21 \%$, aderências em $15 \%$, doença tubária em $9 \%$. O exame foi realizado em ambulatório em $89 \%$ das mulheres, e em $23 \%$ delas foi necessário um segundo procedimento. Em 13 casos, HSG prévia havia evidenciado tubas normais, enquanto a HLT revelou cinco casos de tubas normais e oito casos de anormalidade tubária. Os autores concluíram que as alterações pélvicas encontradas na HLT são similares aos achados da laparoscopia. Também recomendaram a realização da HLT em vez da HSG como meio de avaliação inicial de mulheres inférteis, uma vez que a freqüência de alterações pélvicas entre essas mulheres é relativamente alta.

Cicinelli et al. (2001) realizaram estudo controlado com 23 pacientes e observaram que a HLT associada com mini-histeroscopia foi mais bem tolerada do que a HSG, além de ter fornecido mais informações necessárias a 
uma investigação ambulatorial de infertilidade. Neste estudo, não houve diferenças significativas entre a HLT e a HSG nos achados relativos às condições das tubas.

Brosens et al. (2001c) partiram do conhecimento de que os danos intestinais causados pelo trocarte nas laparoscopias convencionais não são diagnosticados em $10 \%$, e de que a taxa de mortalidade decorrente desses danos não tratados chega a 33\%, para avaliarem retrospectivamente a prevalência e o tratamento desses danos durante a realização de HLT. Registraram taxa de $0,7 \%$ de danos intestinais em amostra de 2.126 procedimentos, ressaltando que, após os primeiros 50 procedimentos, essa taxa reduziu de $1,3 \%$ para $0,3 \%$. Não observaram nenhum caso de diagnóstico retardatário. Os autores concluíram que a obediência às contra-indicações e a experiência com a técnica reduzem significativamente os riscos de danos intestinais.

Gordts et al. (2001) realizaram levantamento retrospectivo multinacional visando determinar o risco e a evolução de danos intestinais associados às técnicas de endoscopia pélvica transvaginal. Para tanto, encaminharam 
questionário confidencial para todos os médicos ginecologistas que, sabidamente, já estavam usando a HLT ou a fertiloscopia, com perguntas que envolviam o número de procedimentos realizados, detalhes sobre os procedimentos em que houve complicações intestinais e o tempo de experiência com as técnicas quando da realização do procedimento em que houve dano intestinal. Esse questionário foi respondido por 44 ginecologistas de 18 países diferentes, e cinco deles relataram que não observaram qualquer complicação nos procedimentos realizados. Os outros 39 ginecologistas relataram 24 casos de dano intestinal em 3.667 procedimentos, perfazendo taxa de $0,65 \%$. A incidência dessa complicação caiu de 1,35\% para $0,25 \%$ após experiência com mais de 50 procedimentos.

Mulheres com infertilidade decorrente de infecção por Chlamydia trachomatis parecem constituir um grupo que também se beneficia da HLT. Neste sentido, Shibahara et al. (2002) estudaram 41 mulheres com infertilidade primária e secundária, das quais 14 apresentavam história pregressa de infecção por Chlamydia trachomatis. Todas as 41 foram submetidas à 
HLT, e o acesso ao fundo de saco de Douglas foi possível em $92,7 \%$ das vezes. Em 37 mulheres, os achados da HLT foram comparados aos da HSG, e as aderências peritubárias foram evidenciadas apenas pela HLT, nas mulheres com e sem história da infecção. Esses achados sugeriram que a infecção por Chlamydia trachomatis está fortemente associada com a presença de aderências peritubárias, cujo diagnóstico é bastante difícil apenas pela HSG, razão pela qual os autores recomendaram a realização da HLT em mulheres com história dessa infecção para a exclusão de alterações tubárias e instituição do tratamento adequado. Esses achados foram confirmados posteriormente por Shibahara et al. (2003).

Jónsdóttir e Lundorf (2002) estudaram 120 mulheres com infertilidade primária ou secundária sem doença pélvica evidente. As primeiras 14 pacientes foram submetidas à HLT sob anestesia geral imediatamente seguida de laparoscopia padrão. As demais 106 mulheres foram submetidas à laparoscopia transvaginal sob anestesia local, e a laparoscopia padrão foi realizada apenas naquelas com doença tubária com indicação cirúrgica. O aces- 
so foi possível em $93 \%$ dos casos, e foram identificadas alterações tubárias em 29 casos, dos quais 15 tinham indicação cirúrgica. Dentre 19 pacientes com aderências, duas apresentavam oclusão bilateral das tubas. Não foi registrada qualquer complicação. A partir desses resultados, os autores incluíram a HLT como procedimento de rotina para a investigação de estruturas ovarianas e avaliação das condições tubárias em pacientes inférteis.

Brosens et al. (2002) realizaram ampla revisão da literatura, no sentido de compreender se a HLT em combinação com mini-histeroscopia e cromotubagem poderia ser disponibilizada como procedimento realizado a um só tempo na investigação de infertilidade, de modo a substituir a HSG e, eventualmente, mesmo a laparoscopia. Observaram que a grande maioria dos estudos revisados documentou a acurácia, a tolerabilidade e a segurança da HLT realizada em regime ambulatorial. O acesso à cavidade pélvica tem sido obtido, em média, em $96,4 \%$ dos casos. Em $44 \%$ das pacientes com HSG normal ou suspeita, os achados da HLT são anormais. A HLT apresenta acurácia comparável à da laparoscopia no diagnóstico de endometriose 
anexial e aderências. A flutuação dos órgãos em meio líquido permite, inclusive, melhor visualização das aderências ovarianas. Concluíram que, para finalidade diagnóstica, a HLT é tão eficaz quanto a HSG, recomendando a realização de novos estudos randomizados no sentido de determinar se também o seria em termos de fornecer prognóstico de gravidez espontânea.

Na experiência de Moore et al. (2003) com 109 HLTs realizadas em 97 mulheres, o procedimento foi completo em $93 \%$ e adequado para tratamento em $96 \%$. Houve registro de apenas duas complicações: um caso de falha ao acesso pélvico e um caso de perfuração de útero retrovertido. Apenas três procedimentos (4\%) foram incompletos. Os autores indicaram a substituição indiscutível da HSG e da laparoscopia pela HLT em pacientes selecionadas.

Em nosso meio, Ueno et al. relatam sua experiência inicial com a HLT em 1999. Em 2003, Vieira et al. apresentaram a técnica como forma de avaliação das tubas na propedêutica endoscópica de pacientes laqueadas candidatas à RCL e expuseram sua experiência inicial com 20 pacientes, relatando os achados mais comuns durante essas primeiras 20 HLT (Vieira et 
al., 2003b). No ano seguinte, Vieira apresentou sua experiência com 38 HLT, utilizando novo instrumental de acesso à cavidade pélvica desenvolvido por Ueno (Vieira, 2004; Vieira et al., 2004). Ainda em 2004 Ueno et al. relataram seus resultados preliminares na reversão de LT com técnica simplificada após a avaliação prévia das tubas por meio das HLTs realizadas por Vieira.

Desta forma, motivados pelas controvérsias encontradas na literatura em relação à avaliação endoscópica das tubas antes da reversão cirúrgica e face à aparente eficácia da HLT em se obter adequada análise das tubas de forma equiparável à avaliação laparoscópica, mas com os benefícios de realizar-se um procedimento em caráter ambulatorial, com anestesia local e custos mínimos, é que desenvolvemos este estudo prospectivo transversal. 
2. Proposição 


\section{Proposição}

Em pacientes com laqueadura tubária, candidatas à reversão cirúrgica,

propôs-se a avaliar o valor da hidrolaparoscopia por via transvaginal na visualização das tubas uterinas e no prognóstico da reversibilidade da esterilização tubária. 
3. Casuística e Métodos 


\section{Casuística e Métodos}

\subsection{Casuística}

Entre 2001 e 2004 estudaram-se 38 pacientes matriculadas na Divisão de Clínica Ginecológica do Hospital das Clínicas da Faculdade de Medicina da Universidade de São Paulo (HCFMUSP) e do Centro de Referência da Saúde da Mulher (CRSM) do Hospital Pérola Byington. Trinta e uma eram pacientes do Hospital das Clínicas, e sete, do Hospital Pérola Byington. Todas tinham laqueadura tubária e desejo de nova gravidez.

O estudo foi devidamente aprovado pela Comissão de Análise de Projetos de Pesquisa (CAPPesq) da Diretoria Clínica do HCFMUSP (Anexo A). Todas as pacientes assinaram termo de consentimento esclarecido após explicação detalhada de todas as etapas da pesquisa (Anexo B).

Os valores mínimo e máximo, a média e o desvio-padrão relativos à idade, peso, altura e índice de massa corpórea (IMC) das mulheres estudadas se encontram na Tabela 1. Os dados individuais estão no Anexo C. 
Tabela 1. Valores mínimo e máximo, média e desvio-padrão da idade, peso e índice de massa corpórea (IMC) de 38 mulheres com laqueadura tubária candidatas à reversão cirúrgica.

\begin{tabular}{lcccc}
\hline Valores & $\begin{array}{c}\text { Idade } \\
\text { (anos) }\end{array}$ & $\begin{array}{c}\text { Peso } \\
\text { (quilogramas) }\end{array}$ & $\begin{array}{c}\text { Altura } \\
\text { (metros) }\end{array}$ & $\begin{array}{c}\text { IMC } \\
\left(\mathrm{kg} / \mathrm{m}^{2}\right)\end{array}$ \\
\hline Mínimo & 21 & 41,8 & 1,45 & 18,8 \\
Máximo & 39 & 84 & 1,66 & 33,2 \\
Média & 33,9 & 62,2 & 1,58 & 25,0 \\
Desvio-padrão & 4,1 & 10,1 & 0,06 & 4,2 \\
\hline
\end{tabular}

As mulheres não apresentavam alterações ao exame ginecológico nem ao exame ultra-sonográfico pélvico complementar. Foram excluídas do estudo as que apresentavam outra afecção pélvica já diagnosticada ou cujos parceiros tinham espermograma alterado com indicação de fertilização in vitro. 


\subsection{Métodos}

Todas as 38 pacientes foram submetidas à HLT para avaliação prognóstica de eventual RCL. Posteriormente, em 30 dessas pacientes, procedeu-se à minilaparotomia para confirmar os achados da HLT e realizar eventual reversão cirúrgica da laqueadura.

\subsubsection{Hidrolaparoscopia transvaginal}

\subsubsection{Instrumental}

O instrumental utilizado para a HLT consistiu de materiais de uso ginecológico geral, como espéculo vaginal, pinça de Pozzi, pinça de Cheron, seringa, agulhas, anestésico, gaze, anti-séptico (polivinilpirrolidona-iodo), equipo de soro e soro fisiológico ou ringer lactato (Figura 21).

O material de uso específico incluiu agulha de Veress modificada e cânula para agulha (Figuras 22 e 23). 


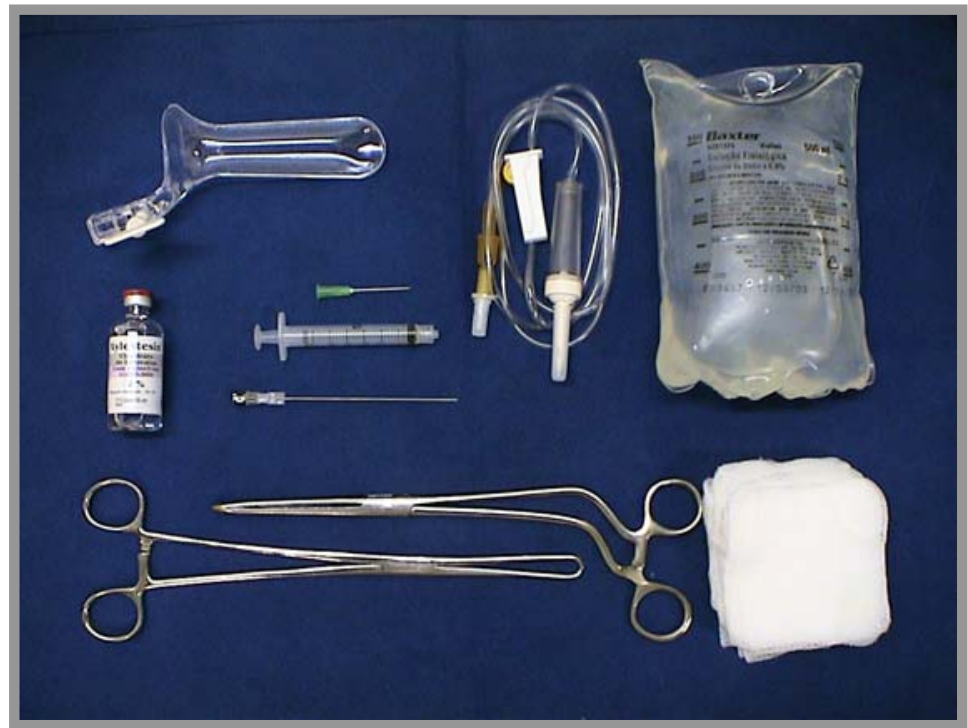

Figura 21. Material de uso ginecológico geral para realização de HLT.

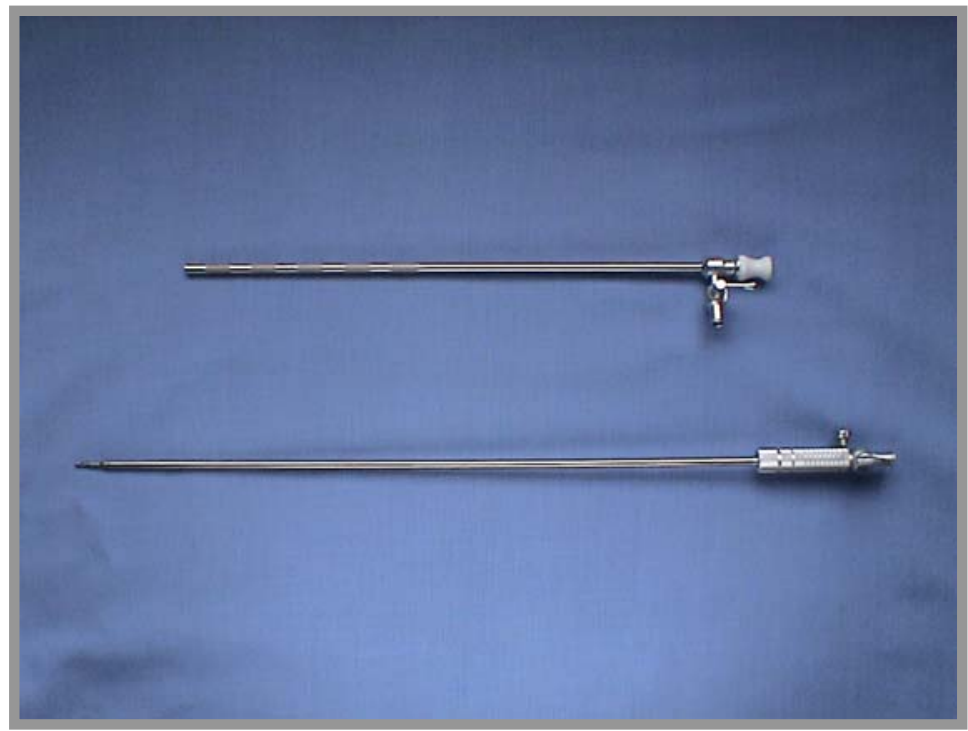

Figura 22. Agulha e cânula de HLT.
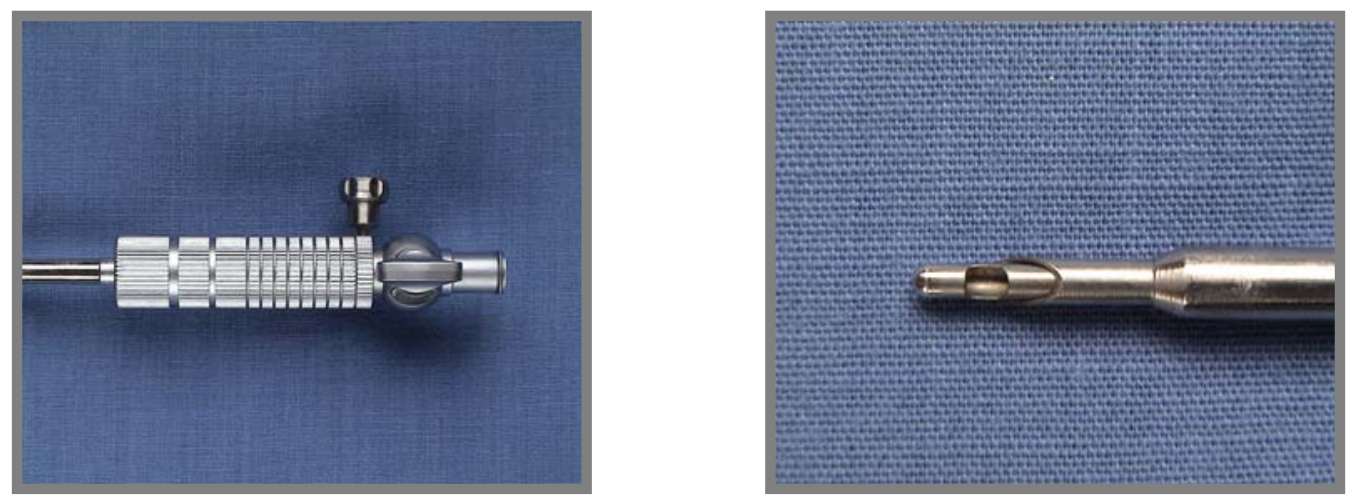

Figura 23. Base (à esquerda) e ponta (à direita) da agulha da HLT. 


\subsubsection{Técnica}

Para a realização da HLT ambulatorial, utilizou-se a técnica descrita por Vieira (2004), cujos procedimentos estão a seguir sintetizados. Todas as HLTs foram realizadas pelo Autor.

TÉCNICA DA HIDROLAPAROSCOPIA TRANSVAGINAL (Vieira, 2004).

- Colocação da paciente em posição ginecológica.

- Anti-sepsia da vulva e vagina.

- Introdução do espéculo vaginal e complementação da anti-sepsia do colo uterino e fórnice vaginal.

- Pinçamento do lábio posterior do colo uterino com pinça de Pozzi.

- Realização de botão anestésico com cerca de 2 ml de lidocaína 2\% com vasoconstritor na linha média do fórnice vaginal posterior, aproximadamente $1,5 \mathrm{~cm}$ abaixo da inserção da parede vaginal no colo uterino (Figura 24). 


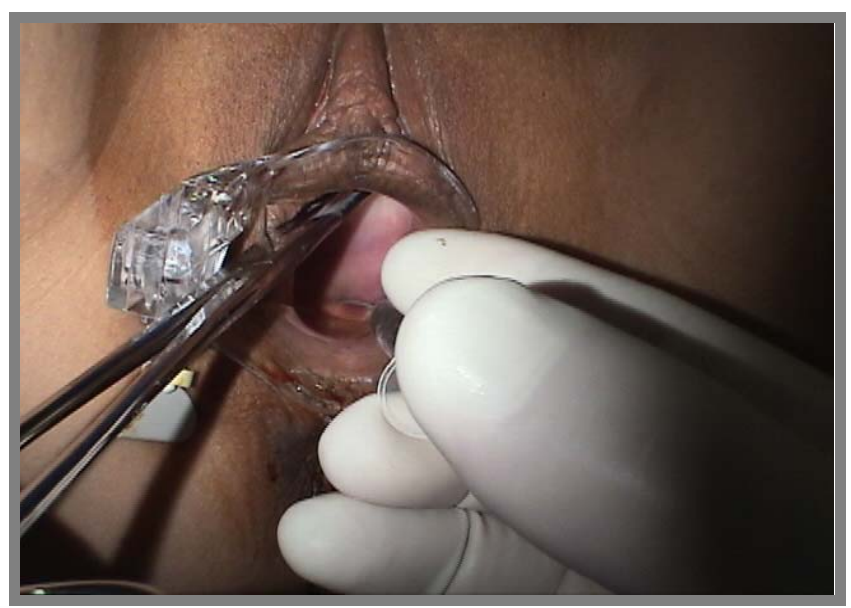

Figura 24. Botão anestésico em fórnice vaginal posterior.

- Testagem do sistema de retração da agulha e da trava de segurança que promove a fixação da sua ponta romba (Figura 25).

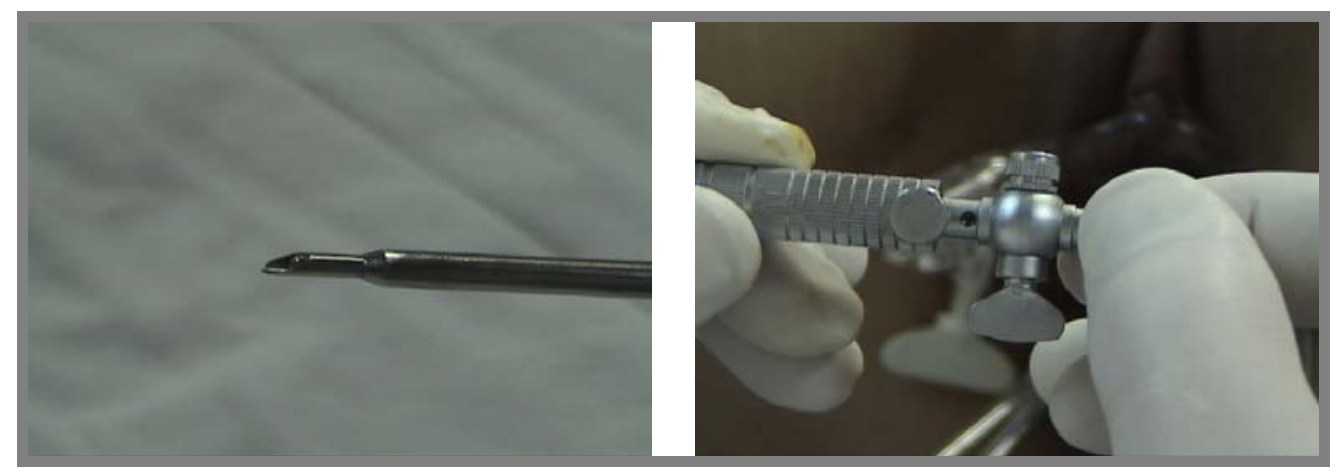

Figura 25. Ponta romba retrátil (à esquerda) e base da agulha (à direita).

- Punção lenta do fundo de saco vaginal no local anestesiado, mantendo-se contato verbal constante com a paciente a fim de colher informa- 
ções relativas à dor ou outros sintomas, evitando-se movimentos bruscos tanto na tração do colo uterino como na introdução da agulha. Neste momento a agulha já deve se encontrar dentro da cânula que servirá como guia para a passagem da óptica (Figura 26).

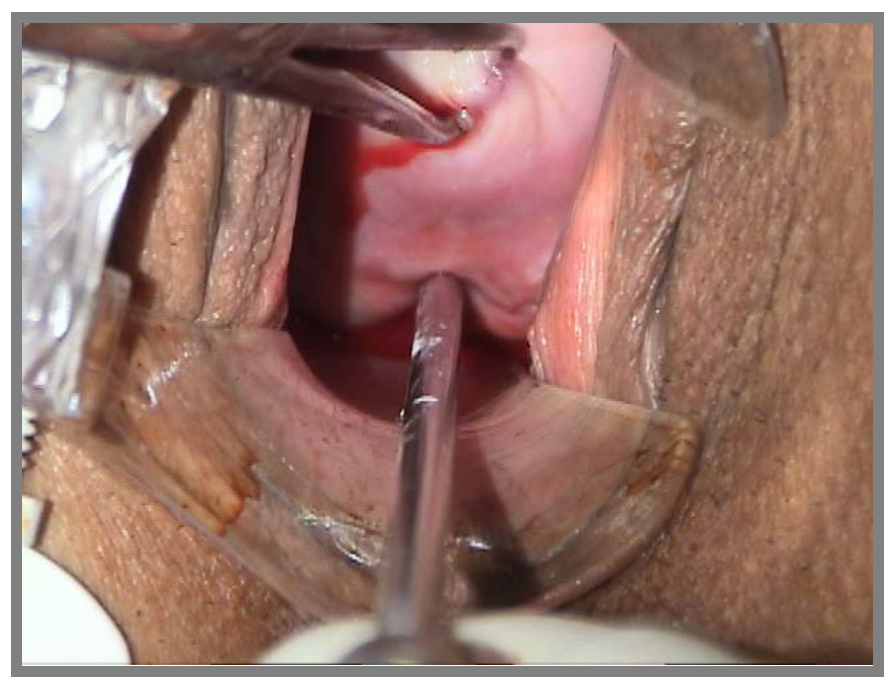

Figura 26. Punção do fundo-de-saco vaginal.

- Após observação e destravamento do sistema retrátil da agulha, fixação da sua ponta romba para evitar lesões com a parte cortante do instrumento (Figura 27). 


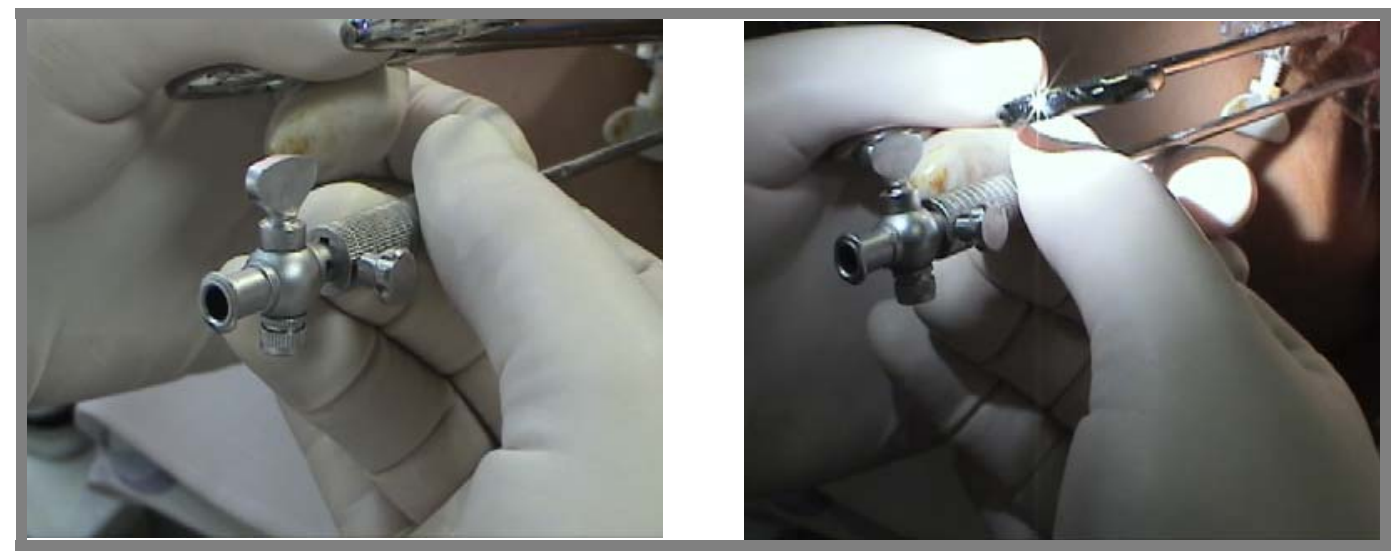

Figura 27. Observação da retração (à esquerda) e destravamento (à direita) do sistema na inserção.

- Introdução complementar da agulha por um ou dois centímetros seguida de transpasse da cânula através da parede vaginal por 2 cm (Figura 28).

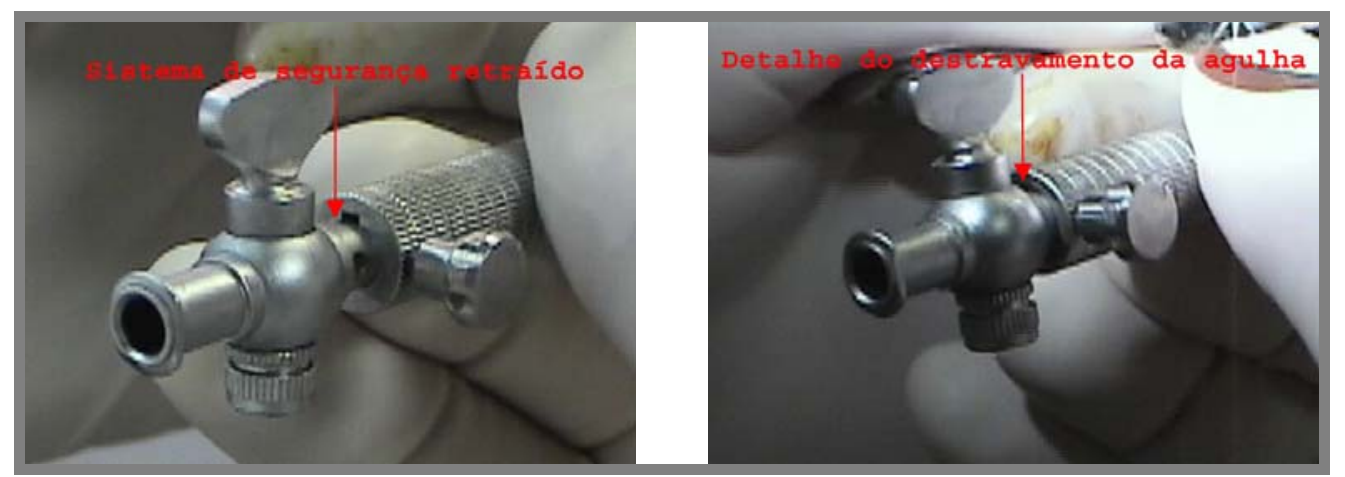

Figura 28. Detalhe da retração da agulha antes (à esquerda) e depois (à direita) de transpassar a parede vaginal.

- Conexão do equipo de soro à base da agulha e instilação de $100 \mathrm{ml}$ de soro fisiológico ou lactato-ringer a $37^{\circ} \mathrm{C}$ com lidocaína $2 \%$ sem vaso- 
constritor, diluída à concentração de 1/100 sob ação da gravidade (Figu-

ra 29).

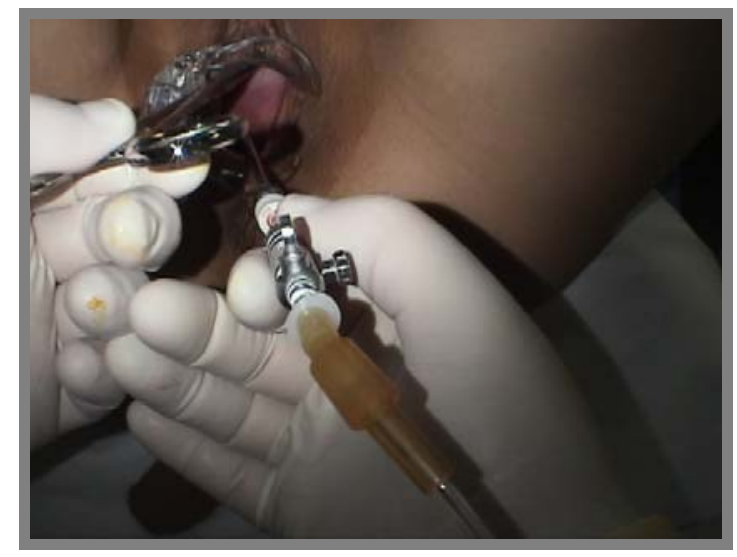

Figura 29. Equipo de soro conectado à agulha.

- Fixação do equipo no local apropriado da cânula e retirada da agulha do seu interior (Figura 30).

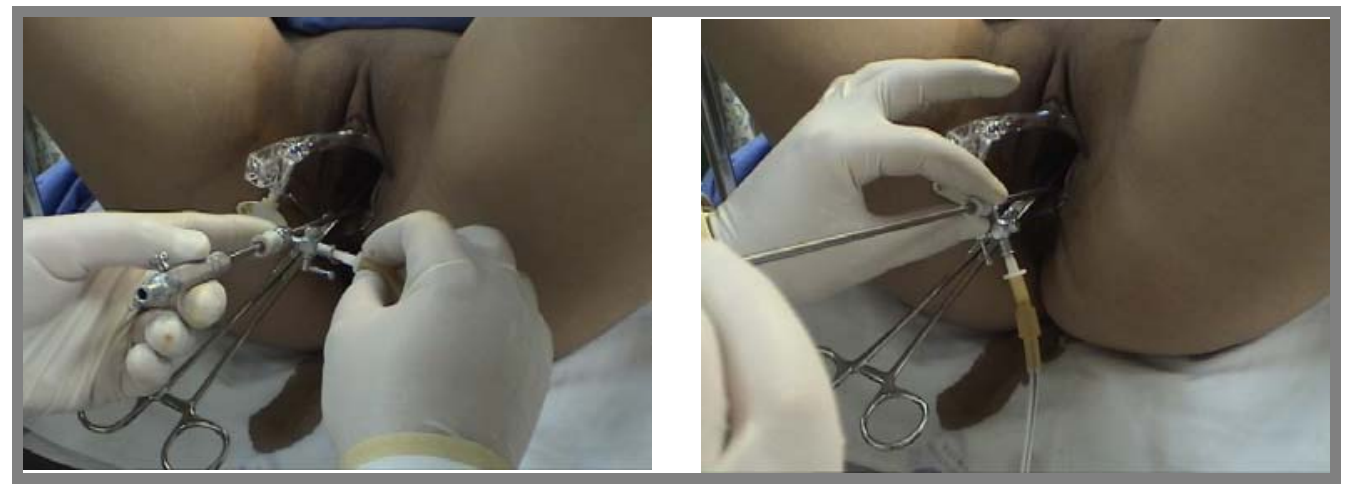

Figura 30. Conexão do equipo de soro à cânula (à esquerda) e retirada da agulha do interior da cânula (à direita). 
- Introdução da óptica acoplada a sistema de videodocumentação (Figu-

ra 31), verificação do sucesso do acesso ao interior da cavidade pélvica,

e retirada do espéculo.

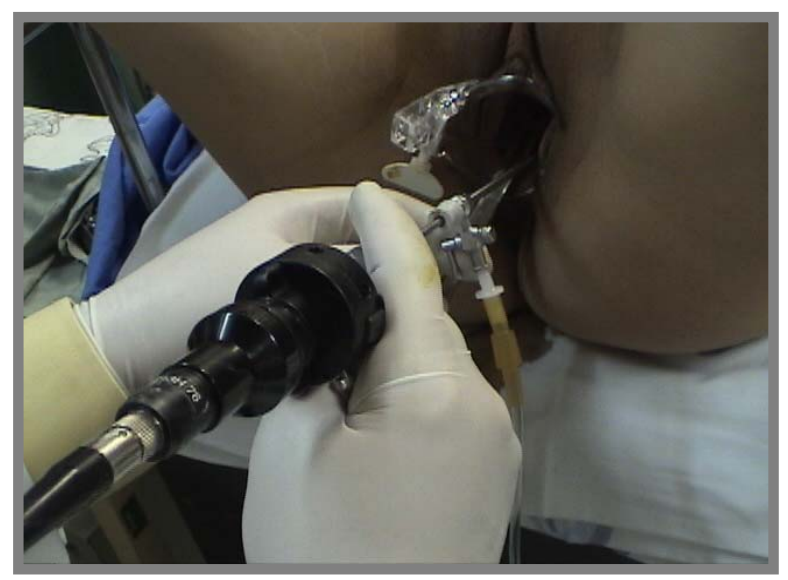

Figura 31. Introdução da óptica através da cânula.

- Instilação complementar de líquido e inspeção dos órgãos internos da pelve.

- Início do inventário da cavidade pela parte posterior do útero, que segue pelo ligamento útero-ovárico direito, ovário direito, fossa ovárica direita e porção distal da tuba direita.

- Observação da cicatriz cirúrgica da laqueadura e da presença de eventual dilatação tubária e aderências, e avaliação das condições das 
fímbrias.

- O mesmo procedimento era realizado do lado esquerdo.

- Retirada da óptica da cânula e desconexão do equipo de soro.

- Colocação da mesa de exame em proclive para saída do líquido da cavidade pélvica.

- Retirada da cânula e reintrodução do espéculo vaginal para revisão de hemostasia.

- Orientação e liberação da paciente após certeza da ausência de sangramento.

\subsubsection{Minilaparotomia}

As minilaparotomias foram realizadas no Centro Cirúrgico do Hospital das Clínicas da Faculdade de Medicina da USP e no Centro de Referência da Saúde da Mulher, Hospital Pérola Byington.

Foi utilizada a técnica minilaparotômica descrita por Pelosi e Pelosi 
(2000) e modificada por Ueno et al. (2004), cujos procedimentos estão a seguir indicados.

MINILAPAROTOMIA COM TÉCNICA SIMPLIFICADA (Ueno et al., 2004)

- Realização de tricotomia suprapúbica momentos antes da incisão na pele, quando necessária.

- Administração de raquianestesia.

- Posicionamento da paciente em posição semiginecológica.

- Anti-sepsia e sondagem vesical com sonda uretral de demora do tipo Foley número 12.

- Colocação do espéculo vaginal e pinçamento do colo anterior com pinça de Pozzi.

- Introdução da ponta do manipulador uterino vaginal de Valtchev (Figura 32) no interior do útero.

- Incisão cruciforme caracterizada por pequeno corte transversal da pele logo acima dos pêlos pubianos de aproximadamente $4 \mathrm{~cm}$, seguido 
de corte longitudinal da fáscia do músculo reto-abdominal.

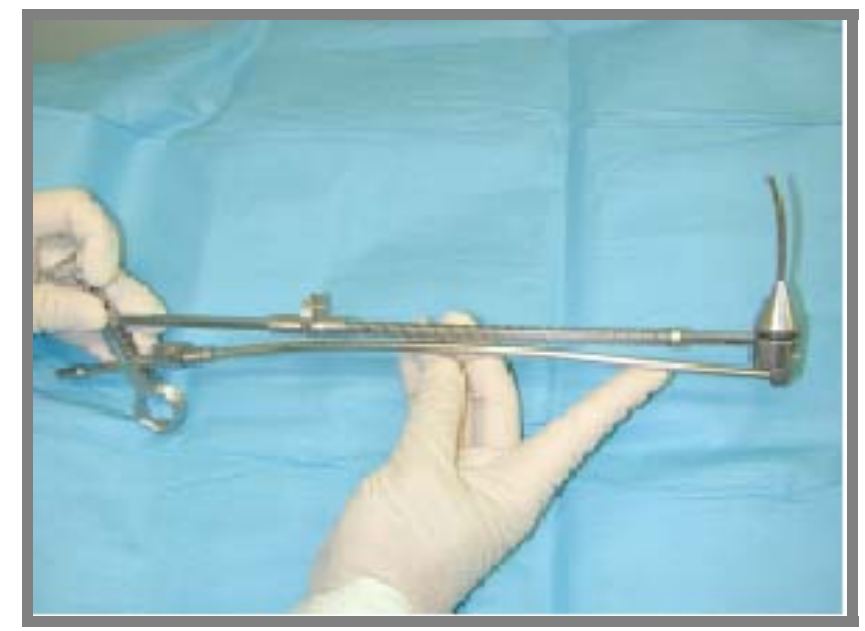

Figura 32. Manipulador uterino.

- Colocação de uma das extremidades do sistema de retração na cavi-

dade peritoneal mantendo-se a outra exteriorizada (Figura 33)

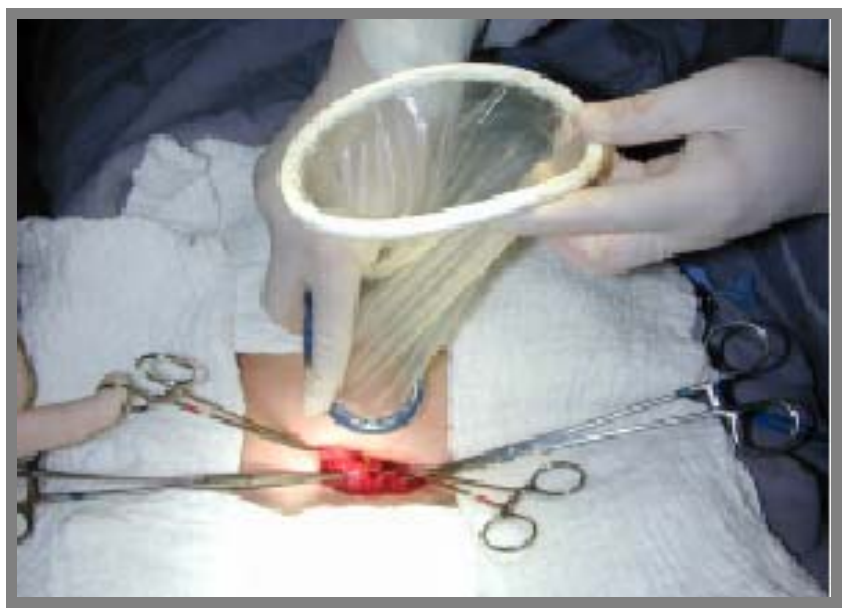

Figura 33. Colocação do sistema de retração na cavidade abdominal. 
- Rotação da extremidade exterior em torno de seu eixo vertical, levando a adequada exposição do campo cirúrgico (Figura 34).

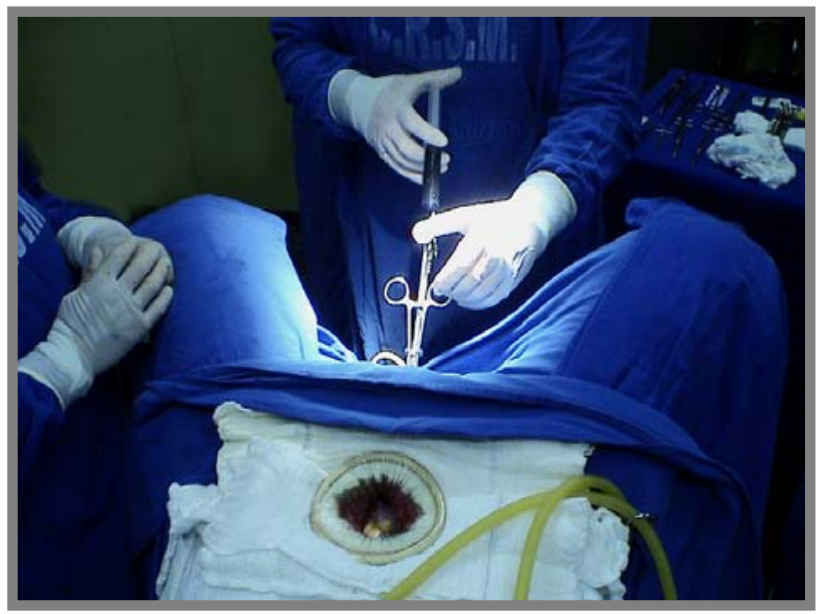

Figura 34. Posição da paciente, equipe médica e campo visual adequado.

- Posicionamento da paciente em posição de Trendelenburg para deslocamento das alças intestinais cranialmente e melhora da exposição dos órgãos genitais internos.

- Inspeção pélvica com manipulação delicada das estruturas descrevendo as alterações identificadas e avaliação do prognóstico inicial das tubas com base na classificação da (The American Fertility Society, 1988).

- Abordagem cirúrgica das tubas após avaliação da melhor conduta. 
- Revisão da hemostasia.

- Fechamento da parede por planos (Figura 35).

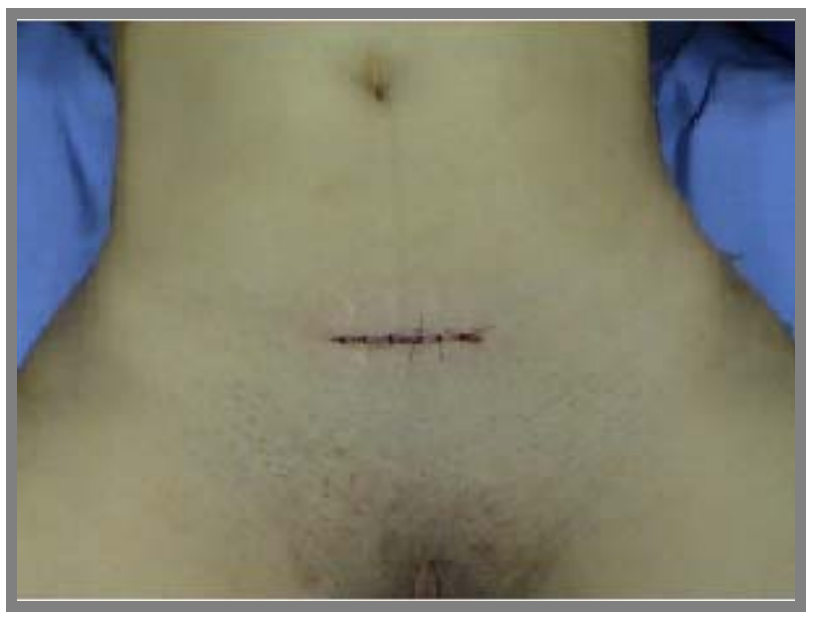

Figura 35. Aspecto final da minilaparotomia.

\subsection{Análise estatística}

Os dados encontrados foram analisados descritivamente, empregando-

se a prova do Qui-quadrado para determinar a associação entre prognóstico

e decisão pela reversão pela HLT. 
4. Resultados 


\section{Resultados}

\subsection{Acesso à cavidade pélvica}

Obteve-se o acesso à cavidade pélvica em 36 (94,7\%) das 38 pacien-

tes submetidas à HLT. Em 31 (81,6\%) o acesso foi obtido na primeira tenta-

tiva. Nas demais cinco $(13,2 \%)$, o acesso foi obtido em uma segunda tentati-

va.

Em duas pacientes $(5,3 \%)$ houve interrupção do procedimento no espaço pré-peritoneal (Gráfico 1).

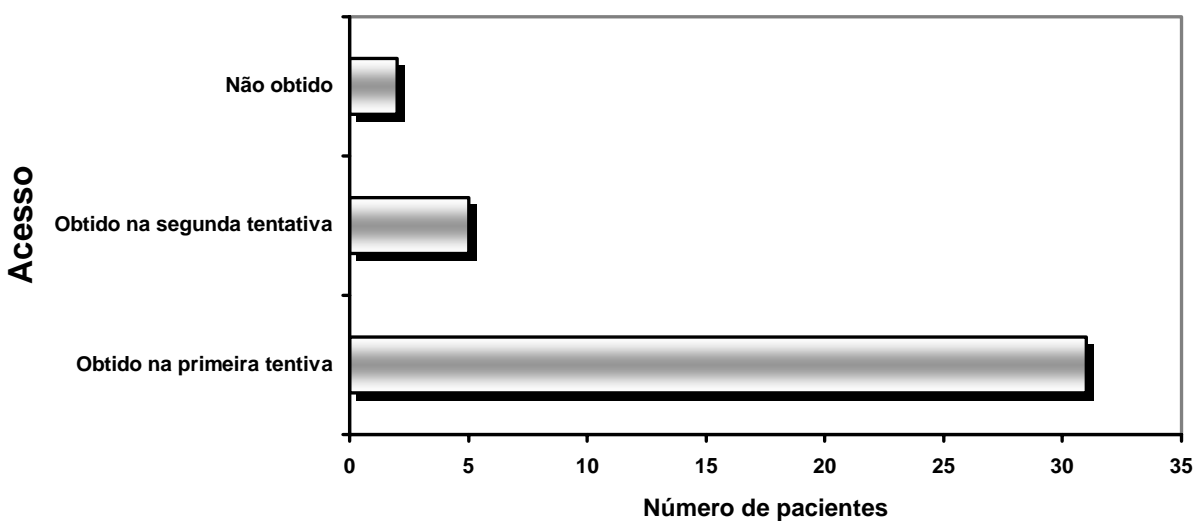

Gráfico 1. Distribuição das pacientes em relação à obtenção de acesso à cavidade pélvica durante HLT. 
Não ocorreu qualquer complicação nas 38 (100\%) pacientes submetidas ao procedimento.

\subsection{Avaliação das tubas pela HLT}

As tubas foram avaliadas quanto à presença de fímbrias e à possibilidade de reversão (Anexos D e E) e foram classificadas quanto ao prognóstico de acordo com a Sociedade Americana de Fertilidade ( The American Fertility Society, 1988).

Oito pacientes evadiram-se do estudo antes da realização da minilaparotomia. Portanto, esse procedimento foi efetuado em 30 casos.

Durante a minilaparotomia, 20 delas foram submetidas à reversão da laqueadura. Nas dez pacientes restantes, realizou-se salpingectomia devido à presença de hidrossalpinge ou pelo prognóstico de reversibilidade ser ruim.

Conforme ilustrado no Gráfico 2, considerando-se as 30 pacientes que realizaram a minilaparotomia e concluíram o estudo, a HLT possibilitou a visualização adequada da porção distal da tuba em 25 delas (83,4\%); em 
três $(10,0 \%)$ a avaliação foi insatisfatória, ou seja, incompatível com os achados à minilaparotomia, e nas duas restantes $(6,6 \%)$ houve falha no acesso pélvico.

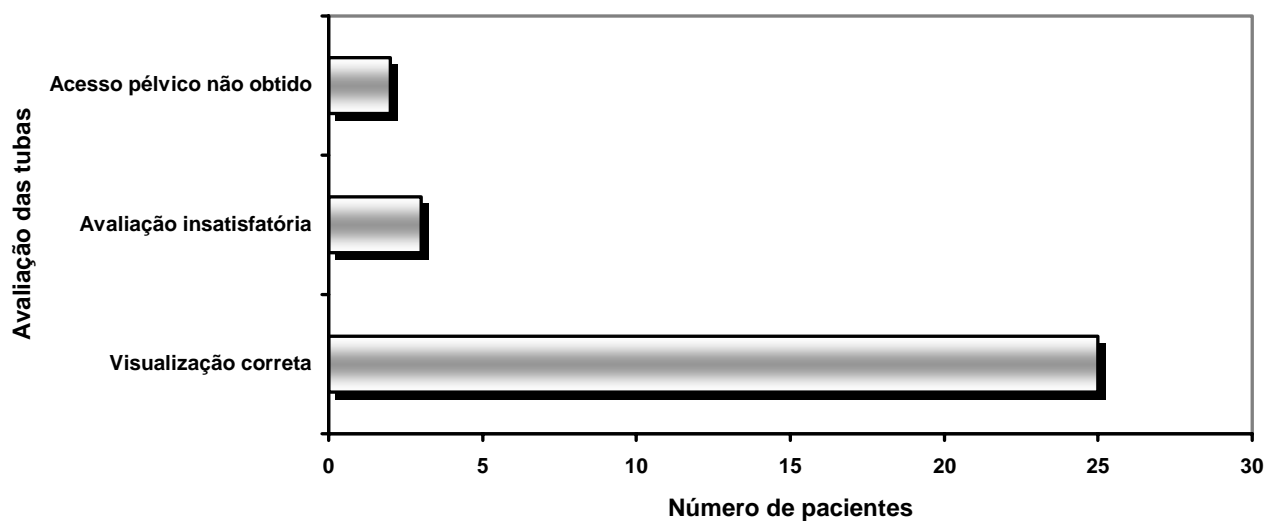

Gráfico 2. Distribuição das pacientes em relação à avaliação das tubas pela HLT.

Em uma das pacientes em que a visualização das tubas foi correta e que foi classificada como de prognóstico excelente por ser a cicatriz cirúrgica em região ístmica e realizada com clipe de titânio (Figuras 36 e 37), não foi possível a recanalização tendo em vista o fato de a luz tubária encontrar-se obliterada, tanto no coto proximal como no distal. 


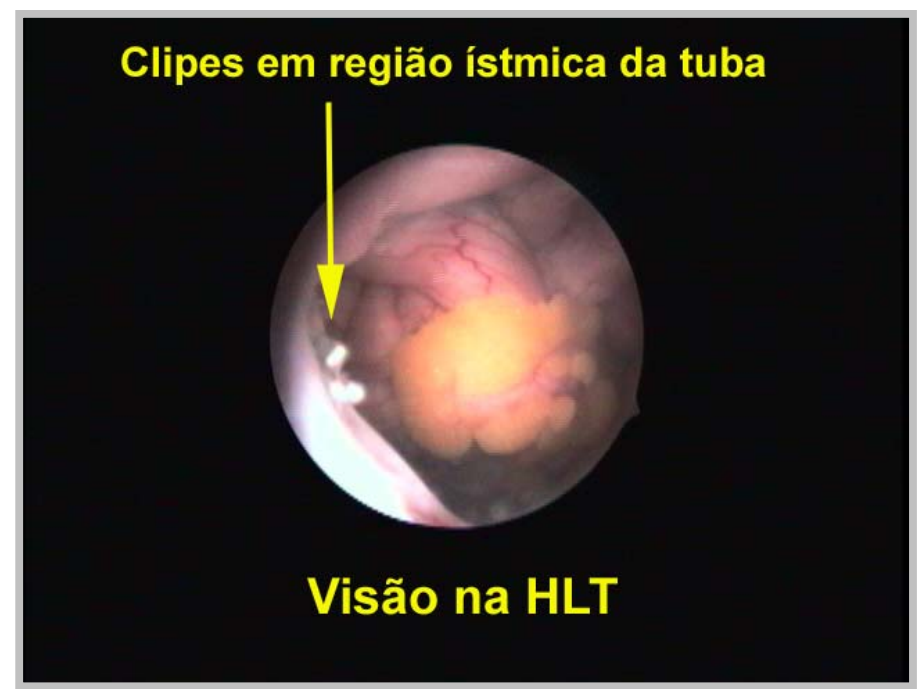

Figura 36. Visualização de clipes de titânio em região ístmica da tuba pela HLT.

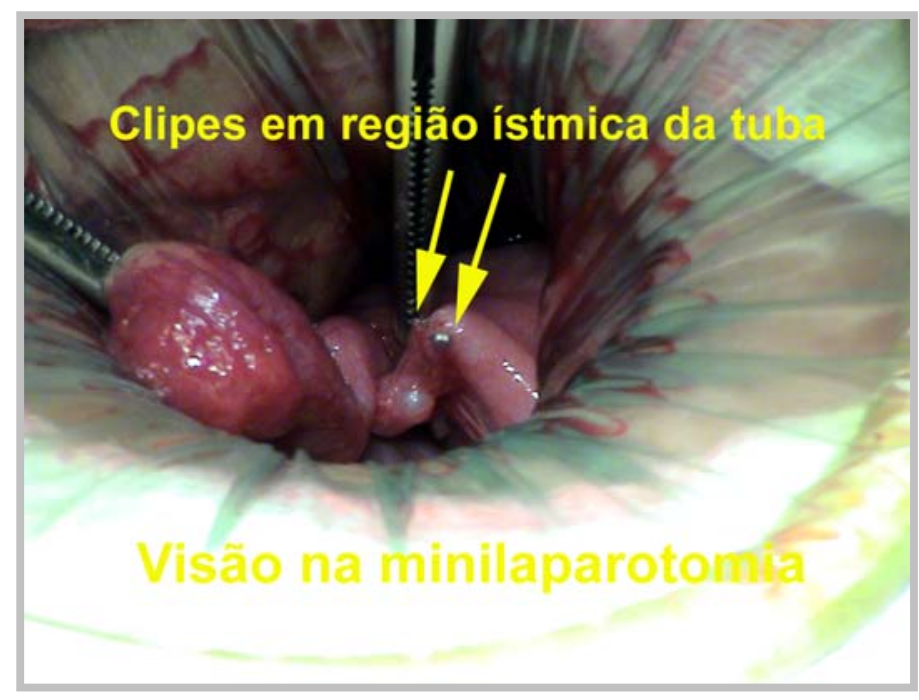

Figura 37. Visualização de clipes de titânio em região ístmica da tuba pela minilaparotomia.

Com relação às três pacientes $(10,0 \%)$ cuja avaliação da reversibilidade tubária pela HLT não foi satisfatória em relação aos achados da minilaparotomia, uma delas apresentava fímbrias à direita, e a tuba esquerda foi vista 
parcialmente devido à interposição de alças; entretanto, no ato operatório encontrou-se cicatriz cirúrgica em dois pontos com a presença hidrossalpinge (Figuras 38 e 39), optando-se então pela realização de salpingectomia.

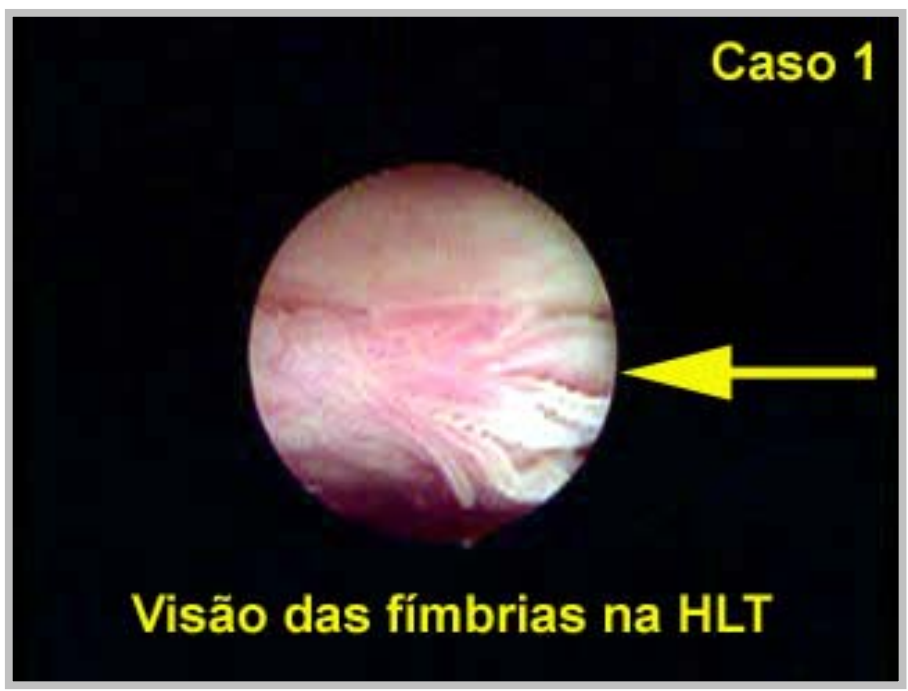

Figura 38. Achado da HLT em que se visualizam as fímbrias.

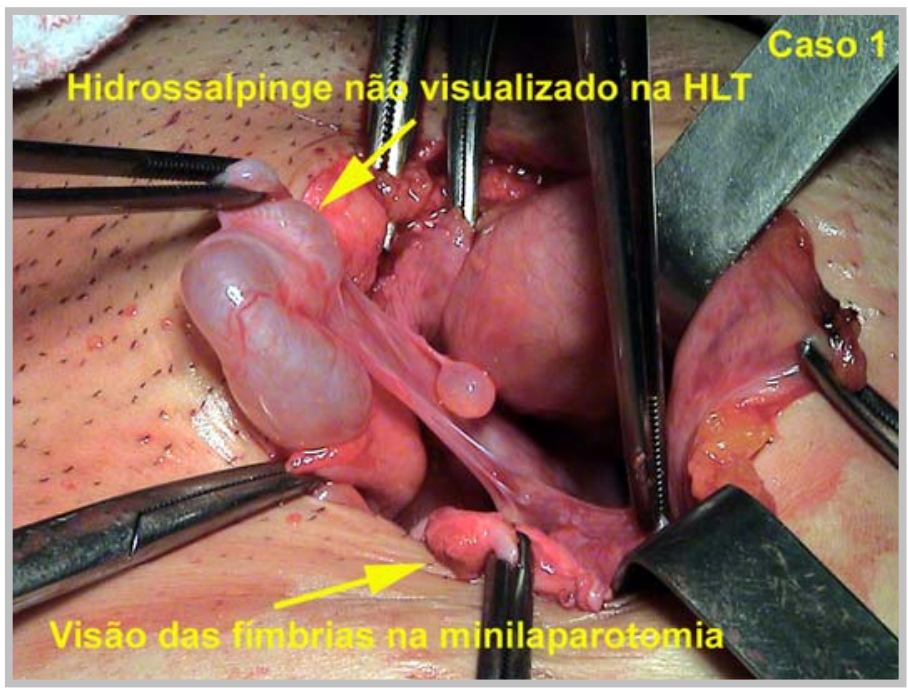

Figura 39. Achado da minilaparotomia: laqueadura em dois pontos e hidrossalpinge. 
Em uma segunda paciente, as fímbrias não eram tão saudáveis pela

HLT, mas se mostraram ainda piores à minilaparotomia. A laqueadura era distal, com hidrossalpinge moderado proximal e encurtamento das tubas (Figuras 40 e 41). Optou-se igualmente pela salpingectomia.

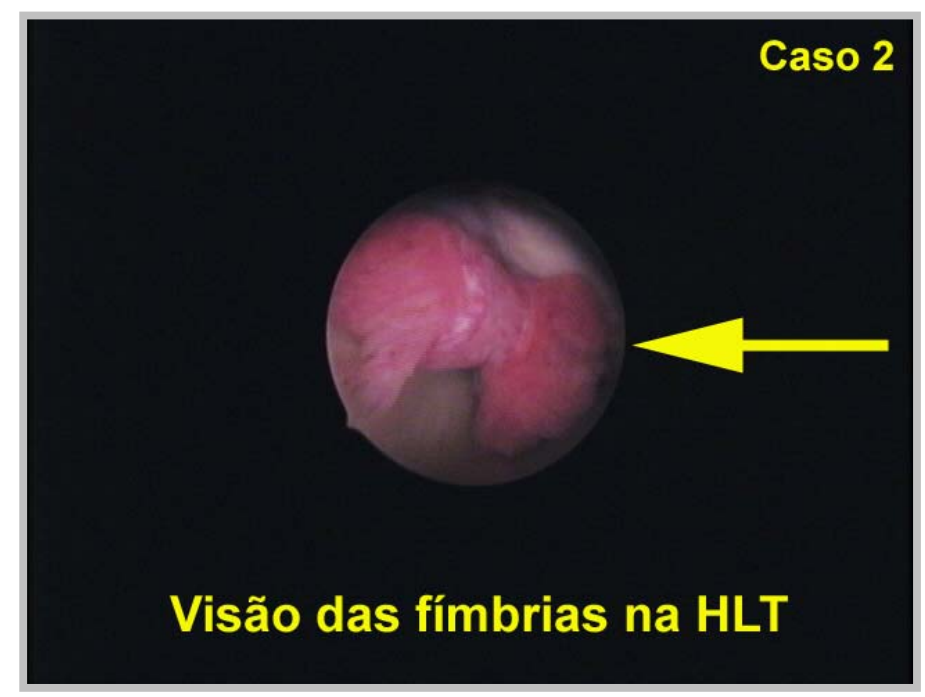

Figura 40. Achado da HLT em que se visualizam fímbrias não saudáveis.

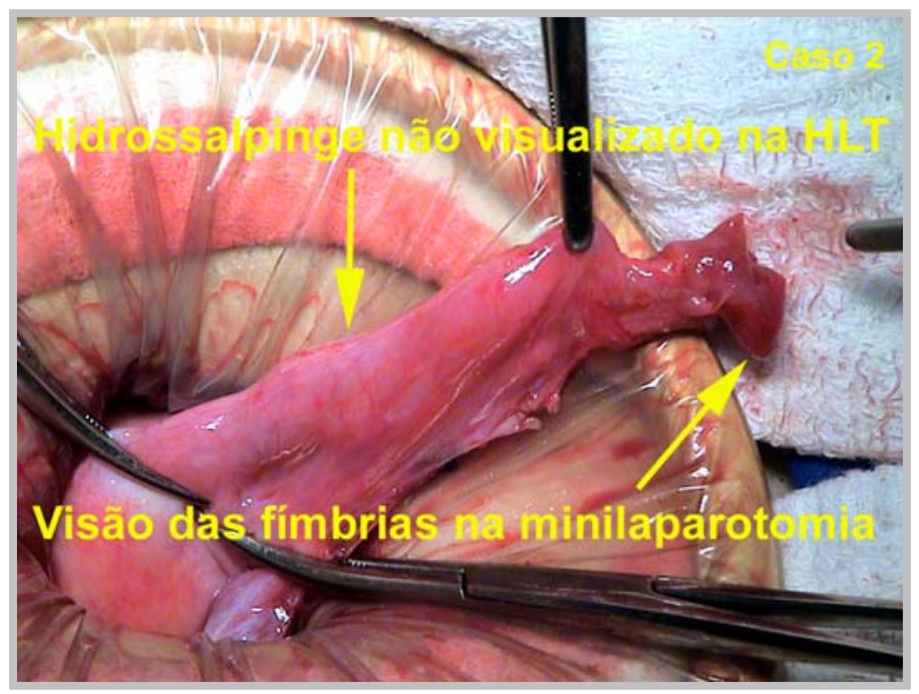

Figura 41. Achado da minilaparotomia: laqueadura distal com hidrossalpinge proximal. 
Finalmente, a terceira paciente parecia apresentar boas chances de

gravidez com a reversão; no entanto, durante a minilaparotomia observou-se

hidrossalpinge revelando péssimo prognóstico (Figuras 42 e 43), sendo en-

tão realizada a salpingectomia.

Estes achados estão sintetizados na Tabela 2.

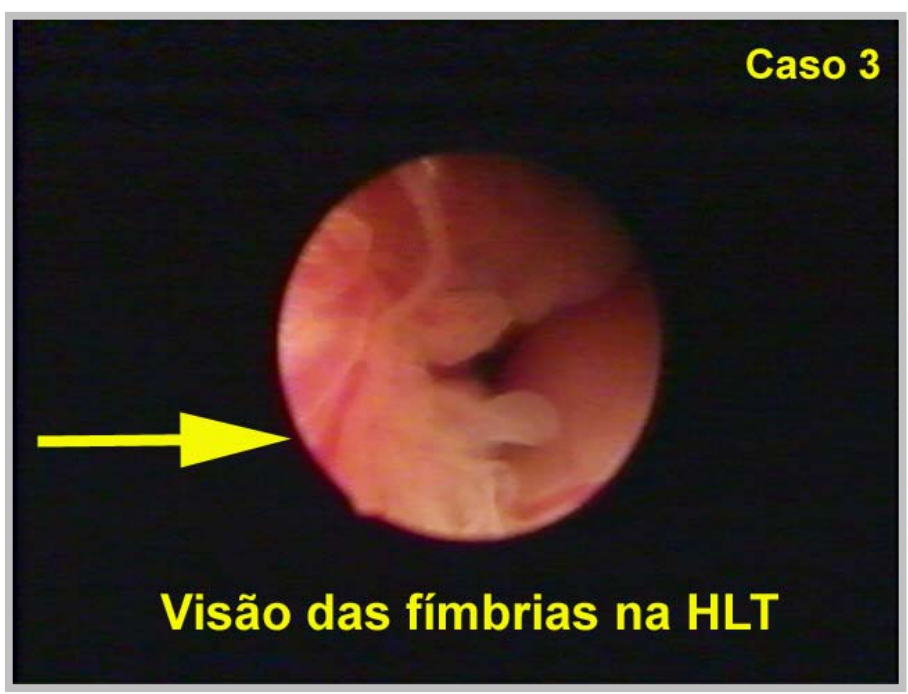

Figura 42. Achado da HLT cuja visualização sugere viabilidade da RCL.

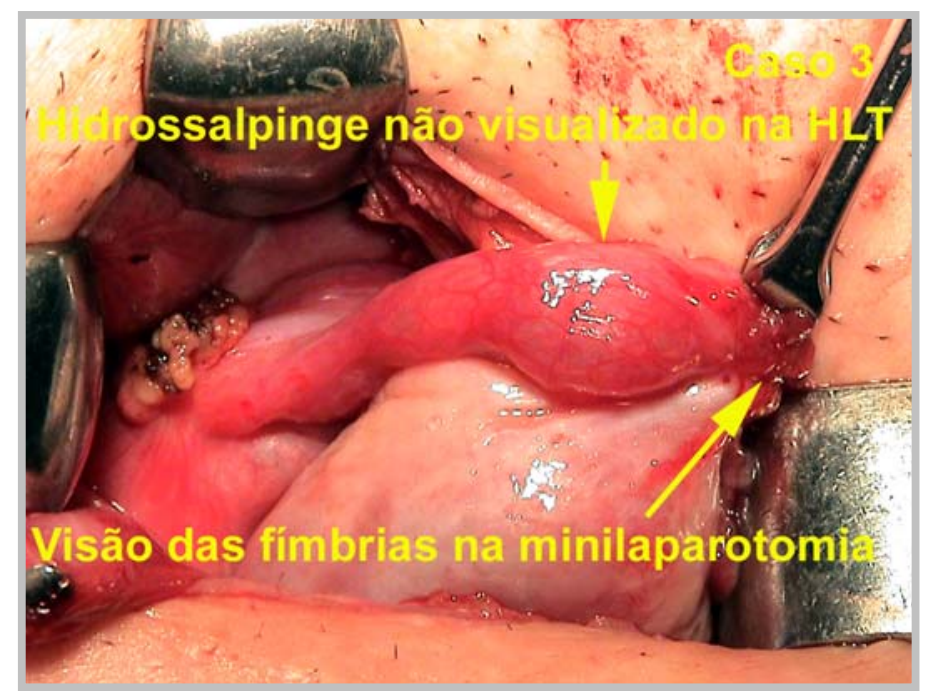

Figura 43. Achado da minilaparotomia: hidrossalpinge com péssimo prognóstico para RCL. 
Tabela 2. Pacientes nas quais a HLT foi insatisfatória em avaliar a reversibilidade tubária.

\begin{tabular}{ccccc} 
Pacientes & \multicolumn{2}{c}{ Reversibilidade pela HLT } & $\begin{array}{c}\text { Achados da } \\
\text { minilaparatomia }\end{array}$ & Conduta \\
& Tuba direita & Tuba esquerda & Hidrossalpinge & Salpingectomia \\
1 & $\operatorname{sim}$ & indeterminada & Laqueadura em dois pontos & \\
2 & $\operatorname{sim}$ & $\operatorname{sim}$ & Hidrossalpinge & Salpingectomia \\
3 & $\operatorname{sim}$ & $\operatorname{sim}$ & Hidrossalpinge & Salpingectomia \\
\hline
\end{tabular}

Além dessas três pacientes, outras seis apresentavam tubas irrecupe-

ráveis devido à forma como foram feitas as laqueaduras. Nestas pacientes

foi possível identificar que as tubas eram ruins já na HLT, e os achados da minilaparotomia vieram a confirmar a irreversibilidade nessas mulheres.

4.3 Prognóstico hidrolaparoscópico comparado com decisão pela reversão cirúrgica no ato minilaparotômico

A HLT permitiu taxa de acerto prognóstico em $89,3 \%$ dos 28 casos em que foi possível o acesso à cavidade pélvica, detectando a viabilidade da recanalização em 19 casos $(67,8 \%)$ e a sua inviabilidade em seis casos $(21,5 \%)$, achados esses confirmados na minilaparotomia (Tabela 3), e estatisticamente significativos (Qui-quadrado $=17,28 ; p=0,0001$ ). 
Tabela 3. Compatibilidade entre os achados da HLT e da minilaparotomia em 28 casos em que foi possível o acesso à cavidade pélvica pela HLT.

\begin{tabular}{ccc}
\hline \multirow{2}{*}{ Prognóstico para reversão pela LT } & \multicolumn{2}{c}{ Achados da minilaparotomia } \\
\cline { 2 - 3 } & Recanalização possível & Recanalização impossível \\
\hline Recanalização possível & $19(67,8 \%)$ & $3(10,7 \%)$ \\
Recanalização impossível & 0 & $6(21,5 \%)$ \\
\hline
\end{tabular}

As taxas de sensibilidade e especificidade da HLT foram de 100,0\% e $66,7 \%$, respectivamente, com valor preditivo positivo de $86,4 \%$ e valor preditivo negativo de $100,0 \%$. 
5. Discussão 


\section{Discussão}

O desejo de RCL ocorre em cerca de $2 \%$ a $26 \%$ das mulheres que se

arrependem de terem realizado a LT (Chi e Jones, 1994; Hillis et al., 1999),

mas apenas $1 \%$ a $3 \%$ delas de fato buscam essa alternativa (Schmidt, 2000;

Sklar, 2004), e nem todas apresentam os critérios mínimos para o procedimento (Escalona et al., 2006).

Para que se estabeleça a viabilidade de realização da RCL, é fundamental a avaliação prévia das tubas. A laparotomia é uma opção para essa avaliação (O'Brien et al. 1983; Soares et al., 1997), a despeito de vir sendo cada vez mais reservada para casos rigorosamente selecionados (Barjot et al., 1999), já que técnicas endoscópicas menos invasivas vêm comprovando efetivamente a sua eficácia, como é o caso da laparoscopia diagnóstica (Opshal e Klein, 1987; Risquez et al., 1992; Ikeda, 2002), ainda assim alguns autores desaconselham enfaticamente a sua realização nos casos de infertilidade sem explicação (Fatum et al., 2002). 
Procedimentos endoscópicos de abordagem transvaginal também vêm se mostrando eficazes para a avaliação das condições tubárias, dentre os quais se destacam a fertiloscopia (Watrelot et al., 1997, 1998) e a HLT (Gordts et al., 1998a,b).

Especificamente em relação à HLT, diversos estudos vêm sendo realizados no sentido de estabelecer a acurácia desse procedimento tanto em relação à laparoscopia e à HSG, quanto em relação à laparotomia (Brosens et al., 2001a; Cicinelli et al., 2001; Moore et al., 2003).

O primeiro relato nacional em que se utilizou a HLT foi realizado por Ueno et al. (1999). Posteriormente, o uso da HTL foi pioneiramente proposto para a avaliação das tubas de pacientes laqueadas candidatas à RCL (Vieira et al., 2003a), e os resultados relativos aos primeiros 20 procedimentos foram apresentados durante o VIII Congresso Paulista de Obstetrícia e Ginecologia e X Congresso de Ginecologia e Obstetrícia da Região Sudeste da Febrasgo (Vieira et al., 2003b). Novo instrumental de acesso à cavidade pélvica desenvolvido por Ueno foi estudado por Vieira (2004), e a experiência 
com 38 HLT foi apresentada por Vieira et al. (2004).

O estudo aqui apresentado é o primeiro a analisar a confiabilidade da HLT para avaliação da possibilidade de RCL e que utilizou a minilaparotomia modificada por Ueno et al. (2004) como padrão-ouro para verificação dos dados obtidos.

Com a utilização da HLT, obtivemos acesso à cavidade pélvica em $94,7 \%$ dos casos, freqüência essa que ratifica os achados da literatura que oscilam entre 90,2\% (Darai et al., 2000) e 100,0\% (Moore et al., 2001; Jónsdótirr e Lundorff, 2002), com média de 96,4\% (Brosens et al, 2002).

Ressalte-se que o acesso ao espaço pélvico retro-uterino não foi possível na primeira tentativa em sete casos $(21,2 \%)$, em cinco dos quais o espaço pélvico pôde ser acessado em uma segunda tentativa, o que significa que em $71,4 \%$ das vezes há possibilidade de sucesso na segunda tentativa. Em amostra estudada por Moore et al. (2001) houve necessidade de segunda tentativa para o acesso em $23 \%$ dos casos. A determinação do melhor local para punção, quantidade de anestésico e a própria curva de aprendiza- 
do foram em nosso entender os principais responsáveis pela necessidade de uma segunda tentativa.

Mesmo na segunda tentativa, não foi possível o acesso pélvico em um caso $(3,3 \%)$. Por fim, não foi realizada a segunda tentativa em uma paciente $(3,3 \%)$ que apresentava suspeita de aderências pélvicas. Uma paciente era obesa (IMC > 30) e a outra tinha sobrepeso (IMC $=28$ ), e a maior quantidade de tecido adiposo pré-peritoneal pode ter impossibilitado o acesso pélvico, fato esse eventualmente associado a possível excesso de anestésico no local da punção. Por outro lado em outras 13 pacientes com sobrepeso e 3 com obesidade, o acesso à cavidade foi possível, o que pode sugerir que tal fator não seja tão relevante.

Soma-se ao exposto que as duas pacientes se encontravam no grupo inicial do estudo e, portanto, a falha de acesso poderia ser atribuída à própria curva de aprendizado.

Neste sentido, é importante salientar que falha no acesso à cavidade abdominal também é registrada para os procedimentos laparoscópicos em 
cerca de $5 \%$ dos casos (Hasson, 1977; Huber, 1984).

Houve compatibilidade dos achados propostos em $89,3 \%$ dos casos em relação à minilaparotomia. Watrelot et al. (2003) encontraram sensibilidade da HLT em $86 \%$ dos seus casos, enquanto a laparoscopia apresentou sensibilidade de $87 \%$. A sensibilidade da técnica aplicada aos nossos casos foi de $100 \%$.

Nos três casos (10,7\%) em que houve discrepância entre os achados, ou seja, em que a HLT não detectou alterações identificadas à minilaparotomia, as tubas apresentavam hidrossalpinge e laqueadura em dois pontos, tratando-se, portanto, de alterações que perpassavam a LT convencionalmente realizada.

Por outro lado, nos seis casos em que HLT indicou impossibilidade de RCL, esse achado foi confirmado pela minilaparotomia. Portanto, a HLT enquanto simples procedimento ambulatorial é suficientemente segura para contra-indicar a RCL. Esse achado nos remete ao um valor preditivo negativo da HLT de $100,0 \%$, superior, portanto, aos $64 \%$ relatados por Watrelot et 
al. (2003), que encontraram valor semelhante também para a laparoscopia (67\%).

Os casos em que houve falha diagnóstica da HLT $(10,7 \%)$ autorizam inferir que, para a indicação segura da RCL, é necessário mais do que a visualização das fímbrias. Uma vez que a visualização panorâmica das tubas é difícil na HLT, todos os segmentos tubários devem ser examinados cuidadosamente, no sentido de poder identificar eventuais alterações na parte mais proximal das tubas. Tanto isso é verdade que a avaliação das tubas pela HLT pode falhar devido à interposição de alças intestinais, à presença de aderências pélvicas, a deslocamento tubário pelo líquido infundido, ou à presença de hidrossalpinge (Brosens et al., 2001a). Neste aspecto, essa dificuldade não existe para a laparoscopia diagnóstica.

Há relatos de complicações da HLT em 1,6\% dos casos (Darai et al., 2000), especialmente associados com danos intestinais (Brosens et al., 2001c; Gordts et al., 2001) e perfuração de útero retrovertido (Moore et al., 2003). Contudo, não observamos qualquer caso de complicação, o que rati- 
fica as afirmativas de Brosens et al. (2001c), segundo as quais os riscos de complicações reduzem significativamente quando as contra-indicações ao procedimento são respeitadas e quando há efetiva aprendizagem e experiência com a técnica.

Muitos estudos indicam a HLT na avaliação diagnóstica de mulheres inférteis. Nossos achados permitem incluir a HLT também como meio eficaz de investigação prognóstica de RCL.

Embora não seja o escopo de nosso estudo, que não foi outro senão o de verificar a acurácia da HLT na avaliação da viabilidade da RCL é importante frisar que a opção pela minilaparotomia foi devida à possibilidade de minimizar o trauma cirúrgico das pacientes, evitando-se incisões maiores e diminuindo a manipulação das estruturas, além de se poder realizar a RCL no mesmo ato operatório. Sabe-se que a incisão pequena oferece menor exposição do peritônio ao ressecamento, dispensa a utilização de compressas, que são causas potenciais de aderências, permite alta hospitalar em menos de 24 horas e deambulação precoce, além de acarretar menor dor 
pós-operatória e oferecer melhor resultado estético (Silva e Perkins, 1995;

Pelosi e Pelosi, 2000; Ueno et al, 2004).

É compreensível que o uso da HLT para avaliação da porção distal das tubas de pacientes laqueadas com desejo de nova gestação possa ser alternativa dispensável em países desenvolvidos cuja população tenha condições sócio-econômicas favoráveis e cujas políticas de saúde pública favoreçam o acesso às técnicas de fertilização in vitro. Por outro lado, nos países em desenvolvimento, como o Brasil e outros países da América do Sul, o acesso a esses recursos é limitado, e a RCL continua sendo a primeira opção para essas mulheres; todavia, principalmente nos serviços de saúde pública, o tempo de espera por uma avaliação laparoscópica das tubas é longo, e o custo desse procedimento é significativamente maior chegando a $70 \%$ dos custos de uma pesquisa de infertilidade (Bates e Bates, 1996). É por essa razão que a HLT realizada em ambulatório pode ser uma alternativa muito satisfatória, especialmente ao considerarmos os índices de acerto prognóstico dessa técnica demonstrados neste estudo. 
6. Conclusões 


\section{Conclusões}

Diante do exposto, conclui-se que a hidrolaparoscopia transvaginal:

1. Permite visualizar adequadamente as fímbrias e o coto distal de pa-

cientes com laqueadura tubária;

2. Tem alto índice de acerto em predizer a possibilidade de recanaliza-

ção cirúrgica, mas a presença de hidrossalpinge prejudica a avaliação do

prognóstico de reversibilidade. 
Anexos 


\section{Anexos}

Anexo A. Aprovação da Comissão de Ética para Análise de Projetos de Pesquisa.

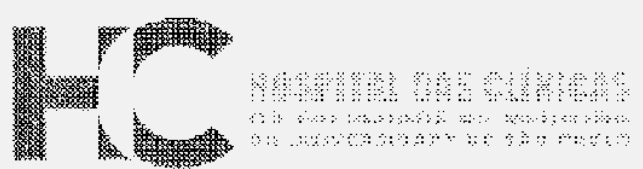

\section{DIRETORIA CLINTCA}

Comissão de Ética para Análise de Projetos de Pesquiso

O Presidente da Comissắo de Ética para Análise de Projetos de Pesquiso - CAPPesq da Diretoria Clínica do Jospital das Clinicas e da Faculdade de Medicina da Universidade de São Paulo, em 07.04.05, tomou conhecimento que a Protocolo de Pesquisa $n^{\circ} 287 / 00$ - intitulado "Hidrolaparoscopia transvaginal avaliação do prognóstico cirürgico em pacientes laqueadas candidet à reversăo cirúrgica", sob a responsabitidade do or. Joji Veno, passań a ser tese de doutorado do Or. Carlos Henrique Fontana Vieira, tendo como título: "Hidrolaporoscopia transvaginal na avaliaça $t$ : prognóstico cirúrgico em pacientes lagueadas candiolatos à reversäo cirúrgica".

CApPesq. 07 de Abril de 2005

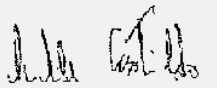

PROF. DR. EUCLIDES AYRES DE CASTILHO

Presidente da Comissão de Ética para Arólise de Projefos de Pesquisa

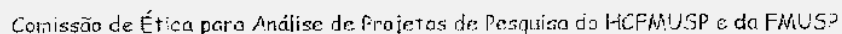

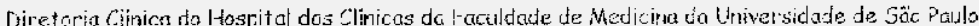

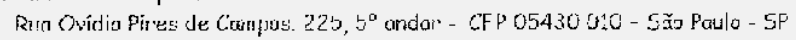

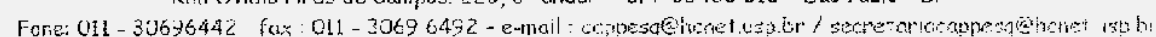




\section{Anexo B. Consentimento esclarecido pós-informado.}

1. Identificação da paciente (representante legal)

Nome:

Idade:

Endereço:

Telefone:

Registro hospitalar:

$\mathrm{CPF}$ :

RG:

Declaro que o doutor:

Explicou-me e eu entendi que devo me submeter a:

2. Hidrolaparoscopia Transvaginal e que:

2.1. O objetivo desta pesquisa é avaliar um novo método de verificar se as minhas trompas que sofreram laqueadura têm condições ou não de serem desobstruídas. Este procedimento pode ser feito sem internação hospitalar e sem anestesia geral, sendo realizado no próprio ambulatório e com anestesia local.

2.2. Este procedimento é realizado com uma óptica de $2,7 \mathrm{~mm}$ de espessura que é colocada dentro da barriga pela vagina. Para isso é necessária apenas uma anestesia local que é feita com uma pequena picada de agulha no fundo da vagina e é parecida com a anestesia do dentista; em seguida é colocado um pouco de líquido (soro fisiológico 0,9\%) esterilizado.

2.3. O desconforto que eu provavelmente irei sentir é o da picada da agulha e um pouco de ardor quando se injeta o anestésico; eu poderei sentir também um pouco de cólica, parecida com a cólica menstrual. Após o procedimento pode ficar saindo um pouco de líquido pela vagina.

2.4. O risco esperado é do método não dar certo e eu ter de fazer uma cirurgia para poder ver as trompas. Caso ocorra algum acidente, o que não é muito provável eu poderei ser transferida para o Centro Cirúrgico para ser mais bem assistida.

2.5. Os benefícios deste procedimento são: não precisar de internação no hospital, não precisar de corte na barriga e nem de anestesia geral.

2.6. A outra opção é fazer uma cirurgia chamada laparoscopia onde a óptica é colocada dentro da barriga através de um corte embaixo do umbigo, porém esta cirurgia necessita de internação no hospital e de anestesia geral.

3 O procedimento deverá ser realizado no ambulatório do HCFMUSP no dia

4 Declaro saber que é possível a qualquer momento antes do procedimento revogar o meu consentimento.

Cidade:..... Data: ___ _ _ _ _

Assinatura do Médico

Testemunha

Nome:
Assinatura da Paciente

Testemunha

Nome: 
Anexo $\mathrm{C}$. Dados individuais de 38 mulheres submetidas à HLT e à minilaparotomia para investigação prognóstica de RCL.

\begin{tabular}{|c|c|c|c|c|c|c|}
\hline Caso & Iniciais do nome & Registro & Idade & Peso & Altura & IMC \\
\hline 1 & AAMP & $13587802 \mathrm{~K}$ & 30 & 60 & 1,63 & 22,6 \\
\hline 2 & ASR & $3356020 \mathrm{~J}$ & 30 & 57 & 1,54 & 24,0 \\
\hline 3 & AMSC & $13491892 \mathrm{D}$ & 34 & 55,5 & 1,48 & 25,3 \\
\hline 4 & BNL & $13468959 \mathrm{~J}$ & 36 & 67 & 1,52 & 28,9 \\
\hline 5 & CVS & $13585656 \mathrm{~J}$ & 31 & 56,6 & 1,64 & 21,0 \\
\hline 6 & DRP & $13596612 \mathrm{D}$ & 34 & 71 & 1,56 & 29,2 \\
\hline 7 & EMV & 2742625 I & 35 & 71,9 & 1,53 & 30,7 \\
\hline 8 & EANR & $13493684 \mathrm{C}$ & 37 & 67,5 & 1,63 & 25,4 \\
\hline 9 & ERS & 489547 & 35 & - & - & - \\
\hline 10 & EAS & $13451326 \mathrm{~J}$ & 21 & 48 & 1,58 & 19,2 \\
\hline 11 & GCS & $3324472 \mathrm{E}$ & 37 & - & - & - \\
\hline 12 & GO & 3357206 I & 30 & 48 & 1,57 & 19,5 \\
\hline 13 & JNB & $13452431 \mathrm{C}$ & 26 & 69 & 1,57 & 27,9 \\
\hline 14 & JMSS & $13452568 \mathrm{E}$ & 38 & 65 & 1,58 & 26,0 \\
\hline 15 & JPS & $13449374 \mathrm{G}$ & 36 & 62 & 1,65 & 22,8 \\
\hline 16 & LMC & $13448415 \mathrm{C}$ & 39 & 56 & 1,59 & 22,2 \\
\hline 17 & LMNS & 278533577 & 32 & 58 & 1,62 & 22,1 \\
\hline 18 & LBC & $13456231 \mathrm{~B}$ & 29 & 62 & 1,45 & 29,5 \\
\hline 19 & LPC & $3357291 \mathrm{H}$ & 34 & 75 & 1,64 & 27,9 \\
\hline 20 & LRB & $13447965 \mathrm{~F}$ & 29 & 51 & 1,64 & 18,9 \\
\hline 21 & MAS & 488725 & 30 & 62 & 1,56 & 25,5 \\
\hline 22 & MAS & $13473555 \mathrm{E}$ & 36 & 61,9 & 1,60 & 24,2 \\
\hline 23 & MCSS & 134802397 & 39 & 51,4 & 1,53 & 21,9 \\
\hline 24 & MCDS & $3355956 \mathrm{H}$ & 37 & 68,9 & 1,57 & 27,9 \\
\hline 25 & MGM & $13445643 \mathrm{C}$ & 33 & 55 & 1,48 & 25,1 \\
\hline 26 & MDMS & 33763371 & 26 & 41,8 & 1,48 & 19,1 \\
\hline 27 & MJR & 2970068 G & 37 & 66 & 1,57 & 26,8 \\
\hline 28 & MLJH & $3362776 \mathrm{H}$ & 37 & 83,8 & 1,62 & 31,9 \\
\hline 29 & MMмO & $13588275 \mathrm{~F}$ & 37 & 71,7 & 1,57 & 29,1 \\
\hline 30 & MPO & $1346141 \mathrm{H}$ & 38 & 78 & 1,60 & 30,5 \\
\hline 31 & MAG & $13452582 \mathrm{E}$ & 34 & - & - & - \\
\hline 32 & MS & 490086 & 37 & - & - & - \\
\hline 33 & MFS & 497023 & 33 & 52 & 1,66 & 18,8 \\
\hline 34 & SMBS & $13488268 \mathrm{~B}$ & 37 & 58,4 & 1,66 & 21,2 \\
\hline 35 & SGB & $13456222 \mathrm{D}$ & 36 & 84 & 1,59 & 33,2 \\
\hline 36 & SACMF & 202572675 & 38 & 70 & 1,55 & 29,1 \\
\hline 37 & TRP & 495074 & 37 & 53 & 1,65 & 19,5 \\
\hline 38 & VLFC & 13495558 B & 33 & 56 & 1,56 & 23,1 \\
\hline
\end{tabular}


Anexo D. Dados individuais de 38 mulheres submetidas à HLT e à minilaparotomia para investigação prognóstica de RCL.

\begin{tabular}{|c|c|c|c|c|c|c|}
\hline \multirow[t]{2}{*}{ Caso } & \multicolumn{2}{|c|}{ Acesso à cavidade pélvica } & \multirow{2}{*}{$\begin{array}{l}\text { Posição } \\
\text { do útero }\end{array}$} & \multicolumn{3}{|c|}{ Achados à HLT } \\
\hline & $\begin{array}{c}1^{\mathrm{a}} \\
\text { tentativa }\end{array}$ & $\begin{array}{c}2^{\mathrm{a}} \\
\text { tentativa }\end{array}$ & & $\begin{array}{l}\text { Aderências } \\
\text { pélvicas }\end{array}$ & Hidrossalpinge & $\begin{array}{c}\text { Salpingectomia } \\
\text { distal }\end{array}$ \\
\hline 1 & + & & AVF & - & - & - \\
\hline 2 & + & & AVF & - & - & - \\
\hline 3 & + & & AVF & + & + & - \\
\hline 4 & + & & AVF & - & - & - \\
\hline 5 & + & & AVF & - & - & - \\
\hline 6 & + & & AVF & - & - & - \\
\hline 7 & Falha & Não realizada & AVF & Não realizada & Não realizada & Não realizada \\
\hline 8 & + & & AVF & - & - & - \\
\hline 9 & + & & AVF & - & - & - \\
\hline 10 & + & & AVF & - & - & + \\
\hline 11 & Falha & + & AVF & - & - & - \\
\hline 12 & Falha & + & AVF & + & + & + \\
\hline 13 & Falha & + & AVF & - & - & - \\
\hline 14 & + & & AVF & - & - & - \\
\hline 15 & + & & AVF & + & + & + \\
\hline 16 & + & & RVF & + & + & - \\
\hline 17 & + & & RVF & - & - & - \\
\hline 18 & + & & AVF & - & - & + \\
\hline 19 & Falha & Falha & AVF & Não realizada & Não realizada & Não realizada \\
\hline 20 & + & & RVF & - & - & - \\
\hline 21 & + & & AVF & + & + & + \\
\hline 22 & + & & AVF & + & - & - \\
\hline 23 & + & & AVF & + & - & - \\
\hline 24 & + & & AVF & + & + & + \\
\hline 25 & + & & AVF & + & - & - \\
\hline 26 & Falha & + & AVF & - & - & - \\
\hline 27 & + & & AVF & - & - & + \\
\hline 28 & + & & AVF & + & - & - \\
\hline 29 & + & & AVF & + & - & - \\
\hline 30 & + & & AVF & + & - & - \\
\hline 31 & Falha & + & AVF & + & - & + \\
\hline 32 & + & & AVF & + & - & - \\
\hline 33 & + & & AVF & + & - & - \\
\hline 34 & + & & AVF & + & - & - \\
\hline 35 & + & & AVF & - & - & - \\
\hline 36 & + & & AVF & + & - & - \\
\hline 37 & + & & AVF & + & - & - \\
\hline 38 & + & & AVF & + & - & - \\
\hline
\end{tabular}


Anexo E. Dados individuais das 33 mulheres submetidas à HLT e à minilaparotomia para investigação prognóstica de RCL.

\begin{tabular}{|c|c|c|c|c|}
\hline Caso & Presença de fímbrias & $\begin{array}{l}\text { Prognóstico de } \\
\text { RCL pela HTL }\end{array}$ & $\begin{array}{c}\text { Prognóstico inicial } \\
\text { de RCL pela } \\
\text { Minilaparotomia }\end{array}$ & Compatível \\
\hline 1 & + & Positivo & Positivo & SIM \\
\hline 2 & + & Positivo & Positivo & SIM \\
\hline 3 & + (à direita) não avaliável à esquerda & Positivo & Negativo & NÃO \\
\hline 4 & + & Positivo & Positivo & SIM \\
\hline 5 & + & Positivo & Positivo & SIM \\
\hline 6 & - & Negativo & Negativo & SIM \\
\hline 7 & Não avaliada & Falha & - & - \\
\hline 8 & + & Positivo & Positivo & SIM \\
\hline 9 & + & Positivo & Positivo & SIM \\
\hline 10 & + & Positivo & Positivo & SIM \\
\hline 11 & & & & SIM \\
\hline 12 & + & Positivo & Positivo & SIM \\
\hline 13 & - & Negativo & Negativo & SIM \\
\hline 14 & + & Positivo & Positivo & SIM \\
\hline 15 & + & Positivo & Positivo & SIM \\
\hline 16 & + (ruins) & Negativo & Negativo & SIM \\
\hline 17 & + & Positivo & Positivo & SIM \\
\hline 18 & + & Positivo & Positivo & SIM \\
\hline 19 & Não avaliada & Falha & - & - \\
\hline \multicolumn{5}{|l|}{20} \\
\hline 21 & + & Positivo & Positivo & SIM \\
\hline 22 & - & Negativo & Negativo & SIM \\
\hline 23 & + & Positivo & Negativo & NÃO \\
\hline 24 & + & Positivo & Positivo & SIM \\
\hline 25 & + & Positivo & Positivo & SIM \\
\hline 26 & + & Positivo & Negativo & NÃO \\
\hline 27 & + & Positivo & Positivo & SIM \\
\hline 28 & + & Positivo & Positivo & SIM \\
\hline \multicolumn{5}{|l|}{29} \\
\hline 30 & + (ruins) & Negativo & Negativo & SIM \\
\hline 31 & & & & SIM \\
\hline 32 & & & & SIM \\
\hline 33 & + & Positivo & Positivo & SIM \\
\hline 34 & - & Negativo & Negativo & SIM \\
\hline \multicolumn{5}{|l|}{35} \\
\hline 36 & + & Positivo & Positivo & SIM \\
\hline \multicolumn{5}{|l|}{37} \\
\hline 38 & & & & \\
\hline
\end{tabular}


Referências bibliográficas 


\section{Referências bibliográficas}

ACOG - American College of Obstetricians and Gynecologists. Sterelization. [ACOG Technical Bulletin, 222, 1996]. Int J Gynaecol Obstet 1996; 53(3):281-8.

Ades, A. Identificação dos fatores associados ao arrependimento após laqueadura tubária. [Dissertação]. São Paulo: Faculdade de Medicina da Universidade de São Paulo; 1996. 136p.

Almeida I, Souza C, Reginatto F, Cunha Filho JA, Facin A, Freitas F, et al. Histerossonossalpingografia e histerossalpingografia no diagnóstico da permeabilidade tubária em pacientes inférteis. Rev Ass Med Brasil 2000; $46(4): 342-5$.

Antoine JM, Dubuisson JB, Tournaiere M, Herat $\mathrm{H}$. Request for reversal of tubal sterilization: Survey conducted by the National College of French Gynecologistas and Obstetricians. J Gynecol Obstet Biol Reprod 1983; 12:58391.

ASRM. The American Fertility Society classifications of adnexal adhesions, distal tubal occlusion, tubal occlusion secondary to tubal ligation, tubal pregnancies, mullerian anomalies and intrauterine adhesions. Fertil Steril 1988; 49(6):944-55.

ASRM. Optimal evaluation of the infertile female. The Practice Committee of the American Society for Reproductive Medicine. Fertil Steril 2006; 86(suppl.):S264-7.

Bajzak KI, Winer WK, Lyons TL. Transvaginal hydrolaparoscopy: A new technique for pelvic assessment. J Am Assoc Gynecol Laparos 2000; 7:5625 . 
Barjot PJ, Marie G, von Theobald P. Laparoscopic tubal anastomosis and reversal of sterilization. Hum Reprod 1999; 4(5):1222-5.

Bates GW, Bates SR. The economics of infertility: developing an infertility managed-care plan. Am J Obstet Gynecol 1996; 174(4):1200-7.

Bauer O, Diedrich K. Laparoscópio de pequeno diâmetro: Indicações em ginecologia. In: Ueno J, Santo NC, Pinheiro WP, Pinotti JA. Cirurgia vídeoendoscópica em ginecologia. São Paulo: Roca; 1997. p. 275-9.

Benadiva CA, Kigman I, Davis O, Rozenwaks Z. In vitro fertilization versus tubal surgery: Is pelvic reconstructive surgery obsolete? Fertil Steril 1995; 64:1051-61.

Berker B, Mahdavi A, Shahmohamady B, Nezhat C. Role of laparoscopic surgery in infertility. Middle East Fertil Soc J 2005; 10(2):94-104.

Billingsley FS, Lebherz TB, Hodges JC. Cudoscopy: An appraisal of results. A review of 450 cases. Am J Obstet Gynecol 1963; 87:172-7.

Bishop E, Nelms WF. A simple method for tubal sterilization. NY State J Med 1930; 30:214-6.

Boyle KI, Colon JM. Fallopian tube reconstruction. [On line]. Disponível em www. emedicine.com/med. Atualizado em 27 de junho de 2006. Acesso em 15 de agosto de 2006.

Brosens I, Boeckx W, Delattin P, Puttemans P, Vasquez G. Salpingoscopy: A new preoperative diagnostic tool in tubal infertility. $\mathrm{Br} \mathrm{J}$ Obstet Gynaecol 1987; 94:768-73.

Brosens I, Gordts S, Campo R. Transvaginal hydrolaparoscopy but not standard laparoscopy reveals subtle endometriotic adhesions of the ovary. Fertil Steril 2001a; 75(5):1009-12.

Brosens I, Gordts S, Campo R. Identification of "sublte" adhesions? [Letter]. Fertil Steril 2001b; 76(5):1081. 
Brosens I, Gordts S, Campo R. The risk and outcome of bowel injury associated with the trocar insertion during transvaginal hydrolaparoscopy. Fertil Steril 2001c; 76(3):S274.

Brosens I, Campo R, Puttemans P, Gordts S. One-step endoscopy-based infertility clinic. Curr Opinion Obstet Gynecol 2002; 14(4):397-400.

Campo R, Gordts S, Rombauts L, Brosens I. Diagnostic accuracy of transvaginal hydrolaparoscopy in infertility. Fertil Steril 1999; 71(6):1157-60.

Cantor B, Riggal FC. The choice of sterilizing procedure according to its potential reversibility with microsurgery. Fertil Steril 1979; 31(1):9-12.

Chi IC, Jones DB. Incidence, risk factors, and prevention of post sterilization regret in women: An updated international review from an epidemiological perspective. Obstet Gynecol Surv 1994; 49:722-32.

Cicinelli E, Matteo M, Causio F, Schonauer LM, Pinto V, Galantino P. Tolerability of mini-pan-endoscopy approach (transvaginal hydrolaparoscopy and minihysteroscopy) versus hysterosalpingography in the outpatient infertility investigation. Fertil Steril 2001; 76(5):1048-51.

Clarke GN. A.R.T. and history, 1678-1978. Hum Reprod 2006; 21(7):1645-50.

Clyman MN. Culdoscopy. Surg Clin North Am 1957; 36:1357-66.

Clyman MN. A new panculdoscope: Diagnostic, photographic, and operative aspects. Obstet Gynecol 1963; 21:343-6.

Copenhever EH. A critical assessment of culdoscopy. Surg Clin North Am 1970; 50:713-8.

Cunanan RG Jr, Courey NG, Lippes J. Complications of laparoscopic tubal sterilization. Obstet Gynecol 1980; 55(4):501-6.

Darai E, Dessolle L, Lecuru F, Soriano D. Transvaginal hydrolaparoscopy compared with laparoscopy for the evaluation of infertile women: A prospective comparative blind study. Hum Reprod 2000; 15:2379-82. 
Dechaud H, Ali Ahmed SA, Aligier N, Vergnes C, Hedon B. Does transvaginal hydrolaparoscopy render Standard diagnostic laparoscopy obsolete for unexplained infertility investigation? Eur J Obstet Gynecol Reprod Med 2001; 94:97-102.

Decherney $\mathrm{AH}$. Anything you can do I can do better or differently! Fertil Steril $1987 ; 48: 374-6$.

Decker A, Cherry T. Culdoscopy: A new method in diagnosis of pelvic desease. Prelimiary report. Am J Surg 1944; 64:40-4.

Escalona JR, Rabischong B, Nohuz E, Moraga AM. Reanastomosis tubárica por vía laparoscópica. Rev Chil Obstet Ginecol 2006; 71(12):104-13.

Fatum M, Laufer N, Simon A. Should diagnostic laparoscopy be performed after normal hysterosalpingography in treating infertility suspected to be of unknown origin? Hum Reprod 2002; 17(1):1-3.

Fernandes AMS, Arruda MS, Palhares MAR, Bentti Jr ND, Moreira CM. Seguimento de mulheres laqueadas arrependidas em serviço público de esterilidade conjugal. Rev Bras Ginecol Obstet 2001; 23(2):1-7. [On line].

Gabos B. A comparisson of hysterossalpingography and endoscopy in evaluation of tubal function in infertile women. Fertil Steril 1976; 27(3):238-42.

Gordts S, Campo R, Roumbauts L, Brosens I. Transvaginal hydrolaparoscopy as an outpatient procedure for infertility investigation. Hum Reprod 1998a; 13(1):99-103.

Gordts S, Campo R, Roumbauts L, Brosens I. Transvaginal hydrolaparoscopy: A new method for the exploration of the female pelvis in infertility. Fertil Steril 1998b; 69(3):588.

Gordts S, Campo R, Roumbauts L, Brosens I. Transvaginal salpingocospy: An office procedure for infertility investigation. Fertil Steril 1998c; 70(3):523-6.

Gordts S, Campo R, Roumbauts L, Brosens I. Endoscopic visualization of the 
process of fimbrial ovum retrieval in the human. Hum Reprod 1998d; 13(6):1425-8.

Gordts S, Watrelot A, Campo R, Brosens I. Risk and outcome of bowel injury during transvaginal pelvic endoscopy. Fertil Steril 2001; 76(6):1238-41.

Groff TR, Edelstein JA, Schenken RS. Hysterosalpingography in the preoperative evaluation of tubal anastomosis candidates. Fertil Steril 1990; 53:417-20.

Gunning JE. The History of laparoscopy. J Reprod Med 1974; 12(6):222-6.

Halbert SA, Tam PY, Blandau RJ. Egg transport in the rabbit oviduct: The roles of cilia and muscle. Science 1976; 191:1052-3.

Halbert SA, Becker DR, Szal SE. Ovum transport in the rat oviductal ampulla in the absence of muscle contractility. Biol Reprod 1989; 40:1131-6.

Hall, RH. Culdoscopy in infertility investigation. Fertil Steril 1967; 18:486-91.

Hasson HM: Open laparoscopy. In: Phillips JM (ed.). Laparoscopy. Baltimore: Williams \& Wilkins; 1977.

Henderson SR. The reversibility of female sterilization with the use of microsurgery: A report on 102 patients with more than one year of follow-up. Am J Obstet Gynecol 1984; 149:57-61.

Hillis SD, Marchbanks PA, Tylor LR, Peterson HB. Poststerilization regret: Findings from the United States Collaborative Review of Sterilization. Obstet Gynecol 1999; 93(6):889-95.

Honore GM, Holden AE, Schenken RS. Pathophisiology and management of proximal tubal blockage. Fertil Steril 1999; 71:785-95.

Huber DH. Open laparoscopy. Biomed Bull 1984; 5(1):5.

Ikeda F. Avaliação da microlaparoscopia no diagnóstico e no tratamento de pacientes com endometriose pélvica nos estádios iniciais. [Dissertação]. São Paulo: Faculdade de Medicina, Universidade de São Paulo; 2002. 
Jamieson DJ, Hillis SD, Duerr A, Marchbanks PA, Costello C, Peterson HB. Complications of interval laparoscopic tubal sterilization: Findings from de United States Collaborative Review of Sterelization. Obstet Gynecol 2000; 96(6):997-1002 .

Jansen RPS. Endocrine response in the fallopian tube. Endocr Rev 1984; 5:525-32.

Jónsdóttir K, Lundorff P. Transvaginal hydrolaparoscopy: A new diagnostic tool in infertility investigation. Acta Obstet Gynecol Scand 2002; 81(9):882-5.

Karande VC, Pratt D, Rabin DS, Gleicher N. The limited value of hysterosalpingography in assessing tubal status and fertility potential. Fertil Steril 1995; 63:1167-71.

Karande VC, Korn A, Morris R. Prospective randomized trial comparing the outcome and cost of in vitro fertilization with that of a traditional treatment algorithm as first line therapy for couples with infertility. Fertil Steril 1999; 71:468-75.

Karasick S, Ehrlich S. The value of hysterosalpingography before reversal of sterilization procedures involving the fallopian tubes. AJR 1989; 153:1247-50.

Kim SH, Shin CJ, Kim JG, Moon SY, Lee JY, Chang YS. Microsurgical reversal of tubal sterilization: A report on 1118 cases. Fertil Steril 1997a; 68:865-70.

Kim JD, Kim KS, Doo JK, Rhyeu CH. A report on 387 cases of microsurgical tubal reversals. Fertil Steril 1997b; 68(5):875-80.

Kodaman PH, Arici A, Seli E. Evidence-based diagnosis and management of tubal factor infertility. Curr Opin Obstet Gynecol 2004; 16:221-9.

Krysiewicz S. Infertility in women: Diagnostic evaluation with hysterosalpingography and other imaging techniques. AJR 1992; 159:253-61.

Lavy Y, Lev-Sagie A, Holtzer H, Revel A, Hurwitz A. Should laparoscopy be a mandatory component of the infertility evaluation in infertile women with nor- 
mal hysterosalpingography or suspected unilateral distal tube pathology? Eur J Obstet Gynecol Reprod Biol 2004; 114(1):64-8.

Lipscomb GH, Stovall TG, Ramanathan JA, Ling FW. Comparison of silastic rings and electrocoagulation for laparoscopic tubal ligation under local anesthesia. Obstet Gynecol 1992; 80(4):645-9.

Lyons RA, Saridogan E, Djahanbakhch O. The effect of ovarian follicular fluid and peritoneal fluid on Fallopian tube ciliary beat frequency. Hum Reprod 2006; 21(1):52-6.

Marana R, Marana E, Catalano GF. Current practical application of office endoscopy. Curr Opinion Obstet Gynecol 2001; 13(4):383-7.

Marana R, Catalano GF, Muzii L. Salpingoscopy. Obstet Gynecol 2003; 15(4):333-6.

Marik J. Identification of "subtle" adhesions? [Letter]. Fertil Steril 2001; 76(5):1080-1.

McCann MF, Cole LP. Risks and benfits of culdoscopic female sterilization. Int J Gynaecol Obstet 1978; 16:242-7.

Mintz M. Actualisation de la culdoscopy transvaginale en decubitus dorsal. Un nouvel endoscope à vision directe muni d'une aiguille à ponction incorporée dans l'axe. Contracept Fertil Sex 1987; 15:401-4.

Mitri FF, Andronikou AD, Perpinyal S, Hofmeyer GJ, Sonnendecker EWW. A clinical comparison of sonographic hydrotubation and hysterosalpingography. Br J Obstet Gynecol 1991; 98:1031-6.

Moghissi KS, Sim GS. Correlation between hysterossalpingography and pelvic endoscopy for evaluation of tubal factor. Fertil Steril 1975; 26(12):1178-81.

Moore ML, Cohen M. Diagnostic and operative transvaginal hydrolaparoscopy for infertility and pelvic pain. J Am Assoc Gynecol Laparosc 2001; 8:893-7. 
Moore ML, Liu GY, Cohen M. Transvaginal hydrolaparoscopy (THL) in the evaluation of the infertile women. Fertil Steril 2001; 76(3):S186.

Moore ML, Cohen M, Liu GY. Experience with 109 cases of transvaginal hydrolaparoscopy. J Am Assoc Gynecol Laparosc 2003; 10(2):282-5.

Mount Sinai School of Medicine, 2006. Disponível em http://www.mssm.edu/misc /history.

O'Brien BM, Sully L, Jolly HF, Morrison WA. Microsurgical repair of the fallopian tubes. Aust N Z J Surg 1983; 53(2):161-7.

Odent M. Hydrocolpotomie et hydroculdoscopie. Nouv Press Med 1973; $2: 187$.

Opsahl MS, Klein TA. The role of laparoscopy in the evaluation of candidates for sterilization reversal. Fertil Steril 1987; 48(4):546-9.

PAISM - Programa de Atenção Integral à Saúde da Mulher. Relatório estatístico referência: 01/01/2000 a 01/08/2004. Disponível em: http://www.usp.br/fm/departamento/ginecologia.htm.

Pelosi MA, Pelosi III MA. Self-retaining abdominal retractor for minilaparotomy. Obstet Gynecol 2000; 96:775-8.

Platz-Christensen JJ, Tronstad SE, Johansson O, Carlsson SA. Evaluation of regret after tubal sterilization. Int J Gynaecol Obstet 1992; 38:223-6.

PNDS - Pesquisa Nacional de Demografia e Saúde. Rio de Janeiro: BEMFAN; 1996. p. 52-61.

PPFA - Planned Parenthood Federation of America. Tubal sterilization. New York: Katharine Dexter McCormik Library; 2002. Disponível em http://www.plannedparen-thood.org Acesso em 15 de agosto de 2006.

RCOG - Royal College of Obstetricians and Gynaecologists. Male and female sterilisation. Evidence-based clinical guideline, 4. London: RCOG; 2004. p. 25-41. 
Risquez F, Pennehouat G, Foulot H, Mathieson J, Dubuisson JB, Bonnin A, Madelenat P, Zorn JR. Transcervical tubal cannulation and falloposcopy for the management of tubal prengnacy. Hum Reprod 1992; 7:374-5.

Rock JA, Guzick DS, Katz E. Tubal anastomosis pregnancy success following reversal of Falope ring or monopolar cautery sterilization. Fertil Steril 1987; 48:13-7.

Roland M. Culdoscopy and laparoscopy: Competitive or complementary techniques? Fertil Steril 1970; 21(4): 361-76.

Schmidt JE. Requesting information about and obtaining reversal after tubal sterilization: Findings from the US Collaborative Review of Sterilization. Fertil Steril 2000; 74(5):892-8.

Scott P, Magos A. Culdoscopy using an optical cannula. Fertil Steril 2002; 78(3):625-7.

Sedbon E, Delajolinieres JB, Boudouris O, Madelenat P. Tubal desterilization through exclusive laparoscopy. Hum Reprod 1989; 4(2):158-9.

Serafini P, Batzolin J. Diagnosis of female infertility. J Reprod Med 1989; 34:29-40.

Shibahara H, Fujiwara $\mathrm{H}$, Hirano $\mathrm{Y}$, Suzuki $\mathrm{T}$, Obara $\mathrm{H}$, et al. Usefulness of transvaginal hydrolaparoscopy in investigating infertile women with Chlamydia trachomatis infection. Int J STD AIDS 2002; 13(4):279-80.

Shibahara H, Takamizava S, Hirano Y, Takei Y, Fujiwara H, Tamada S, et al. Relationships between Chlamydia trachomatis antibody titers and tubas pathology assessed using transvaginal hydrolaparoscopy in infertile women. Am J Reprod Immunol 2003; 50(1):7-12.

Silber SJ, Cohen R. Microsurgical reversal of female sterilization: The role of tubal length. Fertil Steril 1980; 33:598-601.

Silva PD, Perkins HE. Improved combined laparoscopic and minilaparotomy 
technique to allow for reversal of extensive tubal sterilization. J Am Assoc Gynecol Laparosc 1995; 2(3):327-30.

Silva PD, Schaper AM, Meisch JK, Schauberger CW. Outpatient microsurgical reversal of tubal sterilization by a combined approach of laparoscopy and minilaparotomy. Fertil Steril 1991; 55:696-9.

Sklar AJ. Tubal sterilization. [On line]. Disponível em http://www.emedicine. com/med. Atualizado em 7 de agosto de 2004. Acesso em 15 de agosto de 2006.

Soares JBS, Ueno J, Tognotti E, Antunes N. Laparoscopia diagnóstica em ginecologia. In: Ueno J, Santos NC, Pinheiro W, Pinotti JA (org.). Cirurgia vídeo-endoscópica em ginecologia. São Paulo: Roca; 1997. p. 47-55.

Swart P, Mol BWJ, Van Der Veen F, Van Beurden M, Redekop WK, Bossuyt PMM. The accuracy of hysterosalpingography in the diagnosis of tubal pathology: A meta-analysis. Fertil Steril 1995; 64(3):486-91

The American Fertility Society. The American Fertility Society classifications of adnexal adhesions, distal tubal occlusion, secondary to tubal ligations, tubal pregnancies, Müllerian anomalies and intratuterine adhesions. Fertil Steril 1988; 49(6):944-55.

Tulandi T. Modern surgical approaches to female reproductive tract. Hum Reprod Update 1996; 2:419-27.

Ueno J, Ikeda F, Lopes L, Santos NC, Pinotti JA. Hidrolaparoscopia: Experiência inicial no Brasil. In: Congresso Brasileiro de Videocirurgia, IV. 19-22 out. 1999. Florianópolis, SC. [Tema Livre].

Ueno J, Tomioka ES, Pinotti JA. Transvaginal videopelviscopy: A new technique for assessing pelvic cysts. J Am Assoc Gynecol Laparosc 2000; 7(4):535-8.

Ueno J, Vieira CHF, Ejzenberg D, Pinotti M, Freitas G, Mello NR, Pinotti JA. Reversão de esterilização tubária por minilaparotomia com técnica simplifi- 
cada: Resultados preliminares. In: Congresso Paulista de Obstetrícia e Ginecologia, IX; 2004. [Tema livre].

Vieira CHF, Ueno J, Santos NC, Fonseca AM, Pinotti JA. Hidrolaparoscopia transvaginal em pacientes laqueadas candidatas à reversão cirúrgica. In: I Consenso Latino-americano de Procedimentos Clínicos e Cirúrgicos em Reprodução Humana e Imagenologia Relativa in Congresso Paulista de Obstetrícia e Ginecologia, VIII, e Congresso de Ginecologia e Obstetrícia da Região Sudeste da FEBRASGO, X; 2003a. [Tema livre].

Vieira CHF, Ueno J, Santos NC, Fonseca AM, Pinotti JA. Hidrolaparoscopia transvaginal: Achados comuns. In: I Consenso Latino-americano de Procedimentos Clínicos e Cirúrgicos em Reprodução Humana e Imagenologia Relativa in Congresso Paulista de Obstetrícia e Ginecologia, VIII, e Congresso de Ginecologia e Obstetrícia da Região Sudeste da FEBRASGO, X; 2003b. [Tema livre].

Vieira CHF. Estudo da hidrolaparoscopia transvaginal com novo instrumental de acesso à cavidade pélvica. [Dissertação]. São Paulo: Faculdade de Medicina da Universidade de São Paulo; 2004. 85p.

Vieira CHF, Ueno J, Fonseca AM, Pinotti JA. Avaliação de 38 hidrolaparoscopias com novo instrumental para acesso pélvico. In: Congresso Paulista de Obstetrícia e Ginecologia, IX; 2004. [Tema livre].

Watrelot A, Gordts S, Andine JP, Brosens I. Une nouvelle approche diagnostique: La fertiloscopie. Endomag 1997; 21:7-8.

Watrelot A, Dreyfus JM, Andine JP. Fertiloscopy: First results (120 cases report). Fertil Steril 1998; 70(1Suppl):42S.

Watrelot AA, Dreyfus JM, Andline JP. Evaluation of the performance of fertiloscopy in 160 consecutive infertile patients with no obvious pathology. Hum Reprod 1999; 14:707-11.

Watrelot A, Nisolle M, Chelli H, Hocke C, Rongières C, Racinet C. Is laparo- 
scopy still the gold standard in infertility assessment? A comparison of fertiloscopy versus laparoscopy in infertility. Results of an International Multicenter Prospective Trial: The FLY (Fertiloscopy-Laparoscopy) study. Hum Reprod 2003; 18(4):834-9.

Yoder IC, Hall DA. Hysterosalpingography in the 1990s. AJR 1991; 157:675-83.

Yoon TK, Sung HR, Cha SH. Fertility outcome after laparoscopic microsurgical tubal anstomosis. Fertil Steril 1997; 67:18.

Zurawin RK. Tubal sterilization. [On line]. Disponível em: http://www.emedicine.com/ med. Atualizado em 5 de outubro de 2006. Acesso em 10 de outubro de 2006. 